\title{
WestVirginiaUniversity
}

THE RESEARCH REPOSITORY @ WVU

Graduate Theses, Dissertations, and Problem Reports

2006

\section{Win, lose, and draw: Civil war and the determinants of state concessions}

Frank Vaughan

West Virginia University

Follow this and additional works at: https://researchrepository.wvu.edu/etd

\section{Recommended Citation}

Vaughan, Frank, "Win, lose, and draw: Civil war and the determinants of state concessions" (2006).

Graduate Theses, Dissertations, and Problem Reports. 2500.

https://researchrepository.wvu.edu/etd/2500

This Dissertation is protected by copyright and/or related rights. It has been brought to you by the The Research Repository @ WVU with permission from the rights-holder(s). You are free to use this Dissertation in any way that is permitted by the copyright and related rights legislation that applies to your use. For other uses you must obtain permission from the rights-holder(s) directly, unless additional rights are indicated by a Creative Commons license in the record and/ or on the work itself. This Dissertation has been accepted for inclusion in WVU Graduate Theses, Dissertations, and Problem Reports collection by an authorized administrator of The Research Repository @ WVU.

For more information, please contact researchrepository@mail.wvu.edu. 


\title{
Win, Lose, and Draw: Civil War and the Determinants of State Concessions
}

\author{
Frank Vaughan \\ Dissertation submitted to the \\ Eberly College of Arts and Sciences \\ at West Virginia University \\ in partial fulfillment of the requirements \\ for the degree of \\ Doctor of Philosophy \\ in \\ Political Science \\ Jamie E. Jacobs, Ph.D., Chair \\ Subhayu Bandyopadhyay, Ph. D. (Economics) \\ Scott Crichlow, Ph.D. \\ Robert Duval, Ph.D. \\ Joe Hagan, Ph.D. \\ Department of Political Science
}

Morgantown, West Virginia

2006

Keywords: Civil wars, internal conflict, negotiated settlement, conflict resolution

Copyright 2006 Frank D. Vaughan 


\begin{abstract}
Win, Lose, and Draw: Civil War and the Determinants of State Concessions
\end{abstract}

\title{
by Frank Vaughan
}

This research develops an explanation of the causal factors that influence state concessions offered in negotiated settlements ending civil wars. It proposes an explanation drawn from bargaining theory, existing literature addressing the likelihood of negotiated settlements, and inductively derived variables. Specifically, it integrates the link between several general factors associated with conflict - the costs of war, incentives to cheat, the divisibility of stakes, the degree of democracy of the state, the presence or absence of a stalemate, and the timing and location of the settlement - and the degree to which states make concessions to the rebels. The relationships between these factors are analyzed quantitatively using probit and Tobit models as well as with qualitative case narratives using a dataset that describes all civil wars beginning between 1945 and 1997. The basic conclusion of this research is that bargaining theory by itself does not adequately identify the factors that influence state concessions. It does, however, provide some explanatory power and can be enhanced by the inclusion of existing literature and the results of the inductive analysis. 


\section{Contents}

Abstract

Acknowledgements

Tables

Figures

Graphs

Introduction

Existing literature

Bargaining theory and state concessions

Research design and data collection

Evaluating trends and patterns

Quantitative analysis of state concessions

Qualitative analysis of territorial concession

Summary and conclusion ii.

iv.

$V$.

$v i$.

vii.

1

24

43

64

93

112

150

189 


\section{ACKNOWLEDGEMENTS}

This project would not have been completed without the support and encouragement of many people too numerous to mention. I would, however, like to thank my parents, James and Nancy Vaughan, my sister Nancy and my brother Clark for their unending support and encouragement. The same sentiment is extended to a number of friends and colleagues who have patiently put up with me throughout his process.

I would also like to extend my appreciation to a number of faculty members for their assistance throughout the graduate school process. First and foremost, I would like to thank my advisor and dissertation chair, Dr. Jamie Jacobs, for her willingness to put up with an endless stream of late night and early morning phone calls about matters that now seem trivial. Without her support and encouragement, this project definitely would not have been completed. My sincerest appreciation also goes out to the rest of my committee - Subhayu Bandyopadhyay of the WVU Department of Economics, and Political Science professors Bob Duval, Ph.D., Scott Crichlow, Ph.D., and Joe Hagan, Ph.D. - for their input into the dissertation process and my graduate education. I would like to extend my thanks to the great problem-solvers of the WVU Department of Political Science - Leann Greathouse, Donna MacIsaac, and Rebecca Digman. I would also like to thank Jon Overby, DBA, Chair of the Department of Management, Marketing, and Political Science at the University of Tennessee at Martin for his unwavering support and encouragement. It is because of the support of these and many other people that this project has been completed. Responsibility for omissions and errors, of course, mine alone. 


\section{List of Tables}

1.1 Counts of negotiated settlements in civil wars, by author 6

3.1 Hypotheses generated from bargaining theory 58

3.2 Hypotheses generated from existing literature 62

4.1 Discrepancies in the duration of civil wars 72

4.2 Coding categories for the dependent variable "maximum concessions" 77

4.3 Occurrences of “maximum concession”, by type 85

5.1 Counts of negotiated settlements in civil wars, by author 96

5.2 Geographical dispersion of civil wars, 1945-1999 101

5.3 The resolution of civil wars by region and type, 1945-1999 102

6.1 Summary of Tobit models 117

6.2 Results of Tobit analysis of “maximum concessions” 119

$\begin{array}{ll}\text { 6.3 Probit results for power-sharing concessions } & 134\end{array}$

$\begin{array}{lll}6.4 & \text { Probit results for policy concessions } & 144\end{array}$ 


\section{List of Figures}

4.1 No bargaining space exists 46

$\begin{array}{lll}4.2 & \text { Bargaining space exists } & 47\end{array}$

4.3 Occurrences of “maximum concession”, by type 85 


\section{List of Graphs}

5.1 The resolution of civil wars, 1945-99 95

5.2 The onset of civil wars by era, 1945-1999 97

5.3 The resolution of civil by era, 1945-1999 99

5.4 The resolution of civil wars by era and type of resolution, 1945-1999 100

5.5 Civil war outcomes by geographic region, 1945-1999 102

5.6 Percentage of all negotiated settlements by region, 1945-99 103

5.7 Percent of wars ending in negotiated settlement, by region 104

5.8 Relative frequency of maximum concessions 106

5.9 Maximum concessions by historical period, 1945-1999 108

5.10 Maximum concessions by region 110 


\section{Chapter 1: Introduction}

What political price will states pay to end a civil war? Given the nearly limitless range of possible outcomes - ranging from a fight to the finish, at one extreme, to the abdication of territory and power, at the other - this is a question that has both theoretical and practical relevance for many who have an interest in understanding the political role of conflict within states, including civil war specialists, international relations theorists, peace study scholars, area specialists, and policymakers. Although many aspects of civil wars have received substantial amounts of scholarly attention (including conditions that affect the onset, duration, and severity of civil wars; when civil wars are more likely to end in a negotiated settlement; and the conditions that affect the success of negotiated settlements $)^{1}$, this is a topic that to date has not been addressed. As a result of this

\footnotetext{
${ }^{1}$ Influential works on the onset of civil war include: Collier and Hoeffler 2000; Eckstein 1964; Fearon and Laitin 2003; Gurr 1993, 2000; Roseneau 1964; Rule 1988; and Tilly 1978. Works on duration include: Fearon 2001; Ikle 1971; Licklider 1993, 1995; and Walter and Snyder 1999. For severity, see Brass 1985; and Brito and Intrilligator 1990. For the likelihood of a negotiated settlement, see: Mason and Fett 1996; Mason, Fett, and Weingarten 1999; and Zartman 1989. Finally, on the longevity of negotiated settlements, see: Walter 2002 and Stedman, Rothchild, and Cousens 2002.
} 
omission we know very little about the process by which negotiated settlements are constructed.

As detailed below, strong theoretical and practical reasons have been presented within the literature contending that negotiated settlements are notoriously difficult to achieve in civil wars. However, an examination of the empirical evidence clearly indicates that many civil wars are resolved at the negotiating table. Yet we have little or no knowledge of how the terms on which these negotiated settlements rest are determined. Thus, the purpose of this research is to develop a cohesive explanation of the process by which states seek to appease rebel political demands instead of pressing for a military defeat of their adversaries. To do so, this research will focus on the factors that influence the type and degree of political concessions made by the state to the rebels. This research specifically addresses the following question: What factors influence the political concessions states are willing to grant to their rebel adversaries in order to bring about peace?

The remainder of this chapter is devoted to a discussion of the fundamental concepts on which this research is based. In what immediately follows, the gap in the literature addressing how states are compelled to make political concessions to their military adversaries is developed. The issue is addressed from the context of the perceived difficulty of concluding a negotiated settlement in civil wars and the prevalence with which they do in fact occur. Next the contributions this research hopes to make to our understanding of civil wars are developed, which is followed by an overview of the theoretical argument on which this research rests. The concluding section outlines the organization of the remainder of this research. 


\section{The puzzle}

Current thinking within the political science literature presents strong theoretical and practical arguments that describe negotiated settlements of civil wars as being especially difficult and problematic to construct. However, the empirical evidence on this point directly contradicts the prevailing wisdom. As discussed below, by any count a significant portion of civil wars are resolved through some type of negotiated settlement. This raises several puzzling theoretical questions, such as: Why do negotiated settlements occur in the face of such difficulties? When are negotiated settlements more likely to occur? How do such settlements occur? The first two questions - the why and when - have both received significant amounts of scholarly attention, often with impressive results. Because of these efforts, the political science community has developed a good understanding of the factors that make a negotiated settlement more or less likely. However, the third question - the "how" - has yet to receive substantial attention. This research intends to address that gap. To do so, it focuses on the factors that compel the state to make political concessions to its rebel adversaries in order to bring about peace. In what follows, the theoretical difficulties associated with the resolution of civil wars by negotiated settlements and the preponderance with which they occur are addressed.

\section{The difficulties of negotiated settlements}

Until recently, few attempts to explain the occurrence of negotiated settlement of civil wars were made in the scholarly literature. This oversight is easily attributed to two 
conditions. First, most civil wars end in the unqualified military victory by one side. As Modelski (1964, p. 122) writes, "The outright win, the complete and unqualified victory of either the incumbents or the insurgents, is the most usual outcome of an internal war," a contention which is supported by the empirical evidence. Second, within the literature, strong theoretical and practical arguments are proposed that describe the resolution of civil wars by negotiated settlement as being especially difficult, if not impossible, to construct. In direct contradiction to the prevailing thinking within the field, however, negotiated settlements do occur and do so quite frequently, albeit less so than military conclusions. Two major obstacles to a negotiated end to civil war are prevalent within the literature. The first addresses the political relationship of the combatants, while the second argument is based on territorial and geographic considerations. Each is discussed below.

First, according to Pillar (1983, p. 24), the likelihood of a negotiated settlement is conditioned by the extent to which compromise is possible. He argues that, unlike international wars, negotiations are less likely to be successful in civil wars because: the very fact that a civil war has broken out indicates the weakness of any mechanism for compromise, and the war itself tends to polarize whatever moderate elements may have existed. Furthermore, each side in a civil war is a traitor in the eyes of the other and can never expect the enemy to let it live in peace. The struggle for power becomes a struggle for survival as the options narrow to the single one of the fight to the finish. (Pillar 1983, p. 24)

Pillar goes on to note that "in such conditions, not only is successful negotiation next to impossible; even a capitulation may be ruled out” (p. 24, fn 11).

Second, territorial concerns present considerable problems when seeking a negotiated resolution of a civil war. Territorial concerns center on the close proximity of two or more former combatants. The conclusion of a negotiated resolution directly 
implies the continued existence of both parties of civil wars, both of which must live either within the same state or, in the case of a territorial secession, as neighbors. This present an additional difficulty not commonly present in international conflicts. As Licklider (1993) explains,

It is particularly hard to visualize how civil wars can end. Ending international wars is hard enough, but at least there the opponents will presumably eventually retreat to their own territories .... But in civil wars the members of the two sides must live side by side and work together in a common government to make the country work. How can this be done? (Licklider 1993, p. 4)

Thus, good theoretical reasons exist to explain why negotiated settlements are difficult to achieve and therefore less likely to occur in civil wars than in interstate wars. But does this contention hold up to the scrutiny of the empirical evidence? Counts of the frequency with which civil wars are resolved via negotiated settlements vary considerably. Yet by any count, a significant number of civil wars are resolved through some form of negotiation. The wide disparity in the counts of negotiated settlements necessitates a discussion of the source of the discrepancies. The following discussion, then, is intended to establish the prevalence of negotiated settlements ending civil wars as well as to illuminate the source of the variation in the number of such agreements.

\section{The prevalence of negotiated settlements}

Despite the theoretical and practical considerations addressed above, the empirical evidence clearly indicates that a significant number of civil wars do end in negotiated settlements. For example, Modelski (1964, pp. 123-124), counts 100 civil wars between 1900 and 1962 and finds that 80\% end in an outright victory. But, as he points out, the inclusion of several successful coup d'états (while not considering those that were 
unsuccessful or resolved via negotiation) biases his list towards over-counting military defeat as the primary manner in which civil wars end. Pillar (1983, p. 12) develops a different list of civil wars by applying Wright's (1965) definition of civil war to a list of civil wars developed by Singer and Small (1972), which covers a time frame of 1800 to 1980. On this list, Pillar counts 19 civil wars, 6 (or slightly less than 32\%) of which are resolved via negotiation rather than military defeat. Stedman's (1991) counting shows that negotiations contributed to the resolution of 20 of 56 of civil wars, or about $31 \%$.

More recently, Walter (2002, p. 5 fn 2), who focuses on the processes by which negotiations produce lasting resolutions to civil wars, contends that "fifty-one percent of all civil wars that started between 1940 and 1992 experience formal peace negotiations at some point during the conflict.” Walter (2002, p. 6) also indicates that about $62 \%$ of civil war negotiations ultimately produced signed agreements and that $57 \%$ of those settlements were successfully implemented. Analyses by Hoddie and Hartzell (2003)

\begin{tabular}{||l|c|c|c||}
\hline \multicolumn{4}{|c||}{ Table 1.1 } \\
\hline Counts of negotiated settlements in civil wars, by author \\
\hline Author (date of publication) & Time frame & $\begin{array}{c}\text { Number of } \\
\text { settlements/civil } \\
\text { wars }\end{array}$ & $\begin{array}{c}\text { Percent resolved } \\
\text { via negotiated } \\
\text { settlement }\end{array}$ \\
\hline Modelski (1964) & $1900-1962$ & 80 of 100 & 80 \\
\hline Pillar (1983) & $1800-1980$ & 6 of 19 & 32 \\
\hline Stedman (1991) & $1974-1981$ & 20 of 56 & 31 \\
\hline Walter (2002) & $1940-1992$ & 13 of 72 & 18 \\
\hline Hartzell and Hoddie (2003) & $1945-1998$ & 38 of 103 & 47 \\
\hline
\end{tabular}

also support the conclusion that the most frequent way in which civil wars are resolved is by a militaristic conclusion. They find that about $48 \%$ of all civil wars meeting the definitional criteria of Singer and Small's (1982) Correlates of War Project ended in a 
military victory by one of the adversaries, while about $40 \%$ were concluded by a negotiated settlement.

Thus, the empirical evidence makes two points clear. First, many, if not most, civil wars end in the military defeat of one side than end in a negotiated settlement. Second, and more central to the purpose at hand, a significant number of civil wars are in fact resolved via a negotiated settlement. Since negotiated settlements are a common means by which civil wars are brought to an end, it is worth understanding the why, when, and how of negotiated settlements as a means of resolving civil war. Clearly our lack of understanding of the factors that influence state concessions produces a void in the literature, a point which is developed below.

\section{What is Missing}

Existing research has substantially contributed to our understanding of the resolution of civil war and has done so on several counts. First, it has highlighted what kinds of civil wars are more or less open to resolution by negotiated settlement. Second, it has advanced our knowledge of how the presence or absence of certain actors can affect outcomes. Third, existing research has illustrated how different types of actors can influence the likelihood of a negotiated settlement. And finally, we currently have a good understanding of the conditions under which a negotiated settlement is more or less likely to occur. Thus, we know: (1) the conditions under which conflicts are more or less likely to be resolved; and (2) what types of civil wars are more or less likely to be successfully resolves by a negotiated settlement. However, this tells us little (if anything) about the dynamics of the negotiating process itself. 
Understanding how state concessions are determined makes several important contributions to existing research. First and most importantly, this effort shifts the emphasis of existing research from being able to determine when a negotiated settlement is more or less likely to understanding the process by which mutually acceptable alternatives to war (negotiated settlements, in other words) are developed. In this way, the current effort builds on and extends our understanding of the process by which civil wars are resolved. Second, by understanding how the terms of settlement are constructed, we will gain insight into the process by which the political dispute underlying a civil war is resolved. This is important because the point of a civil war is the resolution of the underlying dispute, not who wins or loses on the battlefield. Third, understanding what factors influence terms of settlement will give us a better understanding of when negotiated settlements are likely to occur because it is logical to expect the content of a negotiated settlement to be a primary determinant of a combatant's decision to accept or reject a deal. And finally, by viewing civil war as an extension of or alternative to the domestic political process, this research will contribute to our understanding of the role played by civil war as a means of reconciling domestic political disputes because it highlights the extent to which the combatants are willing to bargain and compromise to resolve political disputes.

Based on existing research, we have little direct knowledge about how the concessions promised by one side affect the likelihood that negotiations are successful. We also know little about the role civil war plays as a political force. That is, we have little understanding of how civil wars may be used as a strategy of interest articulation and aggregation and how these demands may be reconciled by an existing state. Given 
the contention that civil war is at its core a political dispute carried out by militaristic means, understanding this aspect of the phenomenon is essential if researchers are to understand the role that civil wars play in domestic society and the process by which they are (or are not) resolved. The theory outlined below (and fully developed in Chapter 5) goes to the heart of the matter of both the political nature of civil war and its resolution.

\section{The approach}

To address the question at hand, this research draws on what has become know as the bargaining theory of conflict. Largely attributed to the works of Fearon (1995), Morrow (1988), and Wagner (1994, 2000), bargaining theory is an extension of traditional rationalist explanations of conflict (Lake 2003). But bargaining theory and rationalist thought by no means view negotiated settlements as being the outcome of similar processes. The two schools of thought sharply diverge on the role that militarized conflict plays in influencing the final terms of settlement. The key difference between rationalist thinking and bargaining theory is the process by which the terms of a negotiated settlement are developed. Whereas rationalist explanations contend that the terms of settlement each side is willing to accept are determined exogenously to the conflict, bargaining theory views the content of a negotiated settlement as an endogenous product of fighting (Fearon 1995, Werner 1998). Rationalist thinking, then, is useful in that it allows us to understand whose terms are accepted but it does little to inform us about what those terms will be. The victors in a civil war, rationalists argue, are able to impose their predetermined terms on their defeated opponent, who must accept or reject the terms as offered and has no say in their content. Conversely, bargaining theory 
contends that the final terms of settlement as are causally linked to events on the battlefield and that the resulting agreement will reflect the relative might and will of the adversaries. In other words, bargaining theorists argue that the fighting itself is at the heart of the process by which the terms of settlement are constructed and that the final terms will reflect the relative degree of military success enjoyed by each side. As such, this research offers a competing viewpoint to the prevailing expectation within the literature that the terms of settlement are imposed by the dominant combatant by viewing fighting as a form of negotiation in which the final terms of settlement are developed.

The application of bargaining theory developed below essentially views civil war as a part of a larger political process - a demand for change - in which the start and end of militarized conflict represent only a portion of the overall process. In the extreme, civil war can be viewed as an attempt by one side to impose its political will on its adversaries - to force them to accept its demands without reservation or compromise, as contended by rationalists. Such a characterization of civil war is supported by the relatively large number of conflicts that end in a militaristic conclusion. What it does not address, however, is the substantial number of civil wars that are resolved through a negotiated settlement in which each side makes sacrifices in order to resolve the dispute. From this more common, but less extreme perspective, civil war can be viewed as an attempt by one side to force its adversaries to acquiesce to its demands - if not in whole, then in part.

By viewing civil wars as an extension of domestic politics and as an inherently political process all its own, the decision facing combatants is whether their interests will be best served by negotiating and compromising, thereby achieving some, but not all, of 
their goals, or by continuing to fight, with the possibility of achieving all of their goals. Of course, the first option - negotiation and compromise - is the least risky, but provides fewer benefits, whereas the second - continuing to fight - is the most risky, but provides the combatants with possibility of fully achieving their goal. In what follows, a conceptual definition of civil war is developed, followed by an explanation of what is meant by negotiated settlement.

\section{What is civil war?}

Within the literature, two dominant perspectives of civil war exist. The first takes a narrow view of civil war and focuses on it as a militarized contest between groups, at the expense of a political component. Within this body of literature civil wars are defined in terms of the characteristics of the actors and the violence. The second perspective takes a broader view of civil war and views it as an outcome of an underlying political dispute. As this research is based on the contention that civil wars can be viewed as an extension of or alternative to domestic political processes, it seeks to maintain the view of civil war as a military contest while emphasizing the political component. Each of these perspectives is more fully developed below, followed by a discussion of the ways in which civil wars can end.

\section{Civil war as a military contest}

The political science community has reached a loose consensus as to what constitutes a civil war. Clearly civil war is different than and must be distinguished from interstate war as well as other forms of civil violence. It is distinguished from interstate 
conflict by the presence of an opposition group that resides within the borders of the challenged state and is differentiated from other types of widespread civil violence (such as bloodless or nearly bloodless coups, street crimes, looting, and riots) by the magnitude of the violence and the presence of an organized opposition ${ }^{2}$. With respect to the view of civil war as a military contest, this research adopts the conventional definition developed within the literature, which describes civil wars as having the following characteristics: (1) civil war is an armed conflict in which the sovereignty of a recognized state is challenged; (2) armed violence is widespread; (3) fighting occurs predominantly within the recognized boundaries of the state; (4) an organized opposition (meaning that both a leadership and a command structure exist) is involved; and (5) the state is one of the primary participants in the fighting. Thus, civil war can include a range of political claims ranging from policy disputes (such as demands for the equal status of a minority group or for a redistribution of political or economic resources) to territorial claims for autonomy and can even include a direct attempt to alter or replace an existing government, as in a revolution.

Some debate does, however, occur over the characteristics a conflict must possess in order for an episode of civil violence to be considered a full-fledged civil war. For example, the definition of civil war developed by Charles Tilly (1978) and adopted by Licklider $(1993,1995)$ differs slightly from most others on the point of sovereignty. Whereas most definitions require a challenge to an existing sovereign, Tilly and Licklider require the presence of multiple sovereigns, meaning that at least some members of the rebellious population demonstrate their support for the alternative "government" by

\footnotetext{
${ }^{2}$ For an in depth discussion of the difficulties of defining civil war and distinguishing it from other forms of violence, see Rule (1988) and Eckstein (1964).
} 
engaging in activities such as paying taxes, serving in its armed forces, and symbolically expressing their support for it (Tilly 1978, p. 192; discussed in Licklider 1993, p. 9). While seemingly minor, this difference plays an important role when one considers the case of "failed states", which King and Zeng (2001, p. 623) contend occurs when a government loses its political authority or its ability to impose the rule of law. These authors note that, by their definition, 127 state failures occurred between 1955 and 1998, many if not all of which involved civil war (p. 625).

Another issue addresses whether civil violence must, by definition, involve the state. Some scholars (Sarkees and Singer 2001, for example) drop the requirement that the state be an active participant and contend that large-scale social or communal violence may meet the criteria to be considered civil wars. As a result, their definition of civil war expands to include widespread violence that may or may not be directed towards the state. Civil war can therefore include hostilities between two or more nonstate actors, according to this definition. Because the present effort focuses on concessions made by the state to the rebels, only those episodes of violent conflict to which the state is a party are included as a characteristic of civil war for the purposes of this research.

Other points of disagreement center on the severity of the conflict, as measured by the number of deaths that can be attributed to a particular episode. Minimum levels of violence vary according to the number of deaths and the time period in which the deaths must occur. A wide range of minimum thresholds is used by researchers to determine whether the level of violence is severe enough for an incidence of civil violence to be considered a civil war. The most commonly used threshold is that provided by the 
Correlates of War Project (Singer and Small 1972, Sarkees and Singer 2001), which requires a minimum of 1,000 battle deaths annually. Regan (2002), however, uses a relatively low threshold of 200 deaths over the course of the conflict in his investigation of the conditions that draw third parties into civil conflict. Other scholars (Gleditsch, et al 2001) contend that a minimum of 1,000 battlefield deaths is necessary to differentiate civil war from other, less severe forms of civil violence. Doyle and Sambanis (2000) and DeRouen and Sobek (2004) also relax the requirement that the threshold of 1,000 be reached annually and only require that it be reached over the course of the conflict. Debate also exists over whether counts of battle deaths should consist solely of combatants or also include non-combatant deaths measure the severity of civil violence. The latter measure would more accurately reflect the number of deaths due to war, it is argued, because noncombatant civilians are frequently the targets of violence in civil wars (Sambanis 2001a).

Clearly the emphasis within this perspective is on defining civil war based on military outcomes, particularly the number of deaths that can be attributed to combat. Such an approach is valuable for two reasons. First, this approach separates major episodes of political violence from minor ones, which is important because researchers frequently wish to focus on large-scale violence. Second, it distinguishes civil war from other forms of political violence, which the evidence suggests behave differently than civil wars. However, one of the drawbacks of this emphasis on outcomes is that it minimizes the considerations on the political aspects of civil war. Because civil war is at its core a militarized contest between two or more actors intended to resolve a disagreement or eliminate a party to a disagreement, one of the central premises of this 
research is that civil war inherently involves dispute resolution. This shifts the focus from events on the battlefield to the resolution of the underlying source of the conflict, as discussed below.

\section{Civil war as politics}

Civil war is inherently more than widespread violence that meets the previous conditions, though. It also necessarily requires a political component, a feature which has frequently been overlooked within the literature. This point is emphasizes by Eckstein (1964, p. 12), who highlights the political component when he defines civil war as "any attempt to alter state policy, rulers, or institutions by the use of violence, in societies where violent competition is not the norm and where well-defined institutional patterns exist.” Zartman (1993, pp. 27-28) as describes civil war (or internal violence) in political terms when he describes it as a failure of the normal political process. According to him in order to fully understand what constitutes civil war,

one has to go back to the basic notion of politics. In an ideal condition of internal governance that may be referred to as 'normal politics,' issues are brought before government as petitions and are disposed of through appropriate policy responses. Absolute (or time comparative) grievances would be handled through measures to increase production or other causes of resource availability; comparative grievances would be handled through just divisions, allocations, and compensations.... Internal conflict occurs when this process breaks down.

From this perspective, civil war is a failure of the existing political system to

resolve disputes. Looked at from a different perspective, however, civil war is politics, in the sense that it is a demand for change. The point of a civil war isn't simply who wins or loses the military contest, but who wins or loses on the political front. If politics is the 
process of who gets what, when, and how, as suggested by Harold Laswell, then conflict is simply an extension (albeit a costly and extreme one) of the normal political process.

Civil war can, and should, be viewed as a part of the process by which competing demands between a rebel group and a state are reconciled. Civil war should be characterized as a strategy by which a dissatisfied group pursues the resolution of a grievance. This is not a new or original idea. In fact, this idea was first explicated by Clausewitz, who pointed out that:

... war is simply a continuation of political intercourse, with the addition of other means. We deliberately use the phrase "with the addition of other means" because we... want to make clear that war in itself does not suspend political intercourse or change it into something entirely different. (Clausewitz 1976, p. 605; quoted from Wagner 2000, p. 471)

But why do civil wars begin? To date, no generally accepted explanation of the onset of civil wars has been developed, although significant amounts of research have identified many conditions that make civil war more or less likely. Because this research focuses on the resolution of civil wars and not its onset, for present purposes it is more important to understand the role civil war plays as a domestic political process than it is to understand the covariates of its onset. For this purpose, the answer proposed by Zartman (1993) serves well. According to him, civil war is the outcome of an unreconciled political dispute in which the rebels press their claim through unconventional means. As he writes, In the beginning [the rebels] seek a redress of grievances within the rules established by the government. But when they get no satisfaction, their rebellion enters a new phase, protesting both the government's inattention to their grievances and its right to decide the rules by which protest shall be conducted. They contest the legitimacy of the government itself and take on a total and exclusive commitment to rebellion. (Zartman 1993, p. 25) 
While this viewpoint emphasizes the presence of a political dispute underlying the military conflict, it tells us little about the extent to which events on the battlefield translate into a political resolution. The extent to which the means (civil war) is connected to the desired end (political change) can, of course, vary considerably. As Holl (1993, 270-271) argues, the extent to which military goals reflect political goals can range from "the perfect coincidence of military and political objectives to the complete disarticulation of the two". In the first instance, "if political aims have been translated clearly into battlefield objectives, the military effort in a war will more likely conform to a larger, coherent policy designed to achieve a set of objectives thought otherwise not obtainable,” whereas “at the opposite extreme, however, military accomplishments hold little political significance.”

Thus, Holl describes two situations - one in which military outcomes affect political outcomes and another in which the two are not related. Realistically, one could expect that most civil wars fall somewhere in the middle - that each represents a degree of linkage of political and military goals - rather than at one of the extremes. Given this, understanding the role militarized conflict plays as a political process is of primary importance. Because civil war at its most fundamental level is an extension of the political process, to understand the factors that influence the terms of negotiated settlements is necessary to understand the role wars play as an agent of political change.

Thus, the literature presents two different views of civil war - one that emphasizes the magnitude of the violence and another that includes a political component. Since the purpose of this research is to uncover the factors that influence a state's willingness to make concessions to the rebels and because such concessions are 
primarily political in nature, this research integrates the two viewpoints and addresses the extent to which military and political outcomes converge.

\section{The resolution of civil wars}

Given that, for the purposes of this research, civil war is viewed as a demand for change, it follows that the resolution of conflict becomes the mechanism by which competing claims may be reconciled. For the purposes of understanding civil war as politics, the process by which the resolution of the fighting is translated into a political resolution is of central importance. Civil wars can end in one of two ways. First, a civil war can result in a militaristic conclusion, which occurs when one side defeats its adversary on the battlefield. Pillar (1983, pp. 13-15) offers two types of military defeat that are relevant to this discussion. ${ }^{3}$ Generally speaking, conflict can end in extermination/expulsion when an adversary "has rendered its opponent incapable of continuing to fight” (Pillar 1983, p. 14). Similarly, a capitulation can result when an adversary acknowledges it is no longer able or willing to fight. Both types of defeats share a common political resolution - the victor on the battlefield is able to impose a political resolution on the loser, who is either unable or unwilling to oppose it. In this case the victor is able to achieve most, if not all, of its political goals, resulting in the nearly perfect achievement of its political goals.

The second way a civil war can end is in a negotiated settlement. This occurs when both the combatants voluntarily choose to stop fighting and sue for peace. In

\footnotetext{
${ }^{3}$ Pillar also addresses absorption, where a conflict is absorbed into a larger conflict; withdrawal, where combatants remove themselves from the conflict without a written agreement; and the imposition of a resolution by outside actors, but without the acquiescence of the combatants. None of these, however, is relevant for present purposes.
} 
contrast to an outright defeat, the process by which the underlying dispute is resolved in this case is much more complex. An effective negotiated settlement only occurs when the combatants are able to develop a mutually acceptable solution to the underlying political dispute. Bargaining and compromise play a crucial role as each side makes concessions to develop a settlement, which may addresses military as well as the required political issues.

Both negotiated compromises and clear-cut military victories do share something in common, though, in that they both frequently produce agreements addressing how the fighting will end (Pillar 1983; Walter 2002). The product of negotiations in a military defeat, however, should not be seen as being the same as a negotiated settlement. The difference is clear and substantive. In a military defeat, it is common for adversaries to agree to terms that govern the end of fighting, as is common with a negotiated settlement. But when one side is defeated, agreements disentangle military forces (Pillar 1983, pp. 14-16; Walter 2002, pp. 50-54). These types of agreements, which Stedman (1991) refers to as a "negotiated surrender," address issues such as the withdrawal and disarming of troops, the exchange of prisoners, and the disbanding or integration of military forces but do not, by definition, address the underlying political complaints. Pillar (1983, p. 15) phrases the distinction succinctly: "negotiation suggests at least the possibility of giveand-take, whereas capitulation is a matter of one side signing on the dotted line.” Thus, whereas a negotiated surrender is imposed by the winner on the loser and addresses the disentanglement of fighting forces, a negotiated settlement is developed cooperatively by the combatants and addresses the underlying political dispute. Negotiated settlements are discussed in more detail in what follows. 


\section{Negotiated settlements}

At the heart of a negotiated settlement is bargaining. Through the process of bargaining the combatants are able to develop a mutually acceptable resolution that they were unable to agree to prior to the onset of the fighting. According to Pillar's (1983, 3740) foundational work on conflict as a part of the bargaining process, bargaining has three primary components. First, both sides must be able benefit by reaching an agreement. Benefits can be viewed from two contexts - as capturing the gains offered by the other side or as reducing the costs of continuing to disagree.

The second requirement, according to Pillar (1983), is that both sides agree to involve themselves in negotiations. Until both sides are willing to compromise, the underlying disagreement will persist. This component is especially relevant to civil war because adversaries must coexist after the war within the same state or, in the case of a partition, as neighbors (Licklider 1993). In contrast, combatants in an international war may simply walk away and leave the dispute behind, thereby providing some means of resolution.

The third and final component to bargaining addressed by Pillar is the divisibility of the stakes over which the war is being fought. Divisibility directly affects the range of agreements that can be realized. As Pillar (1983) notes,

Peace terms are often subject to minute variation - with quantitative issues the number of possible variations can be infinite - and if both sides find one possible set of peace terms preferable to continued disagreement they are likely to find several others preferable to it as well. Besides, war costs often become sufficiently great to produce a bargaining range large enough to accommodate even gross differences among possible agreements. When one side rejects a proposed settlement, neither opponent may know for sure whether it was rejected as being worse than a 
continued war or rejected in an attempt to make acceptable terms even better. ... It is only if the range vanished entirely, as it would if either side became willing and able to exterminate or expel the other, that a bargaining situation would no longer exist. (p. 40).

But what differentiates a negotiated settlement from agreements following a clearcut military victory? In order to qualify as a negotiated settlement for the purposes of this research an agreement must meet two conditions. The first criterion a negotiated settlement must meet is that it must be one or more documents signed by the state and one or more rebel factions. It may be argued that a better measure would be to identify those negotiated settlements that are actually implemented, but the emphasis of this research is on the factors that influence the content of the agreement and not its success. Since the process of implementing negotiated settlements comes with its own set of problems and difficulties, this research will focus its efforts of the conclusion of an agreement and not the implementation of agreements. (For a detailed discussion of the problems associated with the implementation of peace agreements, see Walter 2002 and Stedman, Rothchild, and Cousens 2002).

The second criterion that must be met for an agreement to considered a negotiated settlement is that the agreement must contain some type of political concession made by one side to the other. The purpose of this criterion is to distinguish between what Stedman (1991) refers to as a "negotiated surrender" (which address the disengagement of fighting forces) and a compromise settlement (which, as Pillar 1983 notes, entails compromise). 


\section{Summary}

The purpose of this research is to expand our current knowledge about civil wars by developing an explanation of the process by which combatants engaged in civil war develop a mutually acceptable negotiated settlement that both sides prefer to fighting. To do so, it will focus on the factors that influence the extent to which the state is willing to make political concessions to the rebels and will adopt a view of civil war as being widespread conflict carried out primarily within the borders of a single state by an organized group that is directly challenging the decision-making authority of the existing state. To qualify as a negotiated settlement, agreements must contain political concessions made by the state to the rebels.

In form, the remainder of this dissertation will begin with an in-depth discussion of the conditions under which negotiated settlements are more or less likely in Chapter 2. To date, a significant amount of research has been conducted that highlights the political, economic, and especially military factors that affect the likelihood of a negotiated settlement while a second school of thought addresses the characteristics of the combatants as predictors of the likelihood of a negotiated settlement. Chapter 3 more fully develops the logic of bargaining theory and applies it to the process by which terms of settlement are developed. The key theoretical construct of bargaining theory - the bargaining space - is developed here as are specific hypotheses to be tested. Chapter 4 will address methodological issues, including the creation of the dataset that will be used for testing the theoretically-derived hypotheses. In Chapter 5, a descriptive and graphical analysis of the data is presented. The purpose of this is to familiarize the reader with the 
data used in this research and to highlight the presence of several trends and patterns in the resolution of civil wars.

Tobit models, probit models, and case studies will be used to assess the factors that affect the extent to which the state offers concessions along three dimensions policy concessions, power-sharing concessions, and territorial concessions. To account for factors that may simultaneously affect the decision of whether or not to negotiate and the content of the terms of settlement, an overall model utilizing Tobit analysis will be presented in Chapter 6, as will a quantitative analysis of policy and power-sharing concessions . Because only three civil wars in the data set contained territorial concessions quantitative analysis is inappropriate. A qualitative analysis will therefore be presented in Chapter 7. A summary of findings is presented in Chapter 8. 


\section{Chapter 2: Existing literature}

The empirical evidence supports the conclusion that fewer civil wars end through negotiated settlements than via military resolutions. However, the empirical evidence also clearly indicates that civil wars do commonly produce negotiated settlements. This raises a question that logically precedes any discussion of state concessions: When are civil wars more likely to be concluded by negotiated settlements rather than an outright military defeat? Several fruitful research agendas have made substantial progress towards explaining the factors that make a negotiated settlement more likely. Two general approaches have emerged that account for the willingness of combatants to resolve their differences at the negotiating table. The first focuses on conflict processes. The second addresses the willingness and ability the actors involved to negotiate a mutually acceptable resolution. In order to place this research within the context of prior efforts to understand civil wars, the existing research is reviewed below.

\section{Conflict processes}

Explanations based on conflict processes address the political, economic, and especially military factors that condition the likelihood of success of war as a means of 
achieving political goals. The focus of this approach is to identify the characteristics of the fighting that increases the likelihood of a negotiated settlement. Three major conflict characteristics are addressed: the "ripeness" of the conflict for resolution, the costs of fighting, and the divisibility of the stakes.

\section{Ripeness}

One popular theme with the literature follows the thinking of Zartman (1989), who contends that negotiations result only when a conflict is "ripe for resolution". This group of scholars contends that negotiated settlements occur only as "a function of economic, military, or political conditions that exist on the ground" and that these factors can encourage combatants to seek a negotiation resolution (Walter 2002, p. 7).

For negotiations to be productive, the timing of the negotiations is considered to be at least as important as the negotiation process itself. Timing is crucial because the combatants will not be able to conclude a mutually acceptable resolution until the conflict is ripe. A conflict is "ripe" when "both parties lose faith in their chances of winning and see an opportunity for cutting losses and achieving satisfaction through accommodation" (Zartman 1995, p. 18). Civil wars produce negotiated settlements only when the warring factions face conditions such that both sides are ready to seek a non-military resolution. When war is no longer seen as a viable or the best means of producing the desired results, combatants will seek to resolve their dispute through negotiation, bargaining, and compromise.

This raises the question of when or under what conditions a conflict become ripe

for resolution. A ripe moment, says I. William Zartman, (2001) is based on a "mutually 
hurting stalemate”, or a condition such that "the parties find themselves locked in a conflict from which they cannot escalate to victory and this deadlock is painful to both of them”. Thus, a mutually hurting stalemate brings about the conditions necessary for the conflicting parties to seek an alternative resolution. Two conditions are necessary for a ripe moment to emerge. First, combatants must perceive war as being an inefficient or ineffective means of achieving their goal. Second, combatants must believe that a solution other than war exists. In short, this line of reasoning suggests that in order for the parties to agree to meet at the negotiating table, they must first decide that fighting is no longer a viable means by which their goals can be realized.

\section{Rational choice arguments}

Rational choice theories of civil war, otherwise known as expected utility, draw most directly from international relations and ultimately from theories of economic behavior ${ }^{4}$. In essence, expected utility theorists view war as a "costly lottery" in which both sides impose and incur costs in order to maximize the benefit each side gains (Wagner 2000, p. 470). These theorists view the onset and termination of war as being inextricably linked. According to their logic, civil war begins when the benefits of fighting exceed that of not fighting and ends in a negotiated settlement when the benefits of doing so exceed the benefits of pursuing a military victory.

Participants in a war are viewed as rational actors because it is assumed that each side bases its decision making process to maximize its expected utility. An actor calculates its expected utility based on three factors - its perceived likelihood of being successful on the battlefield; the benefits of an outright military victory relative to the

\footnotetext{
${ }^{4}$ See, for example, Whitmann (1979), de Mesquita and Lalman (1992)
} 
benefits of a negotiated settlement; and the costs it must endure in order to achieve military victory. The combatants' decision-making process hinges on what each perceives to be in its own best interest. The goal of combatants, according to rational choice theorists, is to convince their opponent to surrender because either the costs of winning will be too great or the probability of success too low to win an outright defeat. The rationalist logic Whittman (1979, p. 744) applies to the settlement of international war holds equally true for civil wars: "an agreement (either explicit or implicit) to end a war cannot be reached unless the agreement makes both sides better off; for each country the expected utility of continuing the war must be less than the expected utility of settlement.”

Empirical assessments of rational choice theories of the termination of civil wars build on the work of Whitmann (1979), who identifies the conditions under which an international war is likely to be resolved through negotiations. His results indicate that a combatant will seek a negotiated settlement only when it believes that it will be better off by doing so than by continuing to pursue a military victory. Mason and Fetts (1996) apply this same logic to the resolution of a civil war. These authors use six independent variables to predict whether or not a conflict will be resolved by a negotiated settlement: (1) the size of the government's forces; (2) the casualty rate; (3) the duration of the conflict; (4) whether or not an intervention by an outside power occurred; (5) the stakes of the conflict (political control versus control over a potion of territory); and (6) whether or not the conflict addressed ethnic or religious divisions.

Mason and Fetts (1996) conclude that only two variables - duration and the size of the government forces - demonstrated a statistically significant effect, with duration 
being positive and the size of government forces being negative. The authors draw several interesting and relevant conclusions from the analysis. First, "the longer a civil war lasts, the more likely the participants are to seek a negotiated settlement as the conflict draws on" (p. 563). Second, "the fact that the size of the army is negatively related to the probability of a settlement indicates that unless the government can subdue the rebels quickly, a settlement becomes more appealing” (p. 563). And third, those variables measuring the "stakes" - revolutionary versus territorial conflict and ethnic/religious versus political divisions, have no perceptible effect. This model provides support for the contention that the costs of war do influence the choices made by combatants of how to end the war. A slightly modified version of this research, in which additional information regarding the presence of outside interventions and an interactive term to account for effects of inventions on the duration of conflicts, corroborate their findings (Mason, Fetts, and Weingarten 1999). The second model correctly predicts the outcome of $86 \%$ of the civil wars reviewed by these authors.

\section{Divisibility of stakes}

It is commonly asserted within the scholarly community that "negotiations in civil wars are futile because the stakes are indivisible” (Stedman 1996, pp. 345). Pillar (1983, p. 24) makes a similar observation: "Stakes are usually less divisible in civil wars than in other types of war; the issue is whether one side or the other shall control the country.” This line of thinking emphasizes the difficulty with which the stakes of the conflict can be subdivided and therefore shared by the combatants. However, the proposition that indivisible goals account for the lack of negotiated compromises in civil wars is a matter

of dispute. Strong arguments have been proposed attributing the dearth of negotiated 
compromises to the divisibility of the stakes but theoretical explanations differ as to the why stakes might be indivisible and the degree to which they are indivisible.

Civil wars start for a seemingly infinite numbers of reasons and are fought to achieve a wide range of political change. On a conceptual level, the goals of the state are relatively simple and straightforward - to reject the demands of the rebels and maintain the status quo. The goals of the rebels, however, can address a wide range of political issues. Generally speaking, rebels can demand changes in three areas. At the most comprehensive level, the rebels can demand changes to the political structure of the state and its operation. Such demands can include changes to the constitution of the state, changes in leadership, or the dissolution of the existing government. Second, the rebels can demand changes that affect a geographic region within a state’s borders. In these territorial disputes some degree of autonomy or even complete independence for the region of the state may be sought. Finally, the demands of the rebels can address the outputs of the policy process of the state. These disputes may include equalizing a real or perceived maldistribution of political or economic rights for a segment of a population or the status of a group within the state, for example. Some stakes are easily subdivided and therefore shared, which makes it at least possible for the combatants to construct an agreement in which each gets some, but not all, of what it wants. Conversely, other goals are considered to be indivisible, thereby producing a situation that can only create winners and losers.

Clearly some goals are more amenable to a negotiated compromise because they allow for success to be addressed as a matter of degree, as in the degree of reform of existing political systems, changes in the allocation and distribution of political goods, or 
degrees of autonomy. On the other hand, some goals are total in nature and therefore not subject to division, such as the dissolution and replacement of an existing system of government, change in leadership, or complete and total territorial succession. Variations in the extent to which stakes are divisible (as well as the willingness of belligerents to divide them) carry important implications the resolution of a civil war. As Pillar (1983, p. 24) notes,

The likelihood that the two sides in any dispute can negotiate a settlement depends greatly on whether compromise agreements are available. If the stakes are chiefly indivisible, so that neither side can get most of what it wants without depriving the other of most of what it wants, negotiations are less apt to be successful.

Of course, not all civil wars are fought over stakes that are divisible or among combatants who are willing to make such bargains, thereby significantly reducing or even eliminating the prospect of a negotiated resolution and contributing to the prevalence of military victories (Walter 2002, p. 13).

Other scholars take a different approach to the matter. The core impediment to a negotiated compromise brought about by the indivisibility of goals, according to Zartman (1993, pp. 24-27), is the nature of the relationship between the state and the rebels rather than the stakes themselves. He contends that "the government enjoys an asymmetry of power, but the rebels compensate with an asymmetry of commitment” (1993, p. 25). The rebels, according to this view, exist solely to pursue the stakes of the conflict and are therefore committed to the stakes with little room to redefine or reduce their demands without losing legitimacy in the eyes of their constituents. As a result, the commitment of the rebels leaves "little possibility of tradeoffs and compromise" because "recognition is their top and bottom line, with nothing in between to contribute to the give and take of negotiation and compromise” (Zartman 1993, pp. 25-26). 
Another factor proposed by Zartman addresses the legitimacy with which combatants view each other. According to him (1993, p. 27), parties to a civil war “retrench on their element of strength and harden their positions" in response to an open challenge posed by their adversary. The parties to a civil war may not be willing to meet with their adversary to discuss subdividing the stakes because doing so simply lends legitimacy to their opponent.

Thus, disagreement regarding the source of indivisible stakes and to the extent to which they are actually indivisible exists, but whether or not stakes are indivisible is conditioned by the perspectives and choices made by the adversaries themselves and influenced by political and military issues on the ground. As Horowitz (1985) and Lijphart (1977) point out, alternatives do exist but may be difficult to recognize or accept. For example, in cases where a demand is made for the removal of a ruling party, a less extreme demand may be ensuring adequate representation through power-sharing arrangements or alterations in the constitutional structure to limit the power of the government. In the case of territorial stakes, if independence is demanded, an alternative may be to increase the political and economic independence of a particular region within the state or to take other measures that promote autonomy short of independence. Of course, not all alternatives may be viable or acceptable to the combatants, but should the combatants chose to revise their aims and goals a negotiated settlement may be possible in many cases.

Given that some stakes of a civil war are at least treated by the combatants as being indivisible, how might the likelihood of a negotiated settlement be affected? Two arguments have been suggested (Walter 2002). First, in political conflicts addressing the 
composition or organization of the government, differences may be observed according to the type of stakes. Where the goals of the rebels pose a direct threat to the existence of the present government, the state can be expected to refuse to negotiate. For example, when the rebels assert a claim for complete and total control of the government the state may be reluctant to join in a negotiated settlement for fear of losing control. However, when the claims of the rebels are limited, such as seeking a revision of discriminatory political or economic policies, a negotiated settlement may present an attractive alternative to going to or continuing war. Second, in the case of territorial conflicts, the situation may be less clear. On one hand, states may be reluctant to give up parts of their territory, especially if the territory in question is strategically located or contains valuable resources and the rebels may be reluctant to acquiesce on their demands for total independence. However, in the extreme the logic becomes clearer. In civil wars where states are forced to choose between giving up territory or facing destruction the choice becomes clear - the existing government may choose a modified existence over no existence at all. In the case of the rebels, partial autonomy and the ability to continue to press their claims in the future outweigh the destruction that a capitulation or clear-cut military defeat will bring about. Therefore, because territorial conflicts do not necessarily threaten the continued existence of either party, negotiated compromises may be easier to construct in territorial conflicts than in non-territorial ones.

\section{Actors and participants}

Explanations focusing on the actors and participants in a civil war address the political make-up of the state, the presence of external actors, and the social identification 
of the participants. The focus is on isolating the effects of the social and political organization of the combatants and the presence of outside actors on the resolution process. Three major issues are raised within the literature - the degree to which the state is democratic, the presence of outside actors, and the ethnic makeup of the participants. Each of these is discussed in detail below.

\section{Democracy}

One factor that has been proposed to explain the occurrence of negotiated settlements focuses on the institutional makeup (or polity type) of the state involved in the conflict. Although civil wars are relatively rare events in democracies and democratizing states, ${ }^{5}$ it is well documented that these states do experience intrastate warfare (Gurr 1993; Hegre, et al 2001, Mansfield and Snyder 1995). In fact, the evidence strongly suggests that fledging democracies are more prone to civil war than are consolidated democratic or authoritarian forms of government (Hegre, et al 2001; Snyder 2000). Also, democracy is not an either-or case, but a matter of degree, which raises the possibility that how democratic a state is may be as important as whether it is a democracy. For these reasons the degree to which a participant state is democratic is worthy of consideration.

Drawing from an extensive literature that explains the absence (or reduced incidence of) interstate conflict between democracies, three reasons have been proposed that address the likelihood of a civil war ending in a negotiated settlement as a function of the political makeup of the state. The central theme in these explanations, which parallels the democratic peace literature that addresses the lack of interstate war between

\footnotetext{
${ }^{5}$ The American Civil War is a prominent an exception (Hegre, et al 2001).
} 
democracies, is that "the decision to negotiate depends on the domestic political constraints placed on individual leaders” (Walter 2002, p. 10). This literature contends that states exhibiting a higher degree of democracy will be more likely to resolve a civil war through a negotiated settlement.

The first reason that democratic states may be more willing to seek a negotiated settlement addresses the relationship between the decision-makers of a state and its populace. In states exhibiting a high degree of democracy, elected leaders are expected to be more responsive to public opinion than their more authoritarian counterparts. Therefore, in democratic state the decision to resolve civil wars short of a complete victory may be conditioned by the degree of popular support within the populace (Russett 1993). Civil wars are relatively bloody conflicts in which a significant degree of the loss of life and destruction, much of which is borne by civilian non-combatants (Snyder 2000). Because the impact of a civil war directly affects the populace, civil wars are likely to evoke opposition among the masses. Leaders in more democratic states may therefore choose to avoid certain wars altogether and when civil wars do occur, public pressure may compel leaders to end the fighting by the quickest or least bloody method available. A negotiated settlement may provide the best option for democratic leaders to avoid a prolonged and bloody conflict because it does not require the absolute defeat of an opponent.

The second reason addresses the credibility of leaders of democracies versus authoritarian governments. According to some scholars (Bueno de Mesquita and Lalman 1992, for instance), the democratic leaders enjoy more credibility with dissatisfied members of the populace than their authoritarian counterparts. Credibility enables 
democratic leaders to be more successful in their efforts to end a conflict via a negotiated settlement because their promises are more apt to be trusted by the opposition, according to the logic with this school of thought. When democratic leaders make agreements, they do so based on the authority bequeathed them by the public that they represent. Their promises of future behavior, then, reflect the collective decision of their constituents. The decisions are directly linked to the collective will of their constituents, which constrains leaders from diverging from the promises they have made. As a result, democratic leaders are less likely to renege on the promises made to their adversaries because doing so entails consequences not just from their adversaries but also from those they represent. This offers a measure of protection to the opponents, which makes them more willing to enter into agreements because of the additional credibility of the promises. As a result, negotiated settlements are considered to be more likely to occur because the adversaries of a democracy have more reason to engage in negotiated settlements.

The third reason that democracies may be more likely to pursue a negotiated settlement draws from normative (or cultural) explanations of democratic peace theory (Russett 1993). Normative explanations of the democratic peace are based on the theory that democratic leaders are more accustomed to accommodating differences of opinion. This vein of thought contends that the leaders of democratic states will be more likely to negotiate a compromised settlement because the leaders are culturally predisposed towards considering compromise as a means of dispute resolution, whereas the leaders in less democratic or more authoritarian states may be more reluctant to do so. In sum, by drawing on the expansive literature that explains the absence of interstate conflict among democracies, strong theoretical reasons exist to suppose the contention that degree of 
democracy of a state combatant may increase its propensity to resolve ongoing fighting via a negotiated compromise.

\section{Interventions}

The involvement of external third parties has also been addressed as a significant factor that affects the likelihood of a negotiated settlement of a civil war. As with international conflicts, states and international organizations frequently have an interest in the outcome of the conflict and so it is common for external third parties to become involved in an ongoing or burgeoning conflict. The aim of the third party can range from helping the combatants settle the dispute, to influence who or how the dispute is resolved, or even to ensure the continuation of the dispute (Regan 2002).

The intervention of third parties who are not direct participants in a civil war is well-documented. Walter's (2002) data indicate that 89 out of 138 (or about 65\%) of civil conflicts with at least 1,000 annual deaths occurring between 1942 and 1992 experienced mediation by outside forces. Regan’s (2002) data indicate that military or economic interventions occurred in 31 of 72 (about 43\%) of all civil wars with at least 200 battle deaths annually between 1944 and 1996. The extensive use of interventions in not limited to states, either, as evidenced by the significant increase in the number of United Nations peace keeping operations (Bobrow and Boyer 1997).

What, then, constitutes an intervention? Conceptually interventions are easy to define. Focusing on unilateral interventions, Regan (2002, p. 9) defines an episode as “the use of one state's resources in an attempt to influence the internal conflict of another state”. The definitional logic can easily be broadened to include the use of resources by a 
state, a group of states, or an international organization. Thus, interventions can be carried out by a number of actors, acting in concert or alone. Actors can be unilateral, multilateral, or international organizations and can pursue a variety of goals.

The purpose of an intervention is to influence the decision-making calculus of the belligerents in favor of the intervener's desired outcome (Regan 2002, pp. 10-12). To achieve their purposes interveners can apply "soft” efforts such as diplomatic and symbolic measures to more forceful "hard" measures intended to coerce. At least one of three policy tools can be used by a third party to influence outcomes. Diplomatic interventions can be as simply as symbolically demonstrating the support or disapproval for the actions of one side or can utilize mediation to alter the flow of information and enhance communication between belligerents (Walter 2002; see also Touval and Zartman 1985). Symbolic efforts may include making public statements that advocating talks or condemning combat, or actions such as recalling officials and canceling meetings. Mediations can influence outcomes by encouraging communication between combatants, assisting the transfer of important information, and facilitating the discussion of issues and the agenda (Walter 2002, pp. 14-15; Touval and Zartman 1985). Diplomatic interventions are the most common form of external involvement, but are considered the least effective, possibly because they do not allow interveners the ability to coerce belligerents (Regan 2002).

"Hard” measures involve the application of coercive force via economic or military pressures, including economic sanctions or the threat or actual use of military force intended to pressure combatants to value one outcome over other possibilities. Coercive forms of interventions enhance the ability of outside actors to manipulate the 
costs and benefits of the combatants' decision-making calculus, but do so at the expense of imposing costs and risks on the intervener. Coercive interventions can involve either economic or military tools of statecraft.

Empirical assessments of the effects of interventions on civil wars focus predominantly on the duration of such wars. The consensus of these studies is that interventions are associated with or directly cause conflicts to last longer in most cases. Addressing interventions by both the United Nations and the United States into Bosnia, Somalia, and Haiti, Betts (1994) presents a twofold argument. He first argues that when an intervention is biased to the benefit of one side, the duration of a civil war will be shortened. This is so, he argues, because when a combatant gains support from external sources, the additional strength can easily tip the balance of power in its favor, thereby enabling that combatant to bring about a quicker defeat. However, impartial interventions, in which no side is given preferential support, the duration of the conflict is likely to last longer than otherwise because neither side is able to achieve a dominant position.

Similarly, Regan (1996), in an analysis of 101 civil wars between 1945 and 1999 in which interventions took place, builds on Betts' (1994) observations. Regan finds that in general interventions are associated with prolonged conflicts, although biased interventions are likely to shorten a conflict. In addition, he concludes that multilateral interventions are more apt to be successful than unilateral ones. His extended booklength analysis (Regan 2002) extends and broadens his findings. Here, he first finds that interventions are more likely to be successful when the state is supported and that mixed interventions, or those combining economic and military measures, are more successful 
than those employing one or the other. Finally, he replicates his previous conclusion that interventions are associated with longer conflicts. Elbadawi and Sambanis (2000) reach similar conclusions, finding that interventions are more likely to be associated with longer conflicts and with higher levels of violence.

Shifting the emphasis to diplomatic initiatives, Walter (1997) finds that diplomatic interventions do not affect outcomes unless the intervening state is willing to enforce an agreement once it is accepted by the combatants. She also finds that combatants are $39 \%$ more likely to engage in negotiations when a mediator is present, which she attributes to the ability of mediators to manage communication and the flow of information between combatants.

\section{Ethnicity}

Another factor prevalent in the literature that may affect the likelihood of a negotiated settlement addresses ethnic politics as a source of conflict. This literature contends that civil wars in which ethnicity plays a role are fundamentally different from ideological civil wars, ot those that are driven by political concerns. Within the literature, the most common assertion is that ethnic wars are less tractable and therefore less apt to be resolved by a negotiated resolution (Walter 2002, Kaufmann 1996, Sambanis 2001). However, Regan (2002) argues that ethnic civil wars are more easily resolved as long as an intervention is present.

At the root of the debate is the contention that ethnic civil wars are inherently and fundamentally different from non-ethnic or ideological civil wars. As Sambanis (2001) succinctly observes, "Not all civil wars are the same.” What, then, differentiates the two 
types of conflict? Kaufmann (1996, p. 446) contends that the loyalties of the belligerents and the goals of the combatants makes the two types of conflict distinct:

Ethnic conflicts are disputes between communities which see themselves as having distinct heritages, over the power relationship between the communities, while ideological civil wars are contests between factions within the same community over how that community should be governed. The key difference is the flexibility of individual loyalties, which are quite fluid in ideological conflicts, but almost completely rigid in ethnic wars.

The most common viewpoint in the literature is that ethnic civil wars are more difficult to settle by a negotiated settlement than ideological wars. As Walter (2002, p. 12) observes, ethnic civil wars are "thought to be less amenable to rational calculations of costs and benefits than conflicts between combatants drawn from similar identity groups” because ethnic civil wars are "frequently depicted as intense value conflicts over issues close to the heart”. Or, as Kaufmann (1996, pp. 445-46) describes it, in ideological conflicts, loyalties are "quite fluid", whereas in ethnic conflicts they are "almost completely rigid”.

Regan (2002, pp. 77), however, reaches the opposite conclusion in the special case of interventions in ethnic civil wars. He contends that ethnic civil wars more likely to be successfully resolved via a negotiated settlement when than ideological civil wars in the presence of an intervention by an external third party. His reasoning is that in an ideological civil war both sides are likely to gain support from an external third party, whereas in an ethnic civil war the possibility is reduced because group affinities are limited. Therefore, in an ideological civil war, an intervention on one side is more likely prompt a counter-intervention. A counter-intervention reduces or nullifies the advantages gained by the recipient of external support, which increases the likelihood of prolonged fighting. When group affinities are limited a counter intervention is less likely to occur. 
No one side will gain an advantage as a result of an intervention which makes a quicker resolution more likely.

Thus, strong theoretical reasons exist to expect ethnic civil wars to behave differently than ideological ones. In large part this distinction is attributed to the differences between ethnic and ideological civil wars. However, disagreement exists as to the direction of the effect and conditions under which such an effect may be observed. Despite the current lack of agreement of the effect of ethnicity on the resolution of civil wars, the scholarly community has made significant progress towards understanding its role. What has yet to be addressed, however, is what factors affect the content of negotiated settlements in those cases where they occur.

\section{What is missing}

Existing research has substantially contributed to our understanding of the resolution of civil war and has done so on several counts. First, it has highlighted what kinds of civil wars are more or less amenable to a negotiated resolution. Second, it has advanced our knowledge of how the presence or absence of certain actors can affect outcomes. Third, existing research has illustrated how different types of actors can influence the likelihood of a negotiated settlement. And finally, we currently have a good understanding of the conditions under which a negotiated settlement is more or less likely to occur. Thus, we know: (1) the conditions under which conflicts are more or less likely to be resolved; and (2) what types of civil wars are more or less amenable to a negotiated resolution. Yet this knowledge does little to inform us about the factors and conditions 
that influence the content of a negotiated settlement. As a result, our understanding of civil war as a political process is at best incomplete.

Based on existing research, we know little, if anything, about how the concessions promised by one side affect the likelihood that negotiations are successful. We also know little about the role civil war plays as a political force. That is, we have little understanding of how civil wars may be used as a strategy of interest articulation and aggregation and how these demands may be reconciled by an existing state. Given the contention that civil war is at its core a political dispute carried out by militaristic means, understanding this aspect of the phenomenon is essential if researchers are to understand the role that civil wars play in domestic society and the process by which they are (or are not) resolved. The theory outlined in Chapter 3 below goes to the heart of the matter of both the political nature of civil war and its resolution. 


\section{Chapter 3: Bargaining theory and state concessions}

In order to identify those factors that influence concessions offered by states involved in civil war, this research draws on what has become known as the bargaining theory of war. Described by Lake (2003, p. 81) as one of the most revolutionary recent advances in international relations theory, bargaining theory explains conflict as an inherent part of the political process. This description is intended to emphasize the inability of rationalists to explain why decision-makers are unable to resolve political differences without encountering the risks and costs of war (Fearon 1995 p. 380). Despite different theoretical explanations of the factors that condition a combatant's willingness to negotiate, bargaining theory builds on rationalist logic by integrating the same rationalist decision-making process.

The rationalist school of thought contends that political actors make decisions from a slate of options based on a comparison of the expected utility (net benefits conditioned by the probability of success) of a range of choices. Actors then select the

option that provides the greatest expected utility (or net benefits). Although bargaining theory utilizes this aspect of rationalist explanations, it differs in its explanation of the 
mechanisms by which conflicts begin and end. According to rationalist explanations the determination of acceptable terms of settlement is exogenous to the conflict. Fighting, then, does not directly affect the terms of any possible agreement, but only determines which side gets to impose their preferences.

Bargaining theory, on the other hand, contends that fighting is an integral part of the process by which the terms of settlement are actually developed. According to this school of thought, the content of political resolution that brings fighting to a halt is determined through combat. Thus, in this approach, the onset and resolution of war are inextricably linked and the final political resolution will reflect the extent to which each side is able to gain concessions from the other. War begins, bargaining theorists suggest, when both sides fail to identify or implement a mutually acceptable resolution to a political dispute. War ends when both sides are able to reach an agreement on the distribution of political goods. In essence, war is an outcome of bargaining failure, or the inability of the combatants to final a mutually agreeable settlement prior to the onset of hostilities. Thus, in order to fully understand why two or more political actors may choose to stop fighting short of a military victory, it is necessary to understand why two or more political actors start conflict. As discussed below, this is a function of what bargaining theorists refer to as a "bargaining space".

\section{Bargaining theory and state concessions}

The key theoretical construct of bargaining theory is the presence and identification of a bargaining space. A bargaining space is a range of one or more outcomes that are mutually acceptable to the combatants. When two or more political 
actors have a disagreement but are unable to create or recognize the presence of a bargaining space, conflict can (and often does) occur. As long as the combatants are willing or capable of continuing to fight but are unable to reach a negotiated settlement that is acceptable to both sides conflict continues. However, when the preferences of the combatants are such that a slate of possible resolutions that are acceptable to both sides is developed (bargaining space emerges, in other words), a negotiated settlement can result. For a bargaining space to develop once war has started, "it is necessary that for both sides the expected utility for settlement increases relative to their expected utility for continued fighting” (Goemans 2000, p. 20), otherwise conflict will continue.

Conceptually, the decision-making process described by bargaining theory is straightforward. Take two political actors, A \& B, each of which has well-defined preferences that can be arrayed along a single dimension. In the extreme case, A's ideal point is that A receives everything and B receives nothing. B's ideal point is the opposite: B gets everything and A gets nothing. The problem here is that there is no mutually acceptable compromise. In Figure 3.1 below, B demands b1, but A is only willing to concede a2, which is far short of B's minimally sufficient outcome and therefore unacceptable to B. Similarly, A demands a1, but B is only willing to concede b2. Again, the demand is short of what is acceptable to A. Because there is no mutually acceptable position that satisfies both A and B, a resolution is not possible because, in the parlance of bargaining theory, a bargaining space does not exist.

At this point, both actors have to make a decision between two alternatives accepting the status quo or increasing the pressure with which they make their demands. 
Conflict represents the ultimate way in which pressure can be increased. Both A and B then compare their perceived expected utility for the two alternatives: accepting the

\begin{tabular}{|c|c|}
\hline \multicolumn{2}{|c|}{ Figure 3.1: No bargaining space exists } \\
\hline \multicolumn{2}{|c|}{ 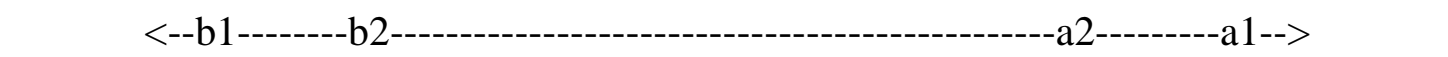 } \\
\hline $\begin{array}{l}\text { A } \\
\text { (B's ideal point) }\end{array}$ & $\begin{array}{c}\text { B } \\
\text { (A's ideal point) }\end{array}$ \\
\hline a1 = A’s initial (or ideal) preference & a2 = A's initial compromise offer \\
\hline b1 =B’s initial (or ideal) preference & b2 = B's initial compromise offer \\
\hline
\end{tabular}

Adapted from Lake 2003.

status quo and fighting. When one or both sides value the possibility of a better settlement gained through fighting more than they value the existing status quo, war is possible as long as the expected utility for fighting is higher than it is for accepting the status quo. Fighting allows each side to manipulate the expected utility of its adversary by threatening or engaging in combat because, in addition to imposing costs on itself, an actor also imposes costs on its adversary, albeit while simultaneously imposing costs on itself. By increasing the costs its adversary must bear, a combatant is able to decrease the expected utility of conflict for its opponent, which has the effect of increasing the likelihood that the adversary may acquiesce or decrease its demands.

By applying this logic to the process by which political actors decide to end combat, bargaining theory supplies insight into the decision-making process that brings fighting to an end. Once fighting begins, the calculations change, although comparisons between competing choices still occur, but now the options are to continue to fight (which involves both costs and risks) or to seek a negotiated settlement. According to bargaining theory, in order for a negotiated settlement to occur, a bargaining space must 
open up, which can only happen when one or both sides reassess or otherwise alter their expected utility for fighting versus that of accepting a negotiated compromise.

A bargaining space emerges only when one or both parties re-evaluate and modify their minimally acceptable terms for resolution. For a bargaining space to develop, the preferences of both sides must overlap so that a set of one or more resolutions that both sides are willing to accept exists. This is indicated in Figure 3.2 below. In this diagram, Actor A is willing to only accept point a1 prior to the onset of fighting. Once fighting begins, however, the combatant re-evaluates its preferences. Although point a1 is still the preferred outcome, Actor A is willing to accept the less than ideal outcome indicated at point a2. The willingness to accept outcomes that are not ideal is conditioned by the integration of the costs of fighting and the probability of success into the decision-making calculus. Actor B behaves similarly by shifting its minimally acceptable outcome to b2. The result is the creation of a bargaining space, or a range of mutually acceptable outcomes that is indicated by the space between $\mathrm{a} 2$ and b2.

\begin{tabular}{||c||}
\hline \multicolumn{2}{|c||}{ Figure 3.2: Bargaining space exists } \\
A \\
(B's ideal point) \\
(A1's ideal point) \\
b1 = A's preferences without fighting \\
a2 =A's preferences without fighting \\
b2 = B's preferences accounting for the costs of fighting \\
a2:b2 = bargaining space \\
\hline
\end{tabular}

Adapted from Lake 2003. 
By comparing the expected utility for continuing to fight with that of a negotiated settlement, some outcomes that were unacceptable prior to the onset of fighting become acceptable after fighting begins. When the expected utility for a resolution exceeds that of fighting, a negotiated settlement can be reached. Given that in cases where negotiated settlements have been reached, agreements are clearly possible (because they have occurred) the question becomes: Why didn't the combatants reach the agreement before incurring the costs associated with fighting? It is in this sense that bargaining theory contends that war is the result of a bargaining failure.

\section{The Model}

Given that war is inherently costly, both sides would clearly be better off if they were able to reach an agreement prior to the onset of conflict (Morrow 1989). By fighting, each side incurs costs and decreases the overall value of the political good that is the center of the dispute. Fearon (1995) contends that bargaining may fail when at least one of three conditions hold: (1) adversaries have incomplete or inaccurate information regarding a potential opponent's capabilities or commitment; (2) an incentive to disregard agreements exists for either adversary; or (3) at least one side is unable to develop and accept a compromise position. War ends only when (1) one side or another is defeated and no longer able to fight (a capitulation, in other words); or (2) one side or another adjusts its preferences so that a bargaining space - a range of one or more mutually acceptable resolutions - emerges. The question, then, is: what mechanisms alter the expected utility of fighting for one or both adversaries? Or, in other words, what factors 
force the combatants to re-evaluate their perceptions of the bargaining space so that a negotiated settlement becomes possible?

\section{Costs and incentives to misrepresent}

According to Fearon (1995), one of the three possible conditions that must be present to prevent rational actors from identifying a mutually acceptable resolution short of war is the presence of private information about the adversary's capabilities or resolve. "Private information is knowledge an actor possesses that is not available to others" and can include information regarding "the actor's own preferences as well as the strategies of bargaining and fighting it might use” (Lake 2003, p. 82). As Fearon (1995, p. 381) explains, "Leaders know things about their military capabilities and willingness to fight that other states do not know, and in bargaining situations they can have incentives to misrepresent such private information in order to gain a better deal”. In essence, private information makes it less likely for adversaries to conclude deals that each finds acceptable after a period fighting that were unacceptable before fighting because neither side is able to accurately assess its position. As a result, the presence of private information makes it difficult for either side to determine the true preferences or intentions of its adversary.

Drawing from and extending traditional rationalist explanations of conflict, bargaining theory attributes political decision making to a comparison of the expected utility of a range of alternatives. An actor's expected utility is conditioned by three important criteria - the costs and the benefits of each alternative, and probability of success of each possible alternative. The presence of private information artificially 
manipulates an actor's assessment of the costs and probability of success, which leads adversaries to make bad (i.e. inefficient) decisions. The presence of this condition is especially problematic when combat is looming because, as Lake (2003, p. 82) notes, "war plans are especially prone to misrepresentation and, thus, bargaining failures” because such knowledge, when shared, enables the opponent to be better prepared to respond, thereby creating an incentive to misrepresent such information. However, from the time fighting begins, each side gains important information about its adversary's strategies and tactics, its willingness to fight, and its ability to impose and withstand costs. As a result, once the fighting begins and as it continues, each side is better able to assess its expected utility for fighting versus negotiating a settlement. This is so because both sides gain information regarding the intentions and capabilities of its adversary.

In the context of civil war as a political process, when the initial demand is posed by the future rebels to the government, each side has limited information about the capabilities and resolve of each other. The problem is compounded because each side has an incentive to maintain or improve its bargaining position by keeping such information private or even by misrepresenting its capabilities and/or resolve. In other words, each side has reason to bluff in hopes of gaining a better deal. From the perspective of the rebels, a better deal might constitute gaining concessions above and beyond what it is willing to accept as a minimum. From the perspective of the government, a better deal is giving less or giving nothing.

However, once fighting begins the situation changes. As soon as combat is underway, information is necessarily transferred between the rebels and the state. And it is this transfer of information (referred to as "strategic learning by Goemans 2000) that is 
vital in determining the final outcome of the dispute. By simply engaging in conflict each side demonstrates its willingness to fight and also gives up some information about its strategy and abilities. As each side gains new information reveled by the fighting, leaders are better able to assess their own expected utility.

Should a combatant's adversary perform better than expected on the battlefield, a combatant should, according to bargaining theory, downgrade its demands accordingly. In this case, bargaining theory contends that the combatants will decrease its perceived probability of success in response to the increase in the expectation of costs that it must endure in order to achieve a complete victory. Its perceived expected utility for fighting will then decrease relative to its perceived expected utility of negotiating a resolution. The end result is that the combatant whose adversary performs unexpectedly well on the battlefield will be more willing to compromise than it was prior to fighting. Conversely, should an adversary's battlefield performance be less than anticipated, its opponent would be expected to be less willing to extend concessions (or even expect to receive greater concessions) than prior to the start of the fighting.

Although directly measuring perceptions is empirically difficult (if not impossible), it is reasonable to assume that leaders have some knowledge of their own capabilities and resolve at the outset and that they gain some knowledge about their adversaries through fighting. Based on this assumption, it is possible to develop some testable hypotheses derived from the logic of bargaining theory. Generally speaking, as combatants become more knowledgeable about their own military abilities and willingness to engage in conflict, as well as that of their opponents, they become more knowledgeable of their strength relative to that of their opponent. Leaders are then better 
able to assess their bargaining position and are better able to determine what demands they are able to make or what concessions they may be required to offer in order to maximize their expected utility. Therefore, when states are more successful at fighting, they will require more or concede less to the rebels in order to end the fighting. Conversely, when the rebels are more successful than the state, the state will concede more to the rebels in order to reach a negotiated settlement.

If civil war is in fact a means by which to achieve a desired outcome, it is presumably better to achieve that outcome by expending the fewest costs. Conflict is an inherently costly endeavor in which costs increase monotonically. Costs can be real, in which each side loses something of value, or they can be opportunity costs in which each side foregoes the benefits of an unrealized compromise. In the case of civil war, real costs include human losses from causalities and dislocation; material costs due to destruction and the use of military resources. Opportunity costs can include the loss of the benefits both sides may realize through cooperation, the inability to pursue other productive endeavors (including improvements to infrastructure, education, health care), the loss of economic productivity, growth, trade, and investment that frequently occurs during war, and the loss of support (financial and otherwise) from the international community.

Viewing the terms of settlement from the perspective of the state, this leads to the general hypotheses that the more successful the state is at fighting, the less extensive the concessions made by the state will be. The less successful the state is, the more generous the concessions to the rebels will be. Success, or the lack thereof, can of course be measured in many ways. Two commonly used measurements that capture the concept 
are battle deaths and the duration of fighting. Presumably a combatant is more successful in war when an outcome is achieved by minimizing the number of deaths to its side. In other words, fewer deaths indicate a higher degree of success, whereas a high casualty rate infers a relative lack of success. This is so simply because a combatant is better off gaining a particular outcome with fewer rather than more deaths, thereby minimizing costs. In general, then, the more successful combatants will experience a relatively low casualty rate. Viewing the terms of settlement form the perspective of the state, this leads to a concrete hypothesis:

H1: As the number of deaths suffered by the state involved in civil war increases, the political concessions to the rebels will be more extensive.

Similarly, the duration of fighting can also be an indicator of the degree of success simply because the longer a war lasts, the more it costs. By achieving its goals sooner, a political actor incurs fewer real and opportunity costs in achieving its goal. Simply put, if war is inefficient, then more war is more inefficient. Thus, the more successful a combatant is, the sooner it will achieve its goals. Conversely, the less successful a combatant is, the longer it will take to achieve its goals. Again viewing the terms of settlement from the perspective of the state, this implies that the state is better of a given resolution sooner rather than later, which has the effect of ending the fighting sooner. In order to end the fighting sooner rather than later, the state will presumably be more willing to make greater concessions to the rebels. By doing so, the state decreases its costs, which has the effect of increasing the state's expected utility of a negotiated compromise. Therefore, if bargaining theory is correct, the fighting will end sooner rather than later, which produces the following hypothesis: 
H2: The longer a civil war lasts, the greater the political concessions offered by the state to the rebels will be.

\section{Incentives to cheat}

The second condition offered by bargaining theory that can prevent rational actors from concluding a mutually acceptable resolution short of war addresses commitment or credibility problems. Commitment problems are present "in situations in which mutually preferable bargains are unattainable because one or more states would have an incentive to renege on the terms” (Fearon 1995, p. 381). When one side or another (or both) have reason to suspect that their adversary will renege or cheat on the agreement, neither side is likely to enter into an agreement, he argues. According to Lake (2003, p. 83), credibility problems can be created by two conditions. First, the problem may be the result of the informational problems because "when one side is unsure of the other's preferences (its ‘type’), it may not put great faith in its opponent's promises of future behavior.” The second source, according to Lake (2003, p. 83), is “that problems of credible commitment may also arise when relative capabilities shift exogenously over time or there are random shocks that affect capabilities.” Thus, even though a mutually acceptable resolution to a dispute may exist, commitment problems may prevent the implementation of a viable resolution.

If incentives to cheat are a cause of war, then resolving these problems by creating what Walter (2002) calls “credible commitments” should also enable combatants to more successfully reach a resolution to war. One common way credible commitments are achieve is through the involvement of third parties. These outsiders "can guarantee 
that groups will be protected, violations detected, and promises kept” (Walter 2002, p. 26). Such a third party intervention is likely to increase the probability that an agreement is reached because it increases the likelihood that it will be enforced and both sides protected. Presumably the best bet for each party (without regard to costs or the likelihood of success) is to fight until its adversaries are eliminated - capitulation of an opponent, in other words. In case of civil wars that the end in a negotiated settlement, though, such an outcome clearly has not occurred because such agreements require at least two parties. Negotiated settlements, then, are reached when at least one of two factors are present. First, the military capabilities of one side or another must be unable to completely defeat its adversaries to the point of causing a capitulation. Second, one side or another may be able to bring about a capitulation but then may be unwilling to devote the resources or endure the costs necessary to bring about a capitulation. The conclusion, then, is that in cases where credible guarantees are present to enforce the terms of settlement, it is because at least one side is willing to make the political concessions necessary to at least appease its adversaries in order to bring an end to the fighting. Viewed from the perspective of the state, then, if an incentive to cheat prompted the onset of civil war, then the presence of a guarantee should increase the willingness of the state to make concessions to the rebels. This leads to the third testable hypothesis:

H3: Political concessions made by the state to the rebels will be greater when a third-party guarantee is present. 


\section{Divisibility of the stakes}

The third factor offered by bargaining theory that can prevent rational actors from concluding a mutually acceptable resolution short of war addresses the issues over which the war is being fought. Indivisible issues, Fearon (1995) contends, potentially present a problem when the stakes over which the conflict is being fought over are such that subdivision into increasingly smaller increments is either impossible because of the nature of the stakes or is unacceptable to one or more sides. Because compromise necessarily entails the subdivision and sharing of a political good, issue indivisibility can make it difficult or even impossible for the combatants to reach an agreement. As Fearon (1995, 382) observes, "some issues, by their very natures, simply will not admit compromise.” In the words of Pillar $(1983,24)$, "if the stakes are chiefly indivisible, so that neither side can get most of what it wants without depriving the other of most of what it wants, negotiations are less apt to be successful.”

As both Fearon (1995) and Lake (2002) note, however, issue indivisibility is the least likely of the three conditions outlined by bargaining theory to create insurmountable problem. "Despite the attempts of diplomats to persuade one another other wise," notes Lake (2003, 83), “few issues truly take an ‘all-or-nothing’ form.” Fearon (1995, 389) points out two general ways in which problems of issue indivisibility can be overcome in the international realm:

In the first place, most issues states negotiate over are quite complex - they have many dimensions of concern and allow many possible settlements. Second, if states can simply pay each other sums of money or goods (which they can, in principle), or make linkages with other issues, then this should have the effect of making any issues in dispute perfectly divisible. 
Considering that the issues over which civil wars are fought are potentially as complex, if not more so, than those of international wars, presumably the logic applies to civil wars as well.

However, two issues over which civil wars are commonly fought may present significant indivisibility problems. Civil wars fought over the control of territory represent one possible form of indivisibility. While territory may in fact be divisible, conflicts over land may be less apt to be resolved easily because the essence of the stakes is political control of territory, which is not easily shared. Therefore, territorial disputes may be less susceptible to compromise, which produces the fourth testable hypothesis:

H4: Territorial disputes will result in less extensive concessions being made by the state to the rebels.

Another issue that potentially poses problem of issue divisibility addresses the makeup and organization of the participants. Conflicts in which the combatants divide themselves along ethnic lines may also be less open to compromise and therefore susceptible to problems of issue divisibility. This may be so because, while not immutable, ethnic identification is a relatively fixed characteristic by which groups of people define themselves and their enemies. This logic leads to the fifth testable hypothesis:

H5: Conflicts in which combatants are organized along ethnic lines will result in less extensive concessions being made by the state to the rebels.

Thus, bargaining theory presents three conditions that may lead to a less-thanefficient outcome: the conclusion of a compromise settlement that they combatants were not able to reach prior to the onset of hostilities. Based on the explanations proposed by bargaining theory, it seems at least plausible that if the presence of these conditions leads 
to war, then their removal may pave the way for a negotiated compromise. Furthermore, by applying the logic of bargaining theory to the resolution of civil war, several factors are proposed that may influence the extent to which combatants are willing to compromise.

\begin{tabular}{||c|l||}
\hline \multicolumn{2}{|c||}{$\begin{array}{c}\text { Table 3.1 } \\
\text { Hypotheses generated from bargaining theory }\end{array}$} \\
\hline Number & \multicolumn{1}{c||}{ Statement } \\
\hline H1 & $\begin{array}{l}\text { As the number of deaths suffered by the state involved in civil war increase, } \\
\text { the political concessions to the rebels will increase. }\end{array}$ \\
\hline H2 & $\begin{array}{l}\text { The longer a civil war lasts, the greater the political concessions } \\
\text { offered by the state to the rebels will be. The shorter the duration, the } \\
\text { less expansive the political concession will be. }\end{array}$ \\
\hline H3 & $\begin{array}{l}\text { Political concessions made by the state to the rebels will be greater when a } \\
\text { third-party guarantee is present. }\end{array}$ \\
\hline H4 & $\begin{array}{l}\text { Territorial disputes will result in fewer concessions being made by the state to } \\
\text { the rebels. }\end{array}$ \\
\hline H5 & $\begin{array}{l}\text { Conflicts in which combatants are organized along ethnic lines will result in } \\
\text { fewer concessions being made by the state to the rebels. }\end{array}$ \\
\hline
\end{tabular}

\section{Alternative Hypotheses}

The literature addressing the likelihood of negotiated settlements present two additional hypotheses that might provide insight into the factors that affect the terms of settlement in civil wars. The relationship between each of these two variables - the level of democracy of the state and the presence of a hurting stalemate - and the terms of settlement will be used to control for causal factors in addition to those outlined by bargaining theory. The application of these of each of these for the purposes of determining the terms of settlement in civil wars is developed below. 


\section{“Ripe moments”}

As previously discussed, one argument prevalent within the literature is that what Zartman (1989) calls a “ripe moment” must emerge prior to the onset of negotiations. These windows of opportunity for a negotiated settlement emerge when neither adversary is able to gain a dominant position in combat. As a result, both sides incur costs - a “mutually hurting stalemate” in Zartman’s (1989) words - and neither side is able to advance its goals. Essentially the logic is that when both sides are evenly matched and neither side is able to achieve its goals through the use of military force, one or both sides will seek an alternative means by which to do so. A negotiated settlement offers such an alternative.

By turning to a negotiated settlement, the combatants are able to reduce their losses and possibly even claim some gains by removing themselves from the conflict. As Zartman (1995, p. 18) writes, when a "mutually hurting stalemate” emerges, "negotiation offers a way to an alternative somewhere between unattainable triumph and unlikely annihilation". Thus, when a "hurting stalemate develops on the battlefield, the combatants second-best option - a negotiates settlement - becomes their first-best because a total victory becomes unattainable” (Zartman 1995, p. 18).

The outcome of this process, it is reasonable to expect, is a set of concession granted by each side to its adversary. The terms of settlement should reflect a resolution that is less than ideal in the eyes of each combatant, but one that is also superior to continuing a "mutually hurting stalemate". Since the ultimate goal of the rebels is unclear, it is necessary to focus exclusively on the state in observing this effect. For the state, as discussed above, the ultimate goal is easily observed - maintaining the status quo 
of the pre-war state. But if the state engages in civil war that produces a "mutually hurting stalemate” it is unable to achieve a clear-cut military victory and must endure the costs of maintaining a costly stalemate unless it settles. Any settlement, then, should represent some degree of disarticulation between the military and political outcomes, but in the end the extent to which the state makes concessions to the rebels should be greater when a mutually hurting stalemate develops than when one does not. This leads to the following hypothesis:

H6: When a civil war produces a "mutually hurting stalemate", the concessions made by the state to the rebel will be more extensive than when such a stalemate does not occur.

\section{Democracy}

The literature on the likelihood of negotiated settlements also provides theoretical reasons to expect that the level of democracy of the state may also affect the content of the terms of settlement. Based on the reasoning within the democratic peace literature, democratic states may be more willing conclude a negotiated settlement and may also be willing to grant greater concessions to do so. As discussed above, the democratic peace literature presents three reasons that explain why states with a high degree of democracy may be more willing to resolve a conflict through a negotiated settlement. In the paragraphs that follow, the explanations are applied to the content of negotiated settlements to explain why democracies may be willing to make more generous concessions than less democratic or authoritarian states.

The first reason presented by the literature contends that democracies may be more willing to seek a negotiated settlement to end a civil war because the decision to do 
so is conditioned by the degree of popular support for the war by the citizens. If, as the literature asserts, democratically-elected leaders are more likely to enter into a negotiated settlement to appease the public (who bear the brunt of the costs of the war, both in economic and human terms) by extension these very same leaders should be willing to to offer the rebels a better deal in order to end the bloodshed more quickly. When comparing the concessions made a highly democratic state to those of a less democratic or authoritarian state, then, we should expect greater concessions from more democratic states and less extensive ones from authoritarian governments.

The second reason democracies may be more willing to conclude a negotiated settlement centers on the credibility of the state. However, the causal link proposed by this literature explains the increased likelihood of a negotiated settlement as a function of the decision-making process of the rebels, which is beyond the scope of the present effort. The theoretical processes discussed below are only for the purposes of explication and will not be directly tested. According to the literature, offers made by democratic leaders are more believable and therefore more attractive to their opponents. Because democratic leaders are considered to be less likely to renege on their promises, the concessions they offer are more valuable, in other words. If the promises made by the state are more valuable and more believable to the rebels, it follows that the rebels may, as a result, be willing to make more generous concessions to the state. However, as previously discussed, measuring the extent to which the rebels make concessions is, at best, a tricky proposition, which relegates the testing of any formal hypotheses generated from this logic to future efforts. 
The third and final reason the literature proposes to explain why democracies may be more willing to negotiate addresses the norms of dispute resolution in democracies. According to this vein of thought, democratic leaders are more accustomed to accommodating differences of opinion than their more authoritarian counterparts.

Because democratic leaders are more culturally disposed towards compromise as a means of dispute resolution, it seems at least plausible that democratic leaders may be willing to offer greater concessions to resolve an underlying political dispute and bring an end to the fighting. If this is so, the terms of settlement offered by the state to the rebels should increase in their generosity when considering highly developed democracies. Similarly, few concessions can be expected from less democratic or authoritarian states. Thus, the prevailing wisdom contained within the democratic peace literature leads to the following hypothesis:

H7: The more democratic the state is, the more the concessions granted to the rebels will be.

\begin{tabular}{||c|l||}
\hline \multicolumn{2}{|c||}{\begin{tabular}{c}
\multicolumn{1}{|c||}{ Table 3.2 } \\
Hypotheses generated from existing literature
\end{tabular}} \\
\hline Number & \multicolumn{1}{c||}{ Statement } \\
\hline H6 & $\begin{array}{l}\text { When a civil war produces a "mutually hurting stalemate”, the concessions } \\
\text { made by the state to the rebel will be greater than when such a stalemate does } \\
\text { not occur. }\end{array}$ \\
\hline H7 & $\begin{array}{l}\text { As the level of democracy of the state increases, the concessions made to the } \\
\text { rebels will also increase. }\end{array}$ \\
\hline
\end{tabular}

\section{Summary}

The purpose of this research is to develop an understanding of the process by which states determine what concession they are to offer rebels in order to achieve a negotiated settlement to a civil war. To do so this research will utilize a popular theory within international relations - bargaining theory - as well as existing explanations from 
existing literature. Bargaining theory emphasizes the role of misperceptions, incentives to cheat, and the indivisibility of the stakes of fighting as explanatory factors of the onset of conflict. This research is based on the idea that if these three factors provide an adequate explanation of the onset of conflict, then their absence should explain the resolution of conflict. In addition, this research also addresses explanation based on the degree of democracy of the state involved in conflict and the presence or absences of a stalemate. In addition, a review of the data produces two more factors worthy of consideration, a topic which is addressed in Chapter 5. In the following chapter, the development of a dataset is discussed. 


\section{Chapter 4: Research design and data collection}

Having addressed the application of bargaining theory to the end of civil wars, this discussion will now turn to the data collection and the process by which the variables in each of the hypothesis were operationalized. Developing measurements of abstract concepts such as civil war, negotiated settlements, and state concessions is at best imprecise and necessarily involves some degree of uncertainty because of measurement biases and random error. To counter these threats to the validity of this research, what follows is an attempt to make the process of translating abstract ideas into quantified measurements as transparent as possible, thereby permitting an informed and critical assessment of the techniques and methods employed.

The first section of this chapter builds on the previous discussion of civil war to detail the process by which the term "civil war" is operationalized and is followed by an explication of the operationalization of "negotiated settlement”. The development of a case list of all civil wars meeting the research parameters is then discussed, followed by a discussion of the process by which the measurement of "state concessions", the dependent variable, was created. The last section of this chapter addresses the measurement of the dependent variables. 


\section{Operationalizing civil war}

The first step in building a dataset is to establish what is meant by "civil war" in order to distinguish this form of civil violence from other types of domestic unrest. As discussed above, for the purpose of this research a political event must contain two essential characteristics to be considered a civil war - large-scale militarized conflict and a political demand made by the rebels to the state. The operational definition of civil war, then, must capture both the motive (the demand for change) and the means by which the demand is pressed (widespread armed conflict) of civil war. To identify when a civil war has occurred, this research utilizes the operational definition of civil war developed by the Correlates of War (COW) Project, which is commonly employed by scholars conducting quantitative analyses of civil war (See, for example, Mason and Fetts 1996; Mason, Weingarten, and Fett; Hartzell and Hodie 2003; Hodie and Hartzell 2003; Walter 2002). In order to be considered a full-fledged civil war according to the definition developed by the COW Project, an episode of intrastate violence constitutes civil war when each of the following five criteria: (a) the sovereignty of a recognized state is challenged; (b) at least 1,000 deaths occur annually; (c) fighting must occur predominantly within the recognized boundaries of the state; (d) an organized opposition must be involved; (e) the state must be one of the primary participants in the fighting. The COW criteria are appropriate for the purposes of this research in several respects, as discussed below.

The first reason the COW definition of civil war is appropriate is that it captures the necessary political component of civil war discussed above. It does so by requiring that an episode of political violence include a challenge to the sovereignty of a state in 
order to qualify as a civil war. As such, it goes beyond identifying a civil war simply in terms of violence. Second, the required annual death threshold differentiates civil war from other small-scale violent episodes, such as coups, riots, assassinations, and violent protests, and allows this research to focus on its intended purpose - the analysis of largescale conflict. The third criterion - that fighting must occur predominantly within recognized borders of a state - effectively differentiates civil wars from international ones. The fourth criterion eliminates other forms of political violence that are qualitatively different from civil war. This would include events such as: revolutions, which are more widespread and far-reaching than civil wars and generally focus on leadership or ideology; coup d'etats, which come from within the state and may or may not involve the actual use of violence; genocides, or an attempt to eliminate a group of people with common ethnic or biological traits; or politicides, or an attempt to eliminate a group of people who hold common political ideas or beliefs. Finally, the requirement that the state be one of the primary participants eliminates instances of widespread communal violence in which a claim is not pressed against the state.

\section{Operationalizing negotiated settlements}

The second step in creating the dataset is to establish what constitutes a negotiated settlement because the purpose of this research is to gain an understanding of the process by which states make concessions to their rebel adversaries in order to end a civil war. To identify instances in which states have made such concessions, this research will limit itself to incidences in which the state formally extends concessions to the rebels through a negotiated settlement that is intended to resolve an ongoing civil war. This research will 
take a broad definition to determine what constitutes a negotiated settlement. In order to qualify as a negotiated settlement for the purposes of this research an agreement must meet two conditions. The first criterion a negotiated settlement must meet is that it must be one or more documents signed by the state and one or more rebel factions. It may be argued that a better measure would be to identify those negotiated settlements that are actually implemented, but the emphasis of this research is on the factors that influence the content of the agreement and not its ultimate success. Since the process of implementing negotiated settlements comes with its own set of problems and difficulties, this research will focus its efforts of the conclusion of an agreement and not the implementation of agreements. (For a detailed discussion of the problems associated with the implementation of peace agreements, see Walter 2002 and Stedman, Rothchild, and Cousens 2002).

The second criterion that must be met for an agreement to considered a negotiated settlement for the purposes of this research is that the agreement must contain some type of political concession extended by the state to the rebels. The purpose of this criterion is to distinguish between what Stedman (1991) refers to as a "negotiated surrender" (which address the disengagement of fighting forces) and a compromise settlement (which, as Pillar 1983 notes, entails one or both sides accepting terms that are less than ideal). These criteria will be instituted by applying the operational definition of "state concessions” (developed below) to the text of peace agreements.

To identify those civil wars that ended in a negotiated settlement, this research relied on Hartzell and Hodie’s (2003) Institutionalizing Peace data set. These operationalize negotiated settlements occurring between 1945 and 1998 written in 
agreements in which direct talks were be held between the combatants ${ }^{6}$ and that the settlement at least temporarily ends the fighting. Where possible, the analysis of the documents was done by examining copies of the text of the documents themselves. The United States Institute of Peace ${ }^{7}$ and INCORE $^{8}$ have gathered a sizeable database of documents texts that served as the primary source for the text of the agreements. Where necessary, other sources of particular documents were utilized, such as in the case of the Lancaster House Agreement ${ }^{9}$. In cases where the actual text of agreements was not located, secondary resources sources including Europa World Year Book, Keesing’s Contemporary Archives, The CIA World Factbook, SIPRI Yearbooks, Library of Congress Country Studies, and case studies conducted by area specialists were used to augment or in place of primary documents.

\section{Case selection}

To test the theoretically-derived hypotheses developed in the previous chapter, this research begins by identifying all episodes of civil wars (according the criteria established by the Correlates of War Project) that started between 1945 and 1992. For wars that did not end within this timeframe, data was collected until 1999 to provide the combatants with the opportunity to reach a resolution, whether resolved by a negotiated settlement or not. To do so, data were integrated from three existing datasets describing civil war: The Correlates of War Projects (1997) Intrastate Wars; Barbara Walter’s (1992) Civil War Resolution Data Set; and data developed and used by Hartzell and

\footnotetext{
${ }^{6}$ This criterion eliminates from the case list those instances in which third parties imposed a resolution. The Korean Conflict and two civil wars in Cyprus are offered as examples.

${ }^{7}$ www.usip.org

${ }^{8}$ www.incore.ulst.ac.uk/

${ }^{9}$ Available at: http://www.zwnews.com/issuefull.cfm?ArticleID=6623
} 
Hoddie in their 1992 analysis of the durability of negotiated settlements, "Institutionalizing Peace: Power Sharing and Post-Civil War Conflict Management”. This approach provides several major benefits to this research effort. First, the time frame of 52 years provides a large number of civil wars (91 total) to reduce the influences of biases in the data that occur as a result of time. As Walter (1992) notes, including civil wars fought both during and after the Cold War reduces any influences that the bipolar structure of the international political system may have had on their conduct or resolution. Such an effect, however, will be limited simply because of the short post-Cold War timeframe that is included produces 11 of the 91 wars. Unfortunately, given the relatively recent end of the Cold War and the lack of data availability extending the analysis is impractical at this time. In addition, this time frame reduces possible influences that may be present as a result of global economic conditions by including cases from a wide variety of economic time periods. And third, the time frame reduces biases that may occur as a result of "waves" or stages of political or economic development.

The second benefit of this approach is that it provides enough cases to permit the quantitative analysis of a large number of civil wars, including those that have been resolved in a negotiated settlement and those that ended otherwise or are ongoing. Finally, because each of these three datasets employ the same operational definition of civil war (that developed by the Correlates of War Project), it allows for comparisons to be made across datasets.

It must be emphasized that the dataset includes civil wars in which the state made concessions through a negotiated settlement as well as those that ended in a military 
victory by either side as well as those that were ongoing as of the end of 1992. Given that the intended purpose of this research is to develop an understanding of the factors that influence the concessions made by the state, the inclusion of civil wars in which the state did not make any concessions to the rebels may be surprising. The reason for including these wars, however, is quite simple. If only those civil wars that were concluded by a negotiated settlement are analyzed, it is at least possible, if not likely, that a bias in the case list is introduced. This is so because many of the factors that influence the content of the concessions offered by the state may concurrently influence the likelihood that concessions are even offered by the state. To avoid this potential bias, all cases of civil war are included regardless of the means of resolution.

Several issues, however, arose in the construction of the case list despite the uniform application of the Correlates of War Project's operational definition of civil war. Although all three datasets use the same operational definition of civil war, differences did in fact exist in the three case lists. Presumably these differences are the result of the use of different sources of information used to determine which violent episodes within states met the criteria for a civil war and which did not. Generally speaking, three types of discrepancies existed, each of which is discussed below as is the remedy applied ${ }^{10}$.

The first type of discrepancy addresses the coding of the start and/or end dates for individual civil wars. This was considered to be a relatively minor problem, and one with an easy fix. In five cases, the start and end dates differed between the COW data and the Hartzell and Hoddie data. In the case of Azerbaijan, COW indicates at start date of 1991,

\footnotetext{
${ }^{10}$ Walter (2002) draws her case list directly from the Correlates of War Project's Intrastate Wars. Therefore the only discrepancies that exist between these two datasets are cases that Walter chose to exclude because they were revolutions or colonial wars and where multiple cases of civil war within a state were collapsed into a single case.
} 
while Hartzell and Hoddie record 1989 as the initial year. In the cases of Sierra Leone and Mozambique COW data documents an earlier start date than Hartzell and Hoddie (1991 versus 1992 and 1972 versus 1982 respectively). For Nicaragua, both the start dates and end dates vary (1982-1990 according to COW, but 1981-1989 according to Hartzell and Hoddie). In the case of Yemen, COW data records an end date of 1969, while Hartzell and Hoddie indicate 1970 as the last year of fighting. These discrepancies do, of course, alter the measurement of the duration of the conflict (discussed in more detail below), but given the fairly small time-frame of the discrepancies and the small number of cases (relative to the total of 92 cases), the effects of this measurement error was considered to be relatively minor. In order to reduce the introduction of bias into the analysis, each of these cases were treated consistently by uniformly taking the start and end dates for each conflict that were provided by the Correlates of War Project's Intrastate War Dataset.

The second group of discrepancies between COW data and Hartzell and Hoddie data involve more severe timing issues that directly affect both the number of civil wars and the types of resolutions. In this category, the number of wars, their duration, and the manner in which some wars were resolved was called into question because in eight states, a civil war similar to the one referenced by Hartzell and Hoddie appears on COW, but the precise war referenced is unclear. The discrepancies in these cases, which are summarized in Table 4.1 below, were resolved on a case-by-case basis. 
The resolution of this group of discrepancies was based on the application of three decision rules and a thorough examination of the historical record. ${ }^{11}$ In cases where civil war was recorded by either dataset as reoccurring between the same participants or over similar political issues, the historical record was examined to determine whether or not

\begin{tabular}{||l|l|l|l||}
\hline \multicolumn{5}{|c|}{ Discrepancies in the duration of civil wars } \\
\hline Country & COW dates & Hartzell and Hoddie dates & \multicolumn{1}{|c||}{ Coded dates } \\
\hline Angola & $1975-91 ; 1992-1994$ & $1975-1989 ; 1989-1991$ & $\begin{array}{l}1975-1991 ; 1992- \\
1994\end{array}$ \\
\hline Cambodia & $\begin{array}{l}1970-75 \text { and 1978- } \\
91\end{array}$ & $1970-91$ & $1970-1991$ \\
\hline Colombia & $\begin{array}{l}1948-49 ; 1959-62 ; \\
1984-\end{array}$ & $1948-57$ & $1948-1961 ; 1984-$ \\
\hline Guatemala & $1954-54 ; 1966-72 ;$ & $1963-96$ & $1954-1954 ; 1963-$ \\
& $1970-71 ; 1978-84$ & & 1996 \\
\hline Iraq & $1961-63 ; 1974-75 ;$ & $1961-70$ & $1959-1959 ; 1967-$ \\
& $1985-93$ & & $1975 ; 1983-1993$ \\
\hline Laos & $1960-62 ; 1963-73$ & $1959-73$ & $1959-1973$ \\
\hline Liberia & $1989-90 ; 1992-95$ & $1989-93 ; 1994-96$ & $1989-1990 ; 1992-$ \\
& & & 1995 \\
\hline Philippines & $1950-52 ; 1972-80 ;$ & $1972-96$ & $1950-1952 ; 1972-$ \\
& $1972-92$ & & 1996 (NPA); 1972- \\
\hline
\end{tabular}

large-scale conflict was reported as having continued. In cases where conflict was continuous, the 1,000 annual battle-death requirement contained in the COW operationalization was relaxed and the incidences of civil war were coded as a single case. This applies to Angola (1975-1994), Cambodia (1970-1991), Colombia (19481962), Guatemala (1963-1996), and Laos (1959-1973). In the case of Iraq, the COW conflicts of 1961-1973 were collapsed into a single event as well. The second rule applied was that conflicts between separate rebel groups or over different political issues

\footnotetext{
${ }^{11}$ Sources consulted include Europa World Yearbook; Keesing's International Archives, INCORE Conflict Data Services, The Minorities at Risk Project, Conciliation Resources, Uppsala Conflict Database and country specific area studies conducted by area experts.
} 
be coded as separate wars. This rule applied to Liberia (against the anti-Doe rebels of 1989-1990 and the NPFL and ULIMO of 1992-1992) and the Phillipines (versus the Huks of 1950-1952, the Moros of 1972-1980, and the NPA of 1972-1992). Throughout this process every reasonable attempt was made to utilize the information contained in the COW dataset.

The third type of discrepancy that was encountered involved all three data sets COW, Walters, and Hartzell and Hoddie. In several instances one or more of the datasets contained cases of civil war that were not included on the other data sets. In other words, each dataset had coded civil wars that were unique to that dataset. To resolve this problem, the dataset constructed for this research integrated all cases. This resulted in several cases that were not listed in all three of the datasets being added to the final product in order to develop the broadest possible list of cases.

\section{Measuring "maximum concessions"}

The purpose of this research is to gain a better understanding of the process by which states engaged in a civil war are willing to make political concessions to their adversaries in order to bring about a quicker or more certain end to a civil war. The emphasis here is on the factors that influence the terms of settlement offered to the rebels, rather than one the likelihood that a negotiated settlement may occur. When states make concessions, they presumably compromise their ideal outcome by offering the rebels concessions in exchange for a quicker or more certain resolution to the civil war. ${ }^{12}$

\footnotetext{
${ }^{12}$ A reasonable argument can be made that the option of offering a compromise at some point may be a central part of the strategy utilized by the state, thereby enabling the state to make concessions while still obtaining their ideal outcome. This research, however, assumes for the purposes of simplicity that this is not the case.
} 
One way combatants involved in a civil war compromise is by giving up or forgoing at least a part of their ideal outcome in order to bring about a quicker or more certain outcome. Obviously, compromise can (and frequently does) occur on both sides of the dispute in order to hasten the end of fighting. Knowing that compromise can occur and measuring how much compromise has actually occurred, however, are completely different concepts. In order to determine those factors that compel a combatant to compromise a lot, a little, or not at all, the first step is to determine how much compromise has taken place.

Measuring how much compromise actually occurs is difficult because ideally it requires knowing the preferred outcome of each participant without considering the costs or the probability of success associated with the conflict. The most obvious way, it seems, to address the problem may be to take the publicly stated goals of the leaders of each side at face value and compare them to the political resolution each side is willing to accept. However, while public proclamations may appear to clearly and definitively state the true goals of combatants, the ideal outcome for each participant may, in fact, be obfuscated for several reasons. First, publicly-stated goals may be artificially inflated in hopes that the party to the conflict may be able to gain more than their ideal outcome. If combatants understate their true goals at the outset, the rebels and the state run the risk of achieving less than they could otherwise achieve. Second, combatants may modify their publicly-stated goals in order to affect the amount of societal support available to a side. By making grandiose claims about what they want to achieve, combatants may be able to attract the support of the more radical elements of society. Similarly, combatants may 
also run the risk of alienating the moderate elements of their support group by making claims that segments of their support find too extreme.

A third reason that combatants may misrepresent their true intentions goes to the issue of external support. In cases where either the rebels or the state seek the support of external actors, they may augment their publicly stated intentions in order to attract or maintain the support of external parties. On the other hand, in other cases the presence of outside actors may encourage the combatants to make less extreme demands publicly in order to avoid any form of international retaliation or retribution. Fourth, either side may publicly overstate their ideal goals in order to draw attention to their position. By expressing their position in an extreme form, either side may increase the amount of attention their side receives either domestically or internationally. And lastly, this approach presents an additional potential problem of identifying which leaders legitimately speak for the group. In cases where more than one leader has made public statements on behalf of the group and where one or more leaders have made conflicting statements, determining which statement is actually the true ideal becomes problematic.

Clearly there are good reasons for not taking the publicly-stated goals of combatants literally. The problem becomes determining what their actual goals really are. In the case of the rebels, this is difficult (if not impossible) because no concrete and objective criteria exist for determining what the ideal political outcomes of the combatants actually are. For the state, however, such criteria do exist - the pre-war status quo. Presumably, a state wants to preserve the existing status quo, otherwise it would not be engaging in combat to avoid acquiescing to the demands of the rebels. By taking the pre-war status quo of the state to represent the initial goals of the state, the difficulties 
associated with measuring compromise decrease rapidly. The task becomes one of measuring how much change the state is willing to accept in order to bring about the end of conflict.

In order to assess the degree to which combatants involved in a civil war compromise their ideal political outcome, this research will focus on the extent to which the state makes concessions to the rebels. Thus, this research focuses exclusively on the degree to which the state compromises and does not address the issue of the degree of compromise made by the rebels. It should also be noted that this measurement is explicitly based on the assumption that if the state agrees with or supports the political demands of the rebels, civil war would be an unnecessary event. By creating an index that describes the extent to which the state acquiesces to the rebels, the creation of a reasonable indicator of compromise is possible. Such data does not, however, currently exist and so must be created.

An ordinal-level categorical variable has been created to measure the degree to which the state successfully negotiates political concessions with the rebels. This variable, called simply “maximum concessions”, was developed by gathering, analyzing, and coding the political concessions contained in the signed agreements intended to end every instance of civil war meeting the operational definition that started between 1945 and 1992. "Maximum concessions" is coded along a seven-point index that ranges from no compromise being offered by the state, at one extreme, to the abdication of control of territory by the state, at the other extreme. The proposed coding scheme to be used is developed below and sketched in Table 4.2 and developed in more detail below. 


\begin{tabular}{||c|l||}
\hline \hline \multicolumn{2}{||c||}{ Coding categories for the dependent variable “maximum concessions” } \\
\hline Value & \multicolumn{1}{c||}{ Type of concession made by the state to the rebels } \\
\hline 0 & No political changes offered by the state. (Rebels capitulate) \\
\hline 1 & $\begin{array}{l}\text { Negligible or symbolic changes only - indicates a resolution in which } \\
\text { only minimal concessions are offered to the rebels; a "face-saving” deal } \\
\text { only }\end{array}$ \\
\hline 2 & $\begin{array}{l}\text { Policy change - represents changes in the policies and decisions made } \\
\text { by the government offered as a concession to the rebels }\end{array}$ \\
\hline 3 & $\begin{array}{l}\text { Expanded political representation - individuals and groups are given } \\
\text { legitimate status within the political system }\end{array}$ \\
\hline 4 & $\begin{array}{l}\text { Guaranteed political representation - Groups are guaranteed positions } \\
\text { within the executive (Cabinet-level or above), legislative, or judicial } \\
\text { branch }\end{array}$ \\
\hline 5 & $\begin{array}{l}\text { Changes in autonomy - full or partial transfer of power or decision- } \\
\text { making authority from the central government to a regional government } \\
\text { or other political decision-making body }\end{array}$ \\
\hline 6 & $\begin{array}{l}\text { Secession of territory - the state cedes its claim of sovereignty over a } \\
\text { territorial region or group of people }\end{array}$ \\
\hline
\end{tabular}

The construction of this index contains several general categories of concessions that have been offered by the state and accepted by the rebels. The development and ordering of the categories is intended to capture variations in the degrees to which the rebels gain influence in the decision-making processes of the government as it affects the entire state or a portion of it. Three general types of changes are considered in the development of this measurement - policy changes, changes in the process by which government officials

\begin{tabular}{|c|c|c|}
\hline \multicolumn{3}{|c|}{$\begin{array}{c}\text { Figure } 4.1 \\
\text { Relative severity of state concessions }\end{array}$} \\
\hline Policy & Power-sharing & Territory \\
\hline Least severe & & Most severe \\
\hline
\end{tabular}

are selected, and changes addressing the control of territory. The categories are ranked according to the increase in severity of the concessions from the perspective of the state, 
which is diagramed in Figure 4.1 below. Deals that grant more influence over decisionmaking are considered to be more severe and therefore receive a higher ranking, while less valuable concessions receive a lower one.

\section{No political concessions}

The extreme value of 0 represents an absence of political concessions offered by the state. A score of 0 is assigned to a civil war when one of two outcomes occurs. First, in this cases in which no negotiated settlement exists, a score of 0 is assigned. This includes instances in which one side defeated the other on the battlefield and no terms of settlement were ever signed and cases which are ongoing as of December $31^{\text {st }} 1999$. In those cases where a negotiated settlement was concluded, the agreements only address the process by which fighting ends and troops are removed from combat rather than actual political changes, while the agreements in which these terms are enumerated are more correctly referred to as cease-fires, according to the definitions utilized in this research.

The inclusion of a measure that does not denote the presence of state concessions along political lines (an essential component of the definition of state concessions, according to the operational definition adopted by this research) may seem unnecessary, but is justified on methodological grounds. As previously mentioned, the data analyzed herein consists of all civil wars that started between 1945 and 1992 without regard to the mechanism of resolution. This was done to avoid biases that may simultaneously affect both the likelihood that a negotiated settlement occurs as well as the terms of a resulting agreement. It becomes necessary, then, to differentiate between those civil wars that 
ended by a negotiated settlement containing political concessions and those that did not end with the state granting concessions. Given the emphasis of this research identifying the factors that influence concessions made by the state to the rebels - all cases in which no negotiated settlement occurred or where a negotiated settlement does not contain concession will receive a score of 0 .

The categories of concessions represented by increasingly higher values (1-6) represent greater degrees of political concessions offered to the rebels by the state. These scores are ordered according to the degree to which each type of concession represents a substantial change in the pre-war political decision-making process. Lower scores indicate relatively less change, while the higher scores demonstrate greater degrees of change. At the lower end of the scale (1-2) are policy changes, which indicate a change brought about by rebel pressures, but ones that do not directly expand the decisionmaking authority of the rebels. This category captures concessions that address specific decisions, outputs, and policies of the pre-war government but that do not address to whom government decision-making authority applies or the process by which the decisions are made. The intermediate levels (3-4) represent concessions in which the state agrees to expand the role of the rebels within the government. In doing so, the state concedes to the rebels the ability to influence a variety of political decisions made by the state. At the higher end of the scale (5-6) are categories that represent changes in which the state abdicates some or all of its political decision-making authority over a territory or group of people, thereby reducing the territorial jurisdiction of the state. These scores are developed in more detail below. 


\section{Policy concessions}

Of the three categories of compromise, policy concessions are considered to be the least severe. Policy concessions are those that address changes in the specific decisions, outputs, and policies of the pre-war state but that do not include changes regarding the selection of the government or its jurisdiction. In essence, policy changes represent "one-shot" deals because these changes do not provide the rebels with a permanent mechanism by which they may influence future political decision-making or increased control over any territory. These types of concessions are limited to specific decisions made by the government but do not address the process by which decisions are made. Therefore, these types of concessions are considered to be least severe from the perspective of the state because they represent only a point-in-time influence in the decision-making process of the state.

The severity of policy changes can, of course, can vary considerably in terms of its value to the state. To account for this, the measurement of policy concessions will divide policy changes into two subcategories. A score of "1" will be assigned to any concession that represents only a symbolic policy change, which is considered to be one that does not directly affect the political, social, or economic resources available to the group. This category is primarily intended to capture concessions made by the state to the rebels that are limited to a "face-saving" deal, such as when the government of Malaysia agreed to recognize the civil rights of the Communist Party of Malaysia in exchange to a halt of the fighting in what is commonly known as the Malaysian Emergency (1948-1956). Other low-level policy concessions would include granting political recognition to the rebel group, but not establishing any new political rights to the 
group, or the creation of a holiday in commemoration of a rebel interest. For example, amnesty was granted to the rebels at the end of the Chadian civil war (1979-1979), while the Angolan government extended amnesty for crimes against the state in its peace agreement bringing the 1975-1991 war to and end. Cambodia, in its 1991 settlement guaranteed the right of refugees to return to their homeland and promise to protect human rights. El Salvador, as a part of the New York Protocols of 1992, affirmed the legal and civil rights of all Salvadorans. Each of these represents what is categorized as a low-level policy concession. Clearly the issues at hand may be of utmost importance, especially to the rebels and their supporters. However, the direct costs to the state in these cases are minimal as each represents a minor concession relative to the other forms of compromise. Since the emphasis of this research is on the concessions made by the state, it follows that the value of the concessions should be viewed from that perspective. And while political costs may be great, when viewed in terms of the expenditure of resources that is required, these types of concessions are relatively minor. This value, then, represents the least severe form of compromise the state can offer because it does not involve the reallocation of political, social or economic resources.

A score of "2" is assigned to agreements in which the greatest concession made by the state to the rebels is the expansion of the rebels' access to political, economic, or social resources. Also included in this category is a reorganization of the state's military forces to include rebel soldiers, a concession which was made in several cases including: Angola (1975-1991), Cambodia (1978-1991), Chad (1989-1996), the Philippines and several others. ${ }^{13}$ Examples involving the reallocation of resources include promises

\footnotetext{
${ }^{13}$ It could easily be argued that a reorganization of the military exceeds the limits of this category because of the obvious security implications involved. The cases in which this occurred presented a difficult
} 
made by the Philippine government to increase social welfare spending and to protect natural resources in the Mindanao region, promises made by the Guatemalan government for assistance in the resettlement of refugees as a part of The Agreement on a Firm and Lasting Peace (Guatemala City, 1996), a clause in the Sitges Agreement ending the Colombian civil war (1948-1962) whereby the government pledged a 10 percent increase in funding for education, and relocation assistance for refugees in Bosnia (1992-1995). In each of these cases, the state must either revise its pre-existing allocation of spending or concede access to resources. While these types of concessions may not be as politically contentious at times, the direct costs to the state do increase. Therefore, this type of concession is considered to be more severe than symbolic changes because it represents a material change to the rebels' access to and claim on the political, social, and economic resources of the state. It is less severe than both factors affecting the makeup of the state and territorial control because these changes do not grant the rebels a permanent influence on the government.

\section{Power-sharing concessions}

In the second category of concessions - power-sharing, where changes in the make-up and selection of government officials are extended - the state concedes some access to the decision-making process of the entire state. Here the state essentially concedes a seat at the table to the rebels, thereby enabling them to influence a wide range of decisions that come before the government. However, the severity of these

choice. The decision was made to include military reorganization in the policy category because such a concession (a) required the state to reallocate resources in order to make the changes; and (b) because the changes did not alter the power-sharing arrangement of the former adversaries in the post-civil war political system. 
concessions can vary as well and so this category is also subdivided into two subcategories. A score of " 3 " is assigned to the case if rebels are granted the opportunity to become decision-makers, but are not guaranteed such a role. Examples of such events include settlements that allow for the participation of a rebel associated political party, the granting of multi-party elections, or an expansion of voting rights. Such was the case in the Vientiane Agreement between Laos and the Pathet Lao in 1973 where the existing monarchy is replaced with a coalition government, free and competitive elections extended by the Sandinista government of Nicaragua to the Contra rebels in 1990, and the constitutional reforms required by the resolution of the Guatemalan civil war of 19631996. The emphasis on this type of concession is on the right to but not a guarantee for political participation. Thus, this case is considered to be more severe than policy changes because it allows the rebels the opportunity to permanently gain influence, but it less severe than the following subcategory, in which the rebels are guaranteed participation.

In cases where the rebels are guaranteed a high-level decision-making role in the post-war government, a score of "4" is assigned. ${ }^{14}$ To be considered a high-level appointment, the positions must be legislative seats, positions in the executive branch at the cabinet level or above, judicial positions at the appellate level, or the uppermost offices of provincial governments. Examples of concessions leading to this score include events such as an agreement guaranteeing a portion of legislative seats being reserved for the rebels or the guaranteed appointment of a number of high-level officials to at least cabinet-level positions in the executive branch or the judicial system. For example, the

\footnotetext{
${ }^{14}$ This subcategory is based on Walter's (2002, p. 64) variable POLPACT, which is an independent variable that tests the effect of a political pact on the outcome of mediation as it relates to the likelihood of a negotiated settlement.
} 
Declaration of Sitges between the government of Colombian the National Front (which ultimately failed) required that an elected presidency alternate between Conservatives and Liberals every four years, while the Taif Agreement ending the Lebanese civil war of 1975-1990 requires an equal split between Muslims and Christians in the Chamber of Deputies. This subcategory is considered to be a greater concession than the previous subcategory because the state in effect ensures that the rebels gain a permanent role in state decision-making, but less severe because the state does not grant the rebels independent political authority or complete sovereignty over territory.

\section{Territorial concessions}

The final category of concessions - those addressing control of territory represent the most severe type of concessions made by the state ${ }^{15}$. This is considered to be so because in this case the state gives up some or all of its territorial sovereignty and, as a result, forgoes access to the resources and benefits of that territory. Again, two subcategories account for degrees of difference with the category. Concessions that grant partial autonomy over a geographic area are coded as a " 5 ” because these concessions are considered to be less generous than those that grant outright sovereignty. Partial autonomy in this case means that the rebels gain or are granted some form of regional governing authority, ranging from administrative powers to the right of self-rule, but short of outright political independence. This type of concession occurred in only three cases: Bosnia (1992-1995), the Government of the Philippine versus Moros (1972-1996),

\footnotetext{
${ }^{15}$ This variable is based on Walter's (2002, pp. 62-63) variable TERRPACT, which is an independent variable that tests the effect of a territorial pact on the outcome of mediation as it relates to the likelihood of a negotiated settlement.
} 
and Sudan (1963-1972). Each of these is discussed in detail below. These types of concessions are considered to more severe than concessions involving political representation because it grants the rebels decision-making authority over a geographic region, but less severe than full autonomy or secession.

The most severe form of concession categorized by this measure is the secession of territory or the granting of complete autonomy, which receives a score of " 6 ", was not observed. However, the category was created to account for extreme concessions involving the control over territory, although such an event did not occur. ${ }^{16}$ When granted sovereignty over a piece of territory, the rebels become empowered with some degree of legitimate authority and are therefore able to influence a wide range of political decisions at the expense of that of the state. In essence, the government created by the rebels replaces that of the state as the legitimate ruling authority. This subcategory is considered to be the most severe because in this case the state gives up access to the resources and benefits of the region. ${ }^{17}$ The results of the data collection are summarized in Table 4.3 below.

\begin{tabular}{|l|c|}
\hline \multicolumn{2}{|c|}{ Occurrences of “maximum concession”, by type } \\
\hline Level of concession & Number of occurrences \\
\hline 0: No concession & 64 \\
\hline 1: Low policy concession & 1 \\
\hline 2: High policy concession & 0 \\
\hline 3: Low power-sharing concession & 15 \\
\hline 4: High power-sharing concession & 8 \\
\hline 5: Low territorial concession & 3 \\
\hline 6: High territorial concession & 0 \\
\hline
\end{tabular}

\footnotetext{
${ }^{16}$ As the example of East Timor demonstrates, such concessions do occur. In this case the government of Indonesia granted full and total independence in May of 2002 after a nearly twenty year attempt to establish peace failed.

${ }^{17}$ This category of concessions is largely based on the prevailing theme within the international relations literature that contends that territory is of utmost importance to the state.
} 
In sum, the measurement of compromise to be developed for this project focuses exclusively on the extent to which the state makes concessions to the rebels in order to construct a mutually acceptable negotiated settlement. At the extremes are those categories that represent the capitulation of the rebels (a score of 0 ) to the the abdication of state authority over a piece of territory (a score of 6). Intermediate categories will account for concessions involving policy changes (scores 1 and 2), the selection of government officials (scores 3 and 4), and the control of territory (scores 5 and 6).

\section{Measuring the independent variables}

Seven hypotheses were discussed above that are used to test the applicability of bargaining theory to the resolution of civil wars. Much of the information regarding the characteristics of particular conflicts and of combatants that will be used to test the hypothesized relationships has been gathered elsewhere. Where possible, this research will make use of pre-existing data. As with the case selection process, the gathering of data will integrate information from a variety of sources, including the Correlates of War Project, Hartzell and Hodie’s Institutionalizing Peace (2003); Walter's Civil War Resolution Data Set (2002); Regan's Civil War and Foreign Powers data set, Keesing's Contemporary Archives, EUROPA World Book, The CIA World Factbook, SIPRI Yearbooks, and detailed case studies. The measurement of these variables is discussed in more detail below. 


\section{Measuring costs and perceptions of success}

One of the primary conditions that can lead to war, according to bargaining theory, is presence of private information each side has about their strength, tactics, and resolve. Once war breaks out and as the fighting progresses, however, each side necessarily gives up information about these characteristics. When a combatant's adversary performs unexpectedly well, it should increase the demands it makes at the bargaining table. Conversely, when a combatant performs unexpectedly poorly, that combatant should then decrease its expectations. Success, then, should be reflected in the final terms of settlement.

Although difficult to measure directly, this research will use to commonly used proxies to account for success: the number of deaths sustained by the state and the duration of the conflict. To measure the total number of deaths sustained by the state in each conflict, the variable "State Deaths" is adopted from the Correlates of War Project. According to the COW codebook, "State Deaths" measures the "total battle deaths of state participants”. COW data will also be used to measure the duration of the conflict. The length of the conflict in months will be calculated from the start and end dates listed in COW, with any month in which the conflict was ongoing being counted as a month.

\section{Measuring incentives to cheat}

Bargaining theory also contends that the presence of incentive to cheat lead to war. Based on the reasoning that the state will be more willing to make concessions if the agreement is likely to be followed, Hypothesis 3 contends that the presence of a third party security guarantee will increase the extent to which states make concessions to 
rebels. To denote the presence of absence of a third-party security guarantee, a dichotomous dummy variable called "guarantee” will be created using Walter’s (2002) Civil War Resolution Dataset. Walter (2002, p. 69) defines a third-party security guarantee as being present if a third party makes a "promise to enforce or verify posttreaty behavior and provision of expected services.” It must be noted that, for the purposes of this research, a third party security guarantee is not analogous to the broader term intervention but is instead a special type of intervention.

To qualify as a third-party security guarantee, an intervention must meet two criteria. First, an outside actor must provide "a verbal or written promise to verify or enforce post-treaty behavior once a settlement was signed” (Walter 2002, p. 65). Furthermore, merely making such a promise does not qualify as a guarantee, according to Walter's coding: “In order for an offer to be classified as a security guarantee, an outside state or international organization had to follow through with its promise and provide the expected services” (2002, p. 65). In contrast, an intervention occurs when a third party provides assistance to combatants "with the aim of affecting the balance of power between the government and opposition forces” (Regan 2002, p. 10). In other words, an intervention can include aid and support to one side to bring about a desired outcome or can be neutral to help settle the dispute, whereas a security guarantee by definition eliminates cases in which an intervention is biased towards the success of one side because the intended purpose is to ensure the implementation of the agreement. 


\section{Measuring indivisibility}

Hypothesis 4 and Hypothesis 5 address matters of issue indivisibility, which, at least theoretically, make the conclusion of a compromise resolution more difficult. According to Hypothesis 4, territorial disputes are predicted to result in fewer concessions being made by the state to the rebels. Conflicts in which the stated goals of the rebels are territorial independence will be coded as a " 1 " with all others being coded as a “0”, based on Walter’s (2002) Civil War Resolution Dataset. Walter (2002, p. 61) defines a territorial war as one in which "the rebels aimed to secede from the original territory or demanded territorial autonomy”. Territorial disputes are a legitimate, although imperfect, measure of indivisibility because territory is in effect indivisible, unless some mutually acceptable mechanism can be created by which access and control can be shared. When the claim on the territory is valuable, combatants are unlikely to concede their claims unless forced to do so. ${ }^{18}$

Hypothesis 5 predicts that ethnic conflicts will also present divisibility problems. According to this hypothesis, when combatants identify themselves according to their ethnicity fewer concessions will be made by the state to the rebels. To denote this condition, this research will differentiate between ethnic and non-ethnic conflicts, as coded by Walter (2002). She defines an ethnic conflict as a civil war in which "the combatants broke down along ethnic lines” to account for ethnic divisions between the combatants (Walter 2002, p.59). Ethnic divisions present a useful measure of indivisibility because ethnicity, as noted by Kaufmann (2001, pp. 452-453), “shrinks

\footnotetext{
${ }^{18}$ This logic is contrary to that posed by Walter (2002, p. 13) who argues that "territorial wars will be more likely to reach a negotiated settlement than nonterritorial conflicts." However, the argument being put forth here is that conflicts over territory will be difficult, but not impossible, to resolve via a negotiated settlement and that the state will make such concessions only when necessary.
} 
scope for individual identity choice”. As he observes, two reasons exist for individuals to value their ethnic ties: the threat of sanctions imposed by extremists within the society and the tendency of adversaries to impose its views of ethnic lines on its opposition. As a result, combatants are likely to view the conflict in terms of ethnic divisions, which are unlikely to be negotiated away.

\section{Alternative explanations}

Two hypotheses in addition to those drawn from bargaining theory have been developed from the literature addressing the conditions under which civil wars are more likely to be settled via a negotiated settlement. As discussed above, this literature may provide additional insight into the factors that influence the content of a negotiated settlement. Two variables are proposed to have and effect - the presence of a "mutually hurting stalemate" and the level of democracy exhibited by the state. The measurement of these variables is discussed below.

According to Hypothesis 6, the presence of a mutually hurting stalemate, or a condition such that neither side is able to achieve defeat and both combatants incur costs, should increase the willingness of the state to make concessions to the rebels. The literature contends that, as a result of this condition, the conflict is "ripe for resolution" and the combatants will perceive war as an inefficient or ineffective means by which to achieve their goals and therefore seek an alternative means of resolving the underlying dispute. When applied to the content of the resolution, this theory logically indicates that combatants involved in a "ripe" conflict will be willing to offer concessions that are 
greater than those offered in conflicts that have not produced a "mutually hurting stalemate”.

To indicate the presence of a "mutually hurting stalemate”, this research will follow the lead of Walter (2002), Zartman (1989), and Licklider (1995), who take the presence of a military stalemate as an indicator of a "mutually hurting stalemate". To indicate the presence of a stalemate, the variable "stalemate", which denotes the presence of a stalemate at any time during a conflict, was drawn from Walter’s Civil War Termination Data Set. To determine whether or not a stalemate existed in any given conflict, she "sifted through reports and historical accounts, noting each time the battlefield situation was described as 'stalemated' or at an 'impasse””. With regards to the obvious subjective nature of the nature, she notes that "in most cases a consensus existed among historians as to whether the fighting ground to a halt”.

The final hypothesis predicts that states that the more democratic the state is, the more generous the concessions made by the state to the rebels. When applied to the likelihood of a negotiated settlement occurring, this literature contends that democracies are more likely to conclude a negotiated settlement to appease public opposition, because their credibility enhances their ability to do so, and because democratic norms of behavior make them more accommodating. When applied to the terms of settlement, this literature implies that democracies may be willing to grant greater concessions than nondemocracies to appease the public more quickly and because of an increased likelihood to compromise.

To measure the degree to which a state is democratic or authoritarian, this research will rely on the commonly-used "Polity Score” from the Polity IV Project. This 
combined score is derived from two composite scores that place indicate the degree to which each state is democratic (“DEMOC”) and autocratic (“AUTOC”). Both DEMOC and AUTOC are eleven-point indicators that range from 0 to 10 . According to the Polity IV Project, DEMOC is computed based on the values of three indicators - the competitiveness of political participation, the openness and competitiveness of executive recruitment, and constraints on the chief executive, while AUTOC has five components the competitiveness of executive recruitment, openness of executive recruitment, constraints on the chief executive, regulation of participation, and competitiveness of participation. To achieve the POLITY score, AUTOC is subtracted from DEMOC, producing a range from +10 , or strongly democratic to -10 , or strongly autocratic.

\section{Summary}

The purpose of this chapter has been to shed light on the process by which abstract concepts are operationalized into concrete measures. This was done to permit an informed and critical assessment of the techniques utilized. The case list covers all civil wars that started between 1945 and 1992, with data collected through the end of 1999 in cases where the war was unresolved. The dependent variable "compromise" is intended to quantify the degree to which states makes concessions to their rebel adversaries. To do so, the texts of written agreements were coded along a seven point scale, a process which entailed the collection of original data. The values for the independent variables were primarily drawn from existing sources and extended where necessary. 


\section{Chapter 5: Evaluating trends and patterns}

The purpose of this research is to identify the factors that influence the extent to which states make concessions as a result of civil war. To do so, this research derives a possible explanation from bargaining theory. This research can also be viewed as an evaluation of the applicability of bargaining theory to explain the factors that influence state concessions. The data collected for these purposes have been analyzed in three stages. First, basic descriptive statistics are presented in order to provide the reader with a familiarity with the data used herein and to serve as a benchmark for further analysis. This part of the discussion focuses on patterns and trends involving the onset and resolution of civil wars, while the second addresses patterns of state concessions. The second stage of the analysis (addressed in Chapter 6) focuses on the extent to which states are willing to compromise, which is analyzed by utilizing a Tobit model to determine how much states are willing to concede. And finally, the two most common types of concessions - policy and power-sharing - are then analyzed by a probit model. ${ }^{19}$ The purpose of this is to focus on any variations in determinants between types of

\footnotetext{
${ }^{19}$ Both the frequency with which territorial concessions were granted as well as their distribution between levels of high and low concessions made the application of inferential statistics impossible.
} 
concessions. Finally, territorial concessions are analyzed in Chapter 7 using a qualitative approach. This is necessitated by both the small number of territorial concessions (three total) and the lack of variation between high and low levels (all are low).

\section{Descriptive statistics and graphical analyses}

In what follows, a variety of descriptive information regarding concessions is presented. The purpose of this is twofold. First, detailed information regarding each of the variables is provided to make the analysis as transparent as possible. The quality of any analysis is, of course, highly dependent on both the validity and the reliability of the measures employed. The assessment of the validity and reliability of any variable is necessarily a somewhat subjective process and one that requires knowledge of both the means by which the information is gathered and the result of those efforts. Therefore, in order to provide the reader with as much information as possible with which to assess the quality of the measures on which this analysis is based, the prevalence with which civil wars begin and the means by which they are resolved are discussed below.

The second reason for this discussion is to address the presence of patterns and trends displayed within the data. Of course, the purpose of inferential statistics and qualitative analysis is to capture the presence and the strength of these empirical regularities. Descriptive statistics do, however, have their place. Not only will such a discussion familiarize the reader with the data used to test theoretically-derived hypotheses (thereby validating or invalidating the theoretical conjectures), but will also serves as a baseline to which further analyses can then be compared. The underlying purpose of this discussion, then, is to construct a framework for analyzing the 
applicability of bargaining theory to understanding the factors that influence political concessions made by a state to its civil war adversaries and to provide the reader with the information necessary to conduct a critical assessment of this research effort.

\section{Comparing datasets}

As previously discussed, the frequency with which civil wars result in a negotiated settlement rather than a capitulation is a highly contention issue. Therefore, it is reasonable to begin an analysis of any such data with a discussion of the prevalence of negotiated settlements. Using the methods developed in the previous chapter, this

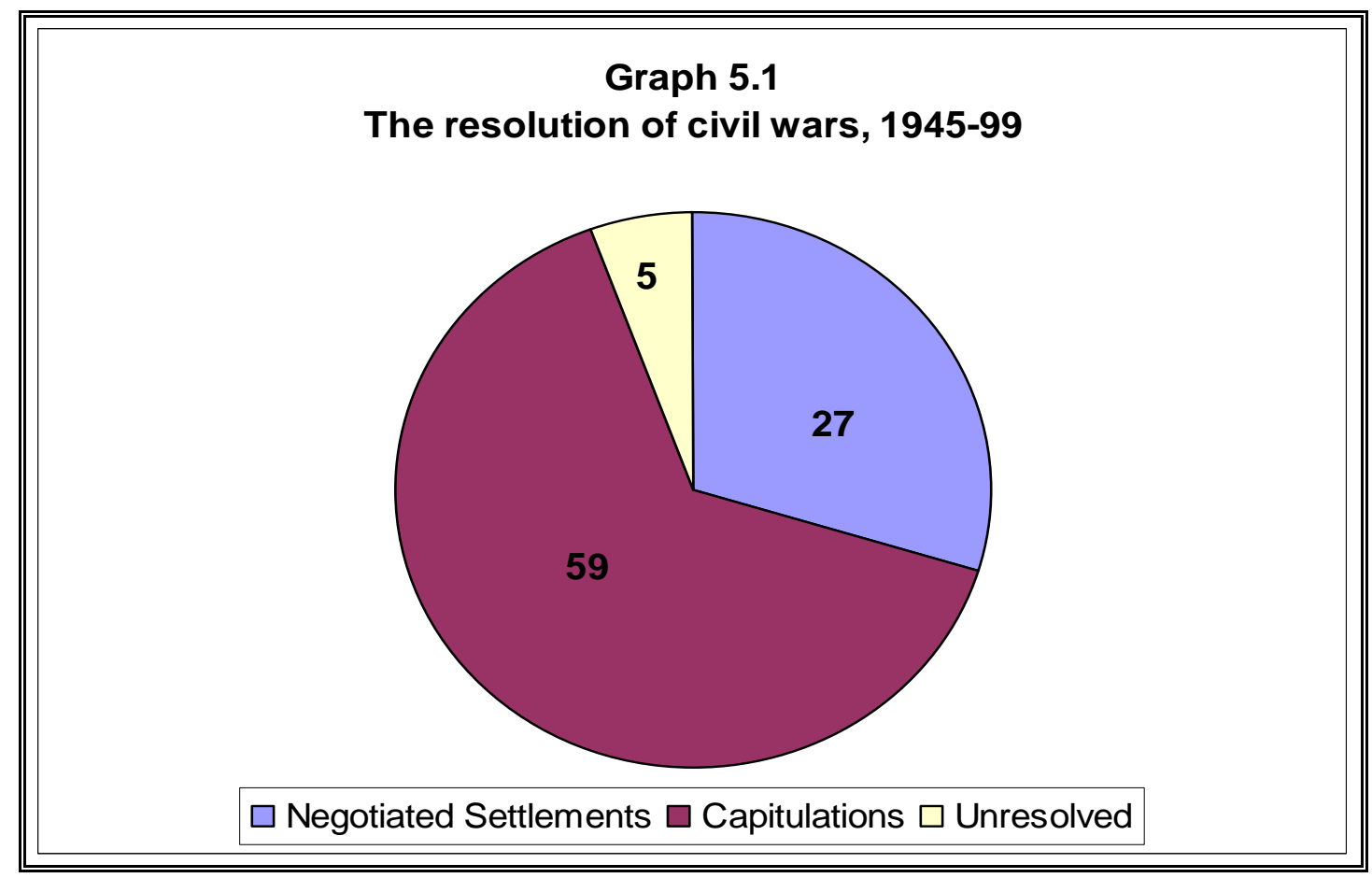

research produced a dataset of 91 civil wars that started between 1945 and 1992. Each of these wars was coded as being ended by a negotiated settlement or a capitulation or as being unresolved by December 31, 1999. Of these wars, a total of $27(29.7 \%)$ ended in a 
negotiated settlement, while 59 (64.8\%) ended in a capitulation and 5 (5.5\%) were unresolved at the time of the cut-off. Graph 5.1 above depicts these differences.

In terms of assessing the quality of the data, however, it may be more valuable and informative to compare the prevalence of negotiated settlements in this dataset with that of similar efforts. Relative to the datasets on which this effort is based, this dataset demonstrates an intermediate likelihood that a civil war ends in a negotiated settlement. In her Civil War Resolution Dataset, Walters (2002) indicates that 13 out of 72 civil wars (or about 18\%) were negotiated. This is far less than the counts produced by Hartzell and Hoddie (2003), who count 38 negotiated settlements out of 103 civil wars (or about 47\%). Relative to the results of other authors, this research produces a count that is relatively low. These counts are further summarized in Table 5.1 that follows.

\begin{tabular}{||l|c|c|c||}
\hline \multicolumn{4}{|c||}{ Table 5.1 } \\
\hline \multicolumn{1}{||c||}{ Counts of negotiated settlements in civil wars, by author } \\
\hline Walter (2002) & Time Frame & Settlements, \# & Settlements, \% \\
\hline Current dataset & $1940-1992$ & 13 of 72 & 18 \\
\hline Stedman (1991) & $\mathbf{1 9 4 5 - 1 9 9 2}$ & $\mathbf{2 7}$ of $\mathbf{9 1}$ & $\mathbf{3 0}$ \\
\hline Pillar (1983) & $1974-1981$ & 20 of 56 & 31 \\
\hline Hartzell and Hoddie (2003) & $1800-1980$ & 6 of 19 & 32 \\
\hline Modelski (1964) & $1945-1998$ & 38 of 103 & 47 \\
\hline
\end{tabular}

\section{Trends and patterns in civil wars}

Other meaningful observations regarding patterns and trends in the onset and resolution of civil wars may also be drawn by making comparisons across time and space. In what follows, descriptive statistics and graphical analyses are used to identify differences and similarities in the behavior of civil wars temporally and geographically. Comparisons are made in the onset and resolution of civil wars both during and after the 
Cold War in what immediately follows. Differences in civil wars are then discussed according to the region of the world in which they occur.

\section{Negotiated settlements across time}

Temporally, the vast majority of the civil wars described in the dataset started in the 45 year period that roughly coincides with the Cold War era. Clearly this is an expected pattern and is easily explained by the differences in the time spans. However, it is interesting to note that a dramatic increase in the rate at which civil wars erupted occurred during the short time period following the Cold War. Although it is difficult to precisely pinpoint the start and end of historical periods of time, this dataset indicates that 80 of the 91 civil wars (or nearly 88\%) began between 1945 and 1989, a time period that roughly coincides with the Cold War, while 11 (or about 12\%) began in the relative short time span of 1990-1992. Such a difference is not surprising, especially given the large

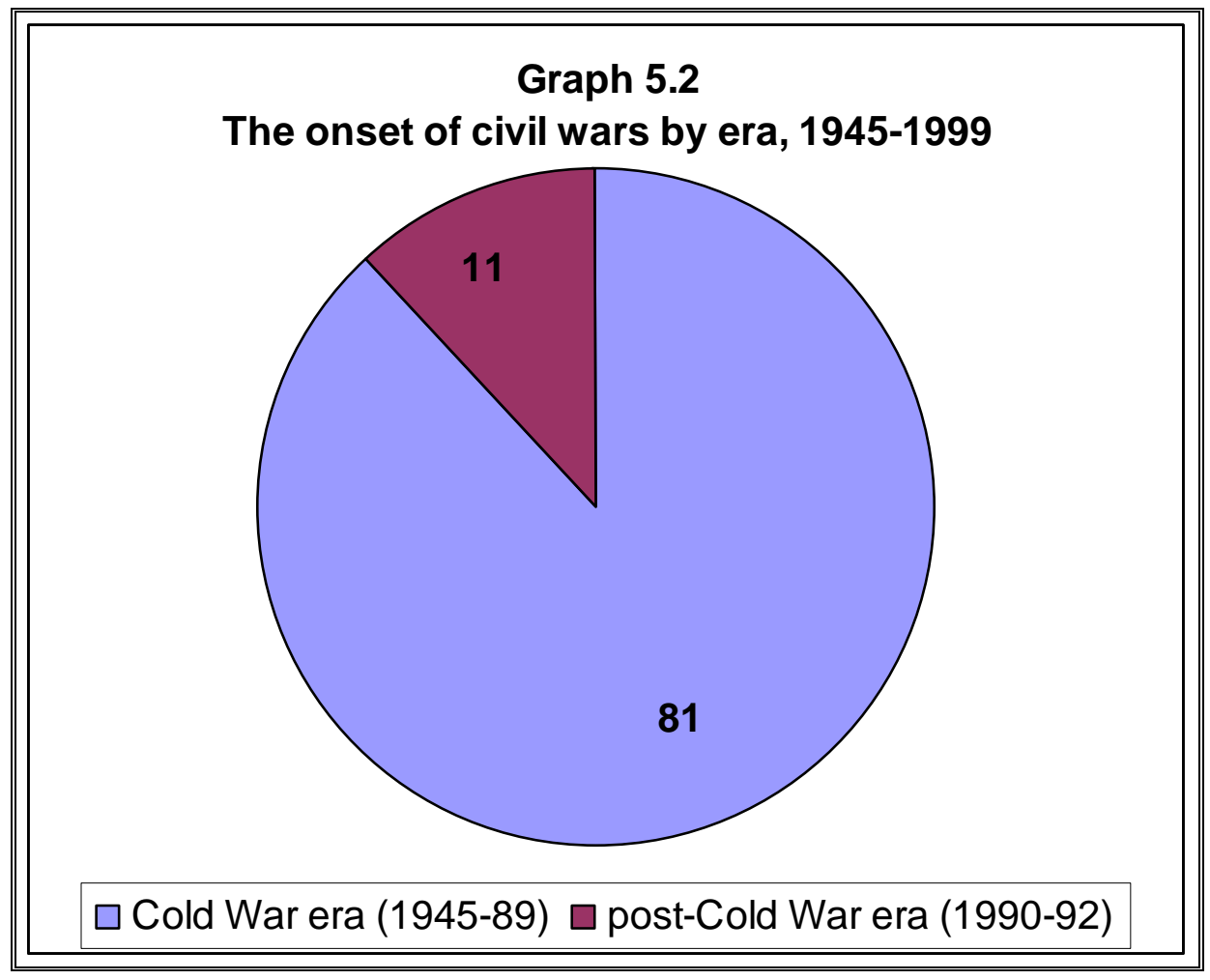


variation in the time span of each historical period. (See Graph 5.2 above). However, a comparison of the rates at which civil wars began is much more enlightening. According to this dataset, civil wars erupted at a rate of roughly 1.8 wars per year from 1945 to 1992. However, in the years following the Cold War (1990-92), this dataset documents outbreaks at the rate of 4 per year, more than a doubling of the Cold War rate. Thus, the data indicate a marked and dramatic increase in the onset of civil wars in the period immediately following the end of the Cold War. ${ }^{20}$

An even more relevant observation for this project that can be drawn from historical patterns by examining the frequency with which civil wars come to an end. Of the wars documented in this dataset, 26 (29\%) were resolved (either by the defeat of an adversary or a negotiated settlement) in brief period of time following the Cold War despite the fact that the overwhelming majority of wars started prior to 1990. Comparatively speaking, 60 civil wars (66\%) were resolved in more extensive time period between 1945 and 1989. This translates into civil wars ending at the rate of 1.3 wars per year drawing to a close during the Cold War and more than twice that rate -2.6 per year - following the Cold War. Briefly, this raises the possibility of at least two explanations: (1) that civil wars started during the Cold War are more likely to end after 1990 simply because wars must, at some point in time, reach a conclusion; or (2) that changes in the structure of the international political system had some causal effect on the likelihood of a war to draw to a close.

\footnotetext{
${ }^{20}$ It should be noted that this has been explained by Gurr (2002) as a short-term spike in the onset of civil wars, which he attributes to the eruption of political and ethnic tensions resulting from the end of the Cold War.
} 


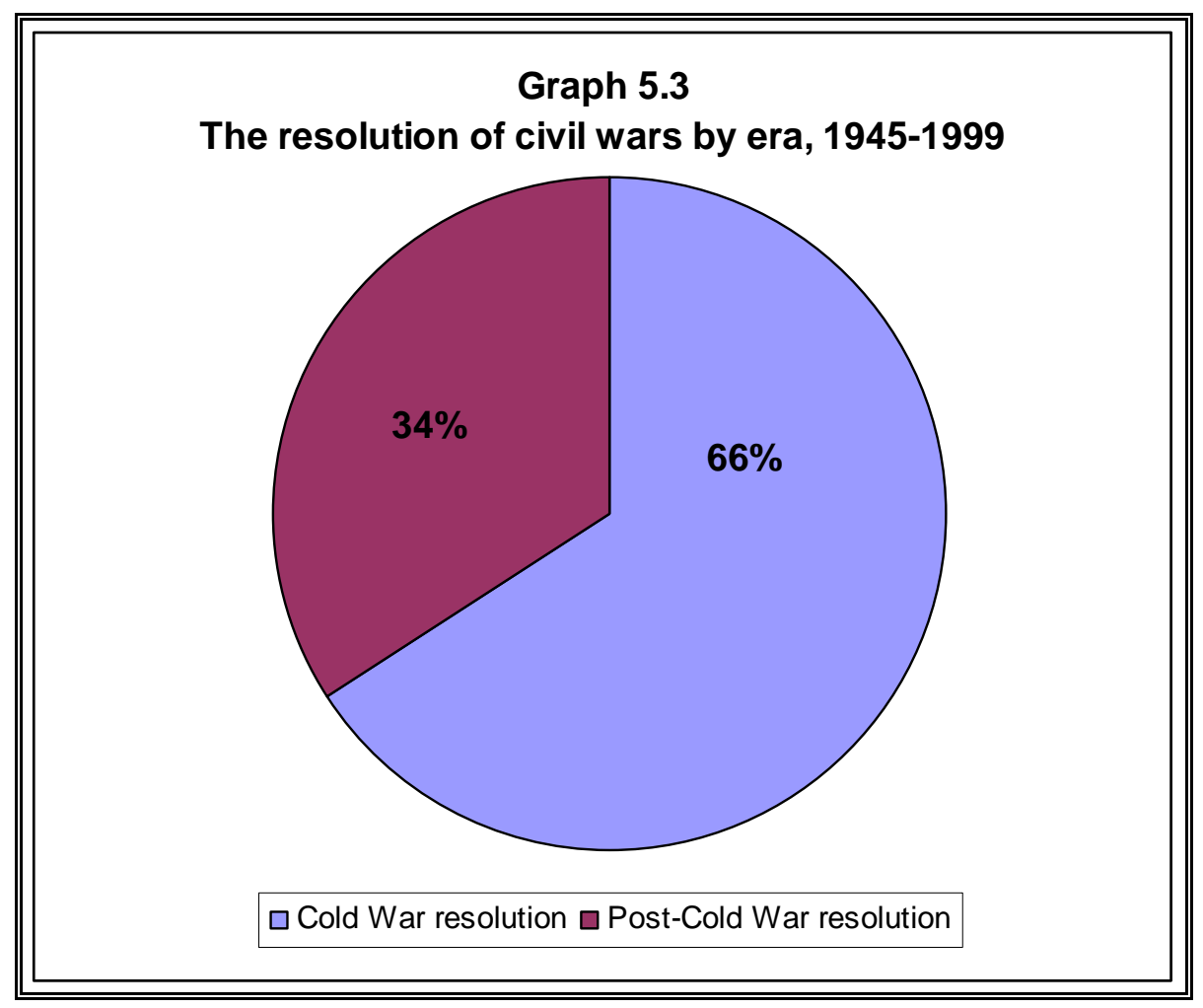

A closer look at these historical patterns is even more informative regarding the means by which civil wars are resolved. This information is summarized in Graphs 5.3 and 5.4 below. In the years following the Cold War, not only does the prevalence with which civil wars are resolved increase, the frequency with which wars are resolved by a negotiated settlement increases and does so at a greater rate than that of capitulations. Of the 60 civil wars resolved between 1945 and 1989, an overwhelming majority of 51 (85\%) ended in the defeat of an adversary, while only 9 (15\%) ended in a negotiated settlement. The propensity of civil wars to result in a capitulation, however, reverses in the post-Cold War period. After 1989, of the 31 wars resolved a clear majority of 18 (58\%) were resolved by a negotiated settlement while only 13 (42\%) resulted in a capitulation. Not only are civil wars more likely to be resolved in the post-Cold War, then, but they are also more likely to be resolved by a negotiated settlement. This raises the possibility that change in the international political system brought about by the end 
of the Cold War may have directly increased the likelihood of civil wars ending in a negotiated settlement in addition to the likelihood that they are resolved.

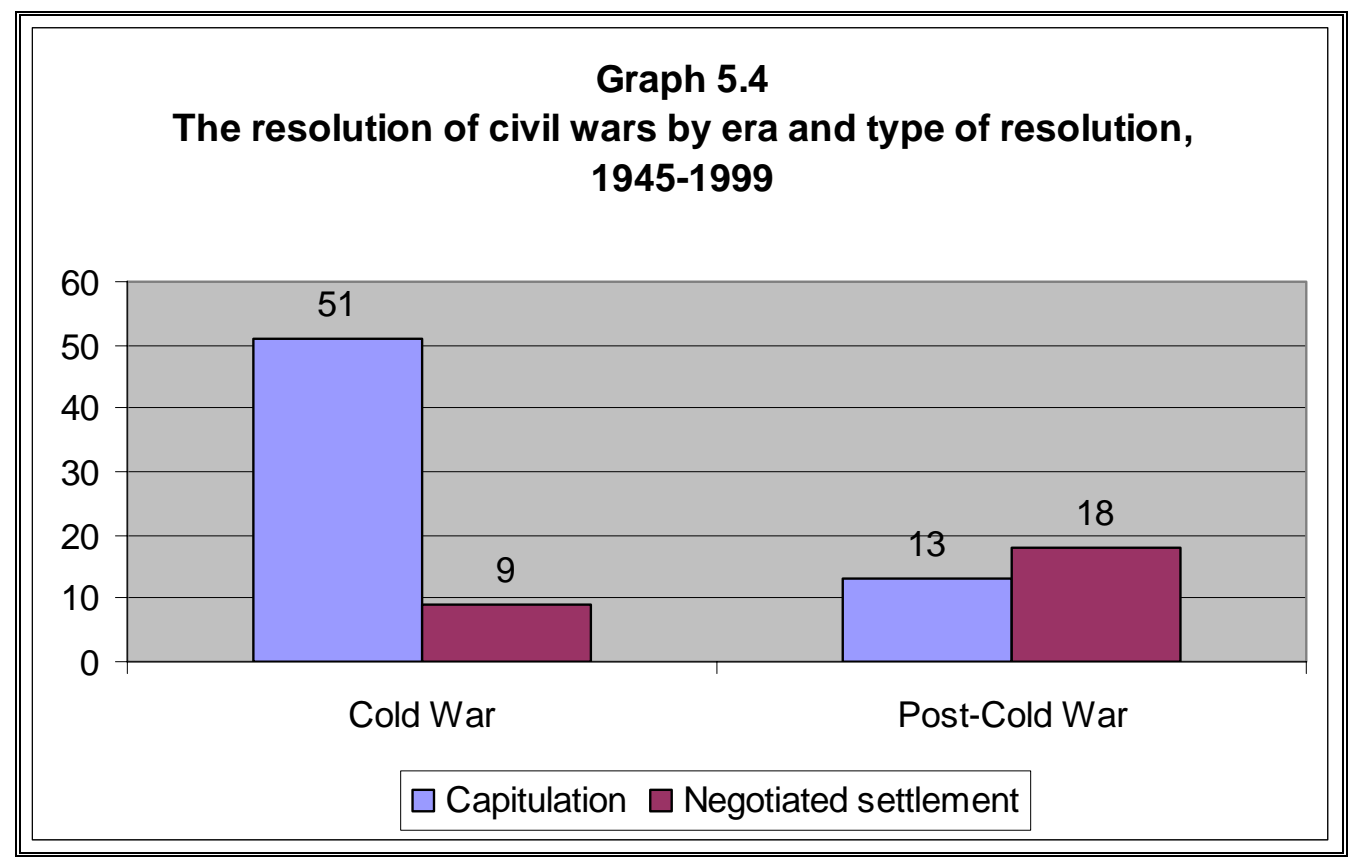

In sum, several interesting patterns in the onset and resolution can be discerned from the data. First, although the number of civil wars that started during the Cold War exceeds that of the post-Cold War period, the annual rate at which wars broke out increases substantially. Second, the post-Cold War period demonstrates a greater likelihood that civil wars will come to an end, whether it be by capitulation or a negotiated settlement. And finally, civil wars that end in the post-Cold War are more likely to end in a negotiated settlement and are more likely to do so than those that end during the Cold War period.

\section{Negotiated settlements across space}

Useful information regarding the patterns and trends exhibited by civil wars may also be gained by examining how civil wars behave across space. Globally, a high 
degree of variation exists in the frequency with which civil wars occur, as summarized in Table 5.2 below. Although a discussion of the possible explanations of why this variation exists is beyond the scope of this project, an analysis of the effects it may have on the content of negotiated settlements may prove to be informative. Between 1945 and 1992, the region of continental Africa experienced the most civil wars, with 30 outbreaks (33\% of civil wars globally), followed closely by Asia at 28 wars (31\% globally). The fewest number of wars occurred in Europe, with 7 wars (8\% globally), while intermediate values were posted by the Middle East (11, or $12 \%)$ and South America (15, or $16 \%)$. In other words, a plurality of the civil wars included in this analysis occurred in Africa and over one-half (58 of 91, or nearly 64\%) occurred in only two of the five regions of the world accounted for in this study. Thus, this analysis is based on a geographic distribution of civil wars that can best be described as uneven, but one that reflects real world variation in the global distribution of civil wars.

\begin{tabular}{|r|c|c|c|c|c||}
\hline \multicolumn{7}{|c||}{ Table 5.2 } \\
\hline & Africa & Asia & Europe & Middle East & South America \\
\hline Count & 30 & 28 & 7 & 11 & 15 \\
\hline Percent & $33 \%$ & $31 \%$ & $8 \%$ & $12 \%$ & $16 \%$ \\
\hline
\end{tabular}

A comparison of the frequency of negotiated settlements indicates that Africa has by far the largest number of negotiated settlements (11 out of 30 wars), with Europe and the Middle East experiencing the fewest, with 5 each. Such a pattern seems reasonable to expect, especially given that Africa has the largest number of civil wars and Europe the smallest (the Middle East has the second fewest, with 11). If one were to assume that the prevalence of negotiated settlements does not vary according to world region, then it 
would necessarily follow that the region with the largest number of civil wars would also have the most negotiated settlements.

\begin{tabular}{||l|c|c|c|c|c||}
\hline \multicolumn{7}{|c||}{ Table 5.3} \\
The resolution of civil wars by region and type, 1945-1999 \\
\hline & Africa & Asia & Europe & Middle East & South America \\
\hline Capitulation & $17(57 \%)$ & $21(75 \%)$ & $4(57 \%)$ & $8(73 \%)$ & $9(60 \%)$ \\
\hline Negotiated settlements & $11(37 \%)$ & $5(18 \%)$ & $3(43 \%)$ & $3(27 \%)$ & $5(33 \%)$ \\
\hline Unresolved & $2(7 \%)$ & $2(7 \%)$ & 0 & 0 & $1(7 \%)$ \\
\hline \hline
\end{tabular}

Such a pattern, however, does not hold. In fact, the data indicate the contrary. An examination of the number of negotiated settlements relative to the number of civil wars within a given region indicates that Europe (which has the fewest occurrences of both civil wars and negotiated settlements) settle the most of its civil wars ending by a negotiated settlement, with $43 \%$. Asia, which has the second highest number of civil wars, settles the fewest of its civil wars by negotiated settlement with $18 \%$. Africa, which accounts for the highest number of civil wars by region, settles $37 \%$ of its civil

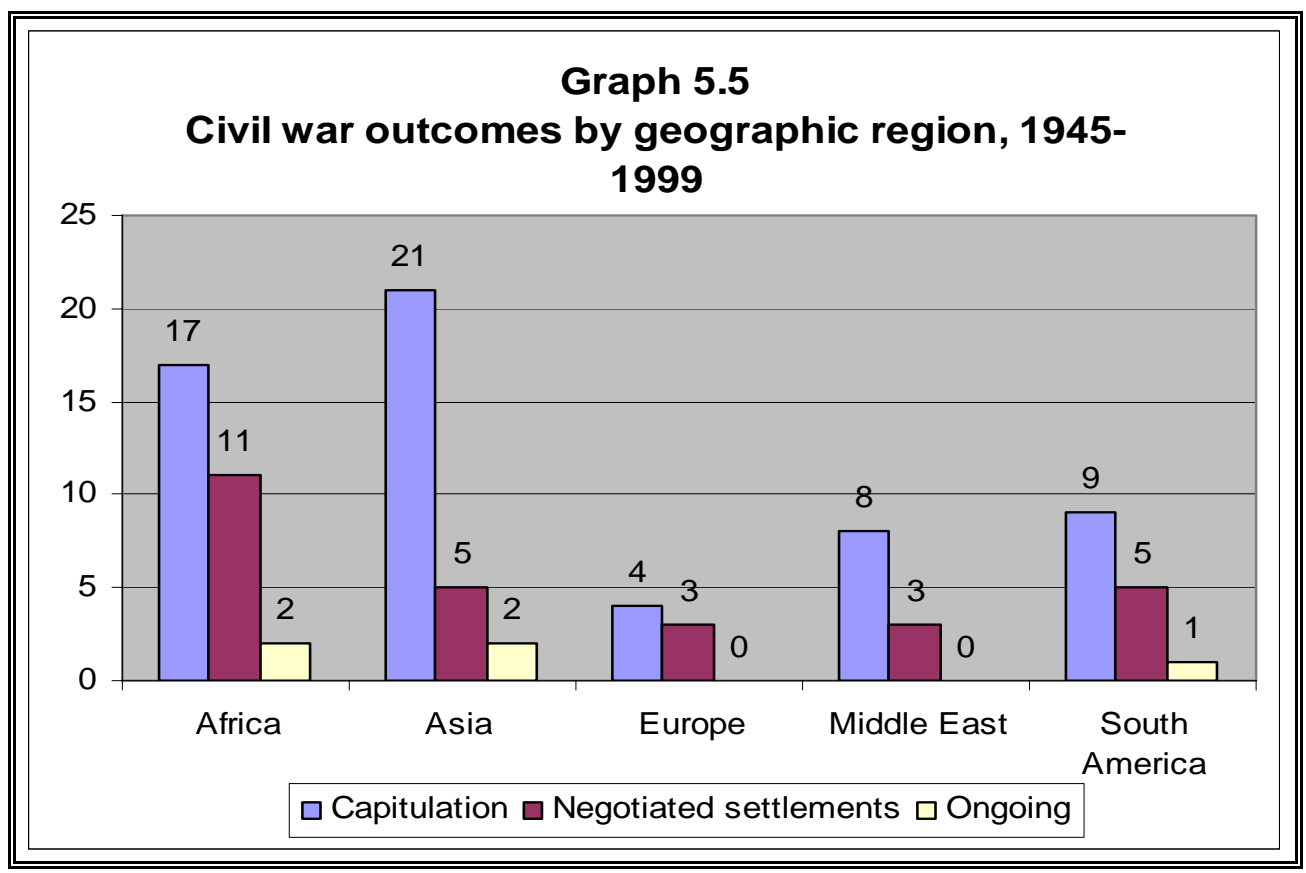


wars by negotiated settlement. Thus, the frequency with which negotiated settlements do occur varies considerable from the overall measure of 30\% globally. Given this, it seems logical to at least tentatively expect that the likelihood of a negotiated settlement may be related to the region of the world in which the war is fought. ${ }^{21}$

However, when examined from a different perspective, a clearer pattern does in fact emerge. As discussed above, the region that resolved the greatest portion of its civil wars by a negotiated settlement was Europe, while Africa had the second highest

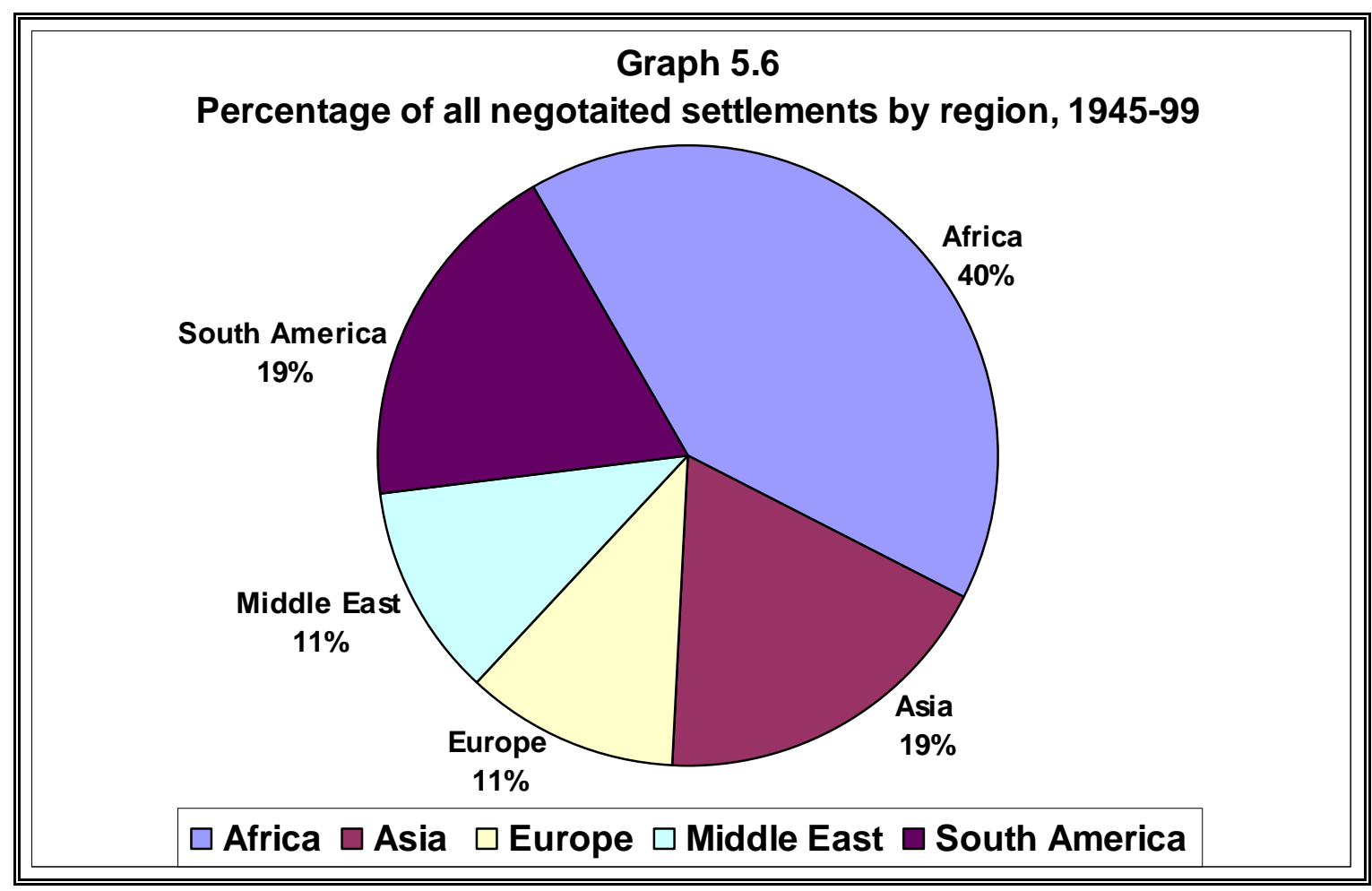

percentage of its wars ending in that way, as indicated in Graph 5.6. But when viewed from a global perspective, Africa accounts for both the greatest number and the highest percentage of negotiated settlements, as indicated in Graph 5.7 below. From this viewpoint, African civil wars do in fact demonstrate a higher percentage of negotiated

\footnotetext{
${ }^{21}$ It should be pointed out that this possible trend is based on a relatively small number of civil wars and negotiated settlements in Europe (7 wars and 3 settlements in Europe). Therefore, any perceived relationship may be the result of a spurious correlation or be the result of a short-term trend.
} 
settlements than any other global region, with about 40\% of its civil wars from 1945 to 1999 being resolved at the bargaining table. In other words, a larger number and a larger portion of civil wars occurring across the globe are accounted for in the region of Africa, although Africa ranks second (to Europe) in the percentage of African civil wars that are resolved by negotiated settlement.

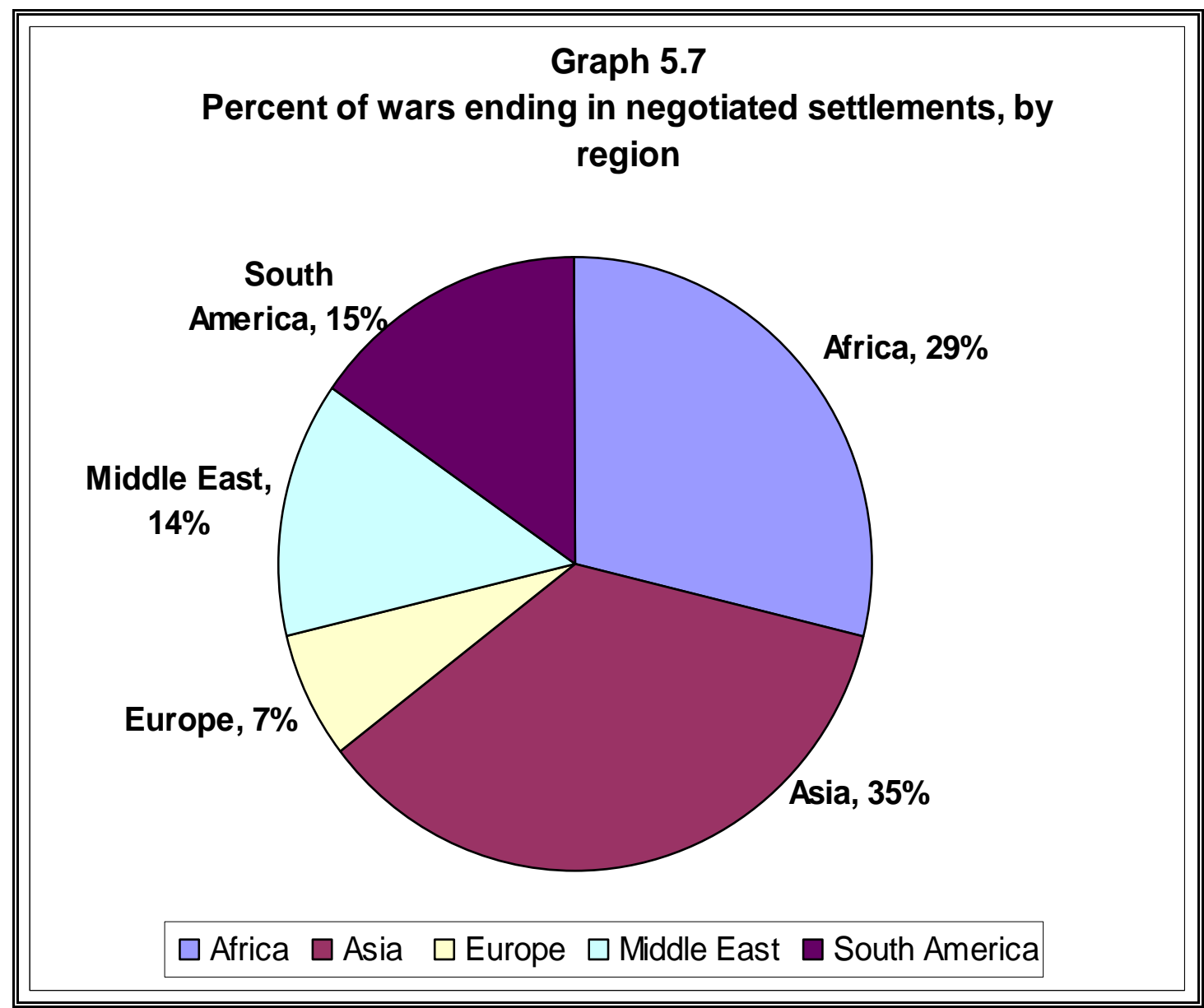

In sum, a basic and simple analysis of the outbreak of civil wars across space is indicates that the onset of civil war is, at best, uneven. Similarly the distribution of negotiated settlement also indicates a high degree of variation and one with a different pattern. The most interesting conclusion drawn from this analysis is that the frequency with which negotiated settlements occur varies according to how frequency is measured - 
whether it is an absolute count or as a percentage of civil wars within a given region. Such an observation suggests at least the possibility that the likelihood of a negotiated settlement varies with geographical region, a pattern that might also extend to the type of concessions offered by the state to the rebels. Given the limited data and crude measures on which such a conclusion would be based, however, a high degree of caution is warranted before making claims of causality.

\section{Trends and patterns in state concessions}

Having discussed at length several trends and patterns in the onset of civil wars and the ways in which they are resolved, this discussion will now turn towards trends and patterns in the content of negotiated settlements. In what follows, trends and patterns in the types of concessions that states offer to rebels in negotiated settlements are discussed. The first portion of this discussion focuses on the relative frequency with which different types of concessions occur. The second and third sections build on the above discussion of temporal and geographic patterns in the frequency of negotiated settlements by applying the same framework to the occurrence of different types of maximum concessions. As with the above discussion, the purpose here is to familiarize the reader with the data that has been collected, to highlight the presence of regularities within the data, and to establish a baseline to which further analyses can be compared. It should be

emphasized that this research focuses exclusively on the maximum concession offered by the state to the rebels. In what follows, the characteristics of the maximum concessions offered by the state to the rebels will be addressed. 


\section{Maximum concessions offered by states}

As previously discussed, each of the negotiated settlements under review were categorized according to whether or not the maximum concession made by the state addressed policy, power-sharing, or territorial concessions. By examining the frequency with which each type of concession (policy, power-sharing, or territorial) occurs as the maximum concession offered by the state to the rebels, several observations can be made. As indicated in Graph 5.8 below, power-sharing concessions make up the vast majority of concessions made by states, while territorial concessions rarely occur and policy concessions (as a maximum) almost never occur. Several implications can be drawn form this observation. First, in the majority of civil wars ending in a negotiated settlement, the state is willing to expand the rebel's access to the decision-making process

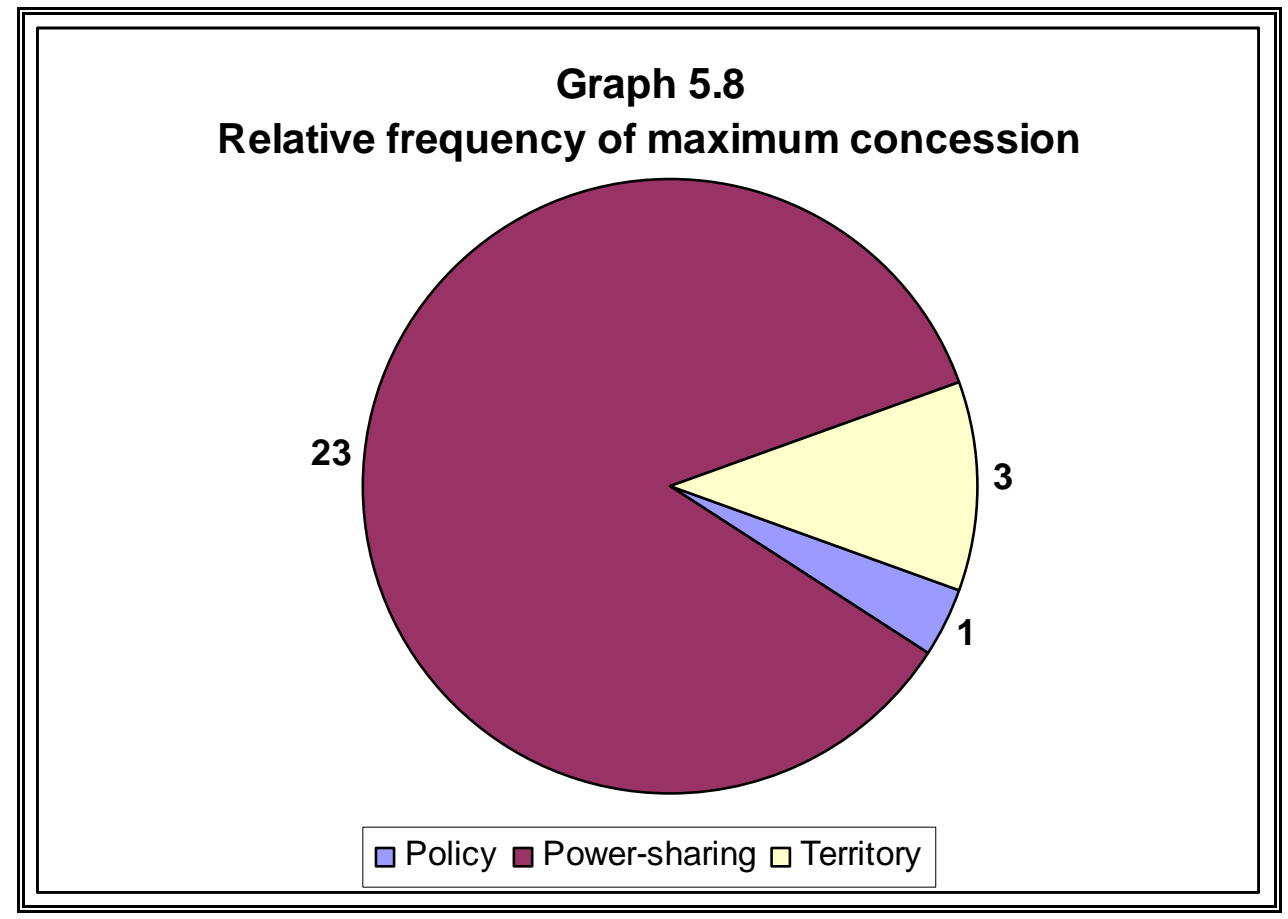

of the entire state by conceding changes in the make-up and selection of government officials, according to the definitions developed and utilized in this research. Second, when negotiated settlements occur, the rebels are highly likely to gain status in terms of 
their ability to influence the makeup and function of the post-war government, especially when compared to the gains they may make along policy or territorial lines. Third, despite theoretical arguments to the contrary, states are willing to grant at least the control of territory to the rebels, at least in a few cases. And finally, the terms of settlement rarely - almost never - are composed exclusively of policy concessions. This carries with it two further implications: (a) that the rebels in a civil war almost never accept only symbolic concessions or those related to the distribution of resources as am acceptable compromise; and (b) that states are willing to make meaningful and important concession to the rebels in order to end a civil war. Overall, the observation that in all but case in which a negotiated settlement occurs, the rebels were able to extract concessions from the state that go beyond the lowest level of concessions operationalized in this research, which indicates that bargaining theory may have some explanatory power.

\section{Maximum concessions across time}

As discussed previously, an analysis of the frequency with which civil wars and negotiated settlements occur indicates the presence of three trends. First, the annual rate at which civil wars start increases dramatically from the Cold War period to the postCold War. Second, the rate at which civil wars come to an end increases, despite the vastly shortened time period that constitutes the post-Cold War period analyzed in this research. And finally, those civil wars that end in the post-Cold War period are much more likely in end in a negotiated settlement than those that ended during the Cold War. In sum, it appears that the change in the international political system marked by the end 
of the Cold War may possibly have some causal effect on when and how civil wars are resolved. Although an explanation of why this is so goes beyond the scope of this research, this observation raises the question of whether or not this trend may have an affect the make-up of negotiated settlements as well.

A descriptive and graphical analysis of the data does suggest that the period of history during which a negotiated settlements occurs may have an impact on the content of the terms of agreement. In addition to the observation that more negotiated settlements occurred after the end of the Cold War than before, a comparison of the type of settlements before and after the Cold War suggests several possible observations and is presented in Graph 5.9 below. First, the number of policy concessions drops in the post-

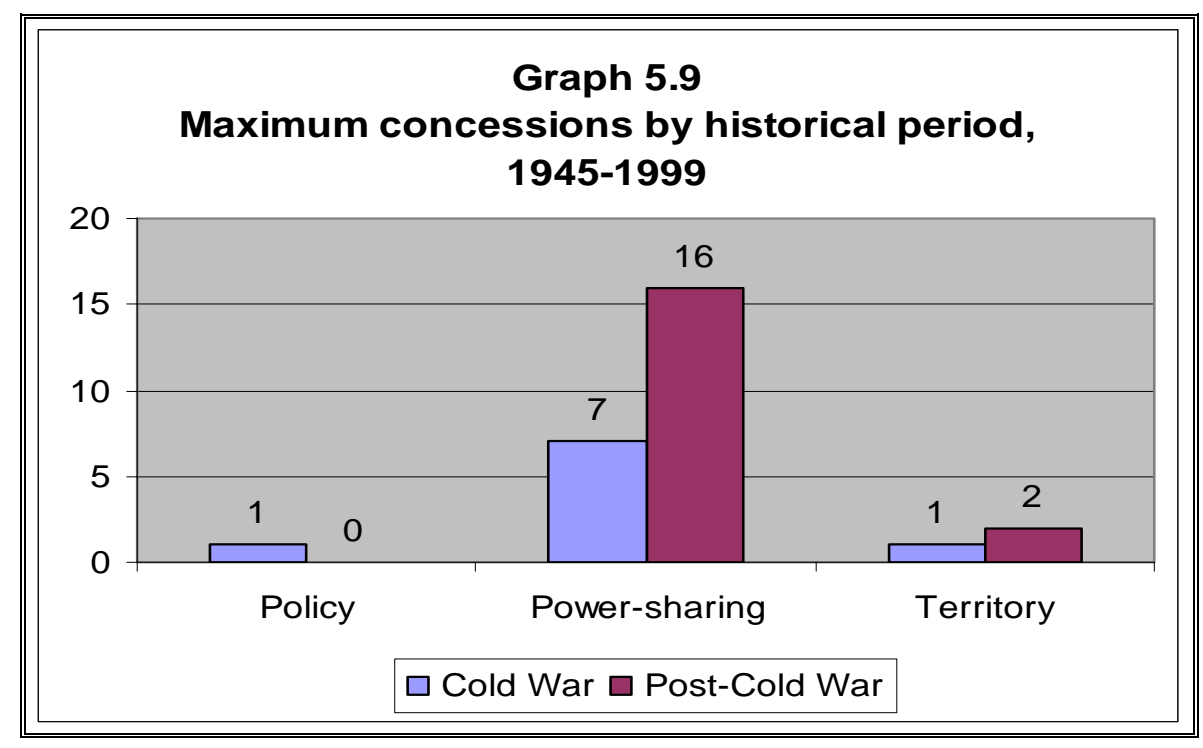

Cold War, albeit from a total of only one during the Cold War. This indicates that when states make concessions to their rebel adversaries, policy concessions (which are considered to be the least generous form of concession a state can make) are extremely 
are during the Cold War and nonexistent in the short period following the Cold War. ${ }^{22}$ Second, power-sharing concessions increased more than any other type of concessions (from 7 to 16 occurrences, or nearly a $44 \%$ increase). This implies that rebels entering into a negotiated settlement after the Cold War ended were more likely to gain an increase in their degree of influence in the post-civil war state and were more likely to do so than they were to gain control over territory. Third, the rate at which power-sharing concessions were granted increased from 7 of 9 concessions (about 78\%) during the Cold War to 16 of 18 (or about 89\%) after, while the percentage of territorial concessions remained steady across the time period (11\% of the total number of concessions in each era). This indicates that it is common for states to extent power-sharing concession to the rebels in negotiated settlements and that states are more likely to do so following the end of the Cold War.

\section{Maximum concessions across space}

With regards to the geographical distribution of civil wars and especially negotiated settlements, the patterns presented in the discussion above were much less clear. Africa accounted for the most civil wars (30 of 91, or 33\%) with Asia following closely behind (28 of 91, or 31\%) and cumulatively, these two regions accounted for over half (nearly 64\%) of all civil wars globally. Clearly these two regions bore the brunt of civil war onsets between 1945 and 1992. However, the patterns regarding the prevalence of negotiated settlements were much less clear. Although Asia accounted for the highest percentage of civil wars occurring with a region reaching a negotiated end, Africa had the

\footnotetext{
${ }^{22}$ Of course, this observation deserves a high degree of skepticism given the small number of cases, the relatively short post-Cold War period documented here, and the proximity of the settlements to the events that both constitute and brought about the change in the international political system.
} 
highest percentage of all civil wars ending at the bargaining table. Thus, given the lack of a clear pattern regarding the prevalence of negotiated settlements, it is difficult to predict what, if any, patterns the data may demonstrate in the frequencies of maximum concessions offered by the state and accepted by the rebels.

An examination of the data describing the maximum concessions offered by the state may, however, be of some use. Several trends and patterns can be observed from Graph 5.10. First, in each region of the world, the prevalence of power-sharing

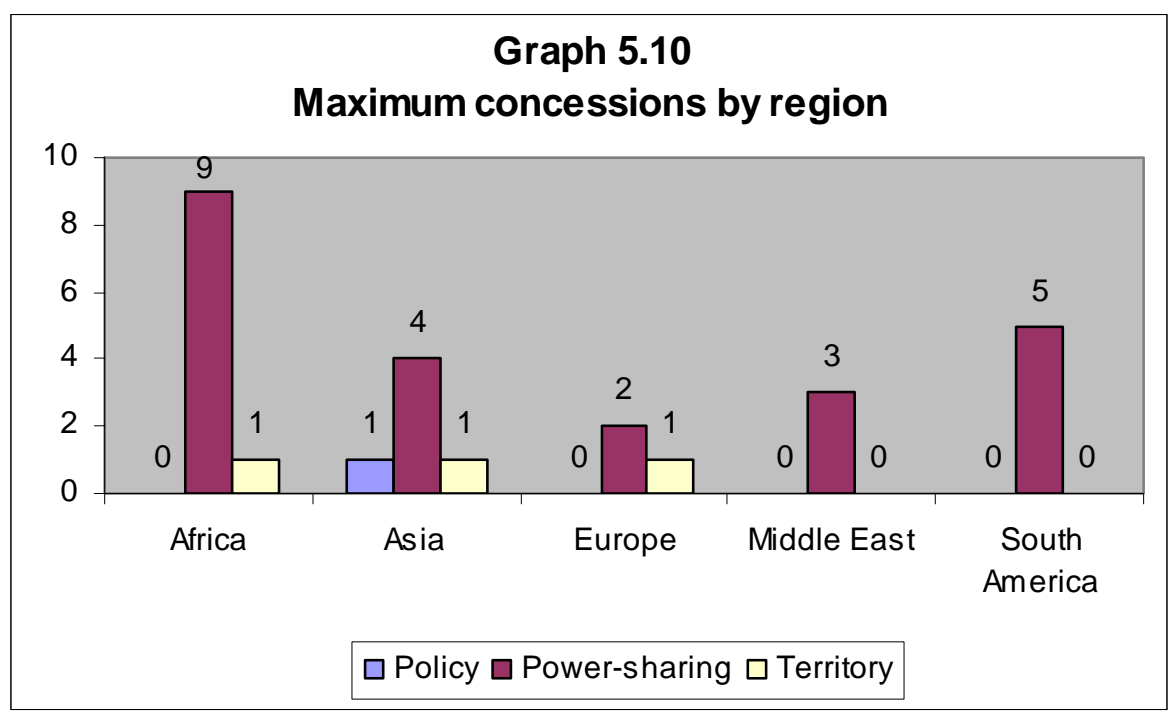

concessions exceed that of territorial and policy concessions by far. Such an observation is not surprising, given that (as discussed above) power-sharing concessions make up the vast majority of all concessions globally. It does, however, emphasize the relative frequency with which these concessions are offered by states, which occur in the majority of cases across the world and in each region. In terms of geographic distribution, Africa accounts for the largest percentage of power-sharing concessions as being the maximum offered by the state (with 9 of 23, or 39\% of power-sharing concession). Europe, on the hand, has the lowest percentage of power-sharing concessions, with 2 of 23 (slightly less 
than 9\%). However, when viewed from the perspective of the ratio of power-sharing concession within a region to all concession with that region, both the Middle East and South America indicate the highest prevalence, each with $100 \%$ of the maximum concessions being power-sharing. Africa, with its $90 \%$, has the second most frequently occurring rate of power-sharing concessions as maximum. It should also be noted that only Asia denotes the presence of all types of concessions as maximum. Therefore, the geographic distribution of the maximum type of concession can best be described as being diverse, with two regions displaying only power-sharing concessions, only one region accounting for all three levels and the ranking of the region with the "most" power-sharing concessions being dependent on how "most" is measured. Thus, it seems reasonable to conclude that patterns and trends in the maximum concession offered by state may vary on a regional but not a global level.

\section{Conclusions}

The purpose of this chapter is twofold. First, it is an attempt to familiarize the reader with the data on which further analysis is based. Second, it intends to highlight trends and patterns in the data that may be useful in later stages of the project. This discussion indicates that the prevalence of civil wars and negotiated settlements contained within the data is consistent with the data gathered by other researchers. Furthermore, the examination of the data indicates that both time and geography may impact the maximum concessions offered by states. A formal analysis of both bargaining theory and the influence of temporal and geographic patterns is taken up in the following chapter. 


\section{Chapter 6: Quantitative analysis of state concessions}

In order to evaluate the utility of bargaining theory as an explanation of the factors that influence the maximum concessions granted by the state, this research will now turn its attention to the use of inferential statistics. The benefit of using inferential statistics is that analyzing a large number of cases is made feasible. The value of socalled large-n studies is that they permit the identification of general patterns with a high degree of objectivity and increase the external validity of the research by drawing from an extensive list of cases. In form, this chapter will begin with a brief review of bargaining theory, followed by an evaluation of the factors that influence the maximum concession offered by states. The emphasis here is on identifying the type of concession offered. This will include an overview of Tobit and probit models, a summary of the results, and a more in-depth evaluation of each variable. The following section will address the results of the analysis of the factors that influence how much states concede within each type of concessions and will follow a similar format.

The following analysis is conducted in three stages. First, the basic concepts of bargaining theory are reviewed for the benefit of the reader. Second, a Tobit model is used to analyze the factors that influence the type of concessions (policy, power-sharing, 
or territorial) granted by a state to the rebels. The point of this analysis is to determine which of the explanations discussed above is best for determining the types of concessions made by the state. Third, a set of probit models are used disaggregate the factors that influence the degree of policy or power-sharing concessions (whether high or low) the state makes. This permits an analysis of the variations in the determinants of state concessions between types of concessions. The analysis of territorial concessions, however, will be analyzed in the following chapter solely on a qualitative basis in Chapter 7. This is necessary because the limited number of territorial concessions and the lack of variation between high and low levels of territorial concessions.

\section{Factors that influence state concessions}

To review, bargaining theory was developed as an explanation of the onset of conflict, which is viewed as being inefficient because of the inherent costs incurred by both sides. The theory is both based on and an extension of more traditional rationalist explanations of war that explain conflict as the outcome of a comparison of perceived costs relative to expected benefits. At its core, bargaining theory contends that conflict is the result of potential combatants failing to identify one or more mutually acceptable resolutions short of war, or a bargaining space. The central tenet of bargaining theory is that, through the process of fighting, combatants are able to develop a set of one or more solutions acceptable to both sides that were either unobserved by or unacceptable to at least one of the parties prior to the onset of conflict. According to the theory, a bargaining space is unidentified and conflict erupts when at least one of three conditions is present: a misperception of the costs of victory; the threat of cheating by one or both 
sides; and the presence of aims that are not easily subdivided and shared. This research is based on the notion that if costs, incentives to cheat, and the indivisibility of issues explain the onset of conflict, then they should also explain the end of conflict. If this is so, bargaining theory should indicate the factors that influence the terms of settlement accepted by both the state and the rebels as an outcome of negotiations that bring war to a close. Because of methodological difficulties, this research focuses exclusively on one side of the bargaining table by examining the concessions granted to the rebels by the state.

\section{Analyzing maximum concessions}

As discussed above, bargaining theory will be evaluated on two levels. First, the utility of bargaining theory as an explanation of the extent to which states make concessions to their rebel adversaries will be examined. The point of this exercise is to identify those factors that influence the type of concessions the state grants to the rebels. The second stage evaluation of bargaining theory will focus on determining the extent to which the state makes concessions within each broader type of concession. At this level, a distinction is drawn (according to the criteria developed in Chapter 3) between "high" and "low" concessions within policy and power-sharing concessions. The second-stage analysis of territorial concessions presents a special case because the small number of territorial concessions (three) and the lack of variation within the category (all low) renders quantitative analysis unsuitable; qualitative methods will therefore be used. It should be kept in mind that the measurement of the dependent variable is based on the assumption that the types of concessions are ordered from the perspective of the state - 
policy concessions are less generous or extensive than power-sharing concessions, which are again less valuable than territorial concessions. Also, it bears emphasizingat this point in the analysis the factors that influence the maximum concession made by the state are being analyzed, not how many.

\section{Analyzing maximum concessions: the Tobit model}

Methodologically speaking, the analysis of the determinants of state concessions presents a problem: the data gathered on state concessions are censored. The dependent variable, "maximum concessions," is censored in that its measured value may not fully reflect the impact of its determinants. The value of the independent variables may influence both the decision of whether or not to negotiate and the calculation of how much to concede, should the state decide to negotiate, but the response of the dependent variable may be unobserved. Thus, the maximum concession offered by the state is censored because the value of the independent variables (the costs of fighting measured as the duration of the conflict, for example) may influence the concessions that a state is willing to make, but these effects go unobserved because the state (for whatever reason) does not negotiate ${ }^{23}$. As a result, the true impact of the variable "duration" (or any other independent variable) on "maximum concessions" is ignored. This of course presents a problem of model under-specification, in which a statistical model fails to fully account for causal processes it intends to capture. As a result, traditional methods of analysis, such as ordinary least squares, are inappropriate.

\footnotetext{
${ }^{23}$ Several obvious reasons that explain why a state may be willing to make concessions but not negotiate are apparent. First, the rebels may choose not to consider or accept a negotiated settlement, thereby leaving the state to fight to a capitulation. Second, while the state may be willing to make some limited concessions, they may be unwilling to open up the negotiation process to the rebels. Third, public and political pressures external to the conflict may prevent the state from engaging in negotiations.
} 
Two possible solutions to this problem exist. The first is to focus exclusively on those cases of civil war that produced a negotiated settlement. This, however, is in itself problematic in that it would most likely introduce a selection bias into data because it assumes that there is a substantive and qualitative difference in those civil wars that end in a negotiated settlement and those that do not. None of the existing empirical evidence on civil war, however, supports such an assumption. In addition, this approach entails discarding the large amount of information that is readily available regarding the independent variables simply because the complementary observations for the dependent variable are unobservable. Finally, this "remedy" fails to resolve the initial problem of under-specification because it does not allow for the inclusion of unobserved information.

A second approach, however, is available and is one that offers a remedy. This approach utilized in this effort involves the use of statistical methods specifically designed to account for censored and truncated data. ${ }^{24}$ The Tobit model, developed by James Tobin in 1958 specifically to address the problem of censored dependent variables, represents the most straightforward way in which to address the issue (Breen 1996, p. 12). The use of a Tobit model to analyze the maximum concessions granted by states accounts for the censored nature of state concessions and allows the inclusion of information describing the independent variables that would otherwise have to be excluded.

To identify those factors that influence the maximum concessions made by states, this research will employ a series of Tobit models. Each of these models is developed to assess the presence, strength, and direction of any relationships between the dependent

\footnotetext{
${ }^{24}$ The difference between censoring and truncation is relatively straightforward: data are censored when some, but not all, values of the all dependent variables are observed; truncation occurs when some or all occurrences of the dependent variable are unobserved.
} 
variable on one hand and each of three groups of independent variables on the other. The dependent variable in each of the models in an ordered categorical measurement of the degree to which the state made concession to the rebels. The lowest level of this measurement indicates an absence of concessions or, in other words, a capitulation by the rebels. As discussed in earlier chapters, more "generous” concessions include (in increasing order of "generosity"): policy, power-sharing, and territorial concessions. The independent variables of the following models are derived from three theoretical sources: (1) bargaining theory, as developed above; (2) alternative explanations present within the literature; and (3) patterns and trends identified in the previous chapter. In all, four models, summarized in the table below, are tested. Model 1 consists solely of the basic bargaining theory model. Model 2 adds the alternative explanations to the basic

\begin{tabular}{||c|l||}
\hline \hline \multicolumn{2}{||c||}{$\begin{array}{c}\text { Table 6.1 } \\
\text { Summary of Tobit models }\end{array}$} \\
\hline Label & \multicolumn{1}{c||}{ Source of variables } \\
\hline Model 1 & Bargaining theory \\
\hline Model 2 & Bargaining theory plus alternative explanations \\
\hline Model 3 & Bargaining theory plus descriptive analysis \\
\hline Model 4 & Bargaining theory, alternative explanations, and descriptive analysis \\
\hline \hline
\end{tabular}

bargaining theory model, while Model 3 replaces the alternative variables with those indicated by the descriptive analysis in Chapter 5 . Model 4 represents the most comprehensive model in that it includes variables specified by all three sources. In the section below, a general overview of the findings is presented, and is followed by a more in-depth discussion of the statistical relationships between the dependent and independent variables. 


\section{Maximum concessions: An overview of the findings}

In general, the findings presented in the table below indicate that, by itself, bargaining theory (as developed and specified in Chapter 3) has only limited value as an explanation of the factors that influence state concessions, but that its explanatory value is increased by the inclusion of additional variables. In fact, in Model 1, only one of the variables generated by bargaining theory - guarantee, which indicates the presence or absence of a third party security guarantee - is indicated as having a statistically significant relationship with the maximum type of concession, which is both strong and positive. In other words, the result of this analysis indicate that the costs of war incurred by the state (measured as the logged deaths and logged duration) and the measures of intractability (whether or not a conflict is over ethnic issues or territorial claims) have no statistically significant impact on the degree to which states make concessions. On the other hand, the presence of a security guarantee enforced by an outside third party does have a strong and positive statistically significant effect on the degree to which the state is willing to grant concessions to its rebel adversaries. This finding corroborates Walter's (2002) Credible Commitment Theory, which contends that parties involved in a civil war are more likely to reach and implement a negotiated settlement when a third party promises to enforce the terms. It does not, however, confirm the findings based on a rational choice approach that find that civil wars are more likely to be resolved via a negotiated settlement when the costs of war to the state are high.

In Model 2, which adds to the basic model variables suggested by the democratic peace literature and by the "ripe for resolution” literature, "guarantee” continues to demonstrate a strong and statistically significant and is joined by "stalemate," which 
indicates the presence of a stalemate at any point in the conflict increases the maximum concession granted by the state. This finding lends support to the theory that states will make more generous concessions when the combatants are more evenly matched, as evidenced by the presence of a "mutually hurting stalemate." Arguments derived from the democratic peace literature contending that cultural and institutional pressure will increase the extent to which a state makes concessions, however, are not supported. The

\begin{tabular}{||l|l|l|l|l||}
\hline \multicolumn{5}{|c|}{ Table 6.2 } \\
\hline Results of Tobit analysis of “maximum concessions” \\
\hline Variable & Model 1 & Model 2 & Model 3 & Model 4 \\
\hline Deaths (logged) & .0825 & -.0422 & .09518 & -.1084 \\
& $(.1835)$ & $(.1894)$ & $(.1794)$ & $(.1341)$ \\
\hline Duration (logged) & .3570 & .3414 & .1110 & .05978 \\
& $(.2184)$ & $(.2155)$ & $(.2195)$ & $(.1455)$ \\
\hline Guarantee & $2.6457^{* * *}$ & $2.521^{* * *}$ & $2.1571^{* * *}$ & $1.1468^{* * *}$ \\
& $(.6683)$ & $(.6464)$ & $(.6331)$ & $(.4231)$ \\
\hline Ethnic & .2644 & .3799 & .0047 & .1732 \\
& $(.7351)$ & $(.7171)$ & $(.7328)$ & $(.5264)$ \\
\hline Territory & -.8951 & -.9457 & -.7572 & -.5404 \\
& $(.8575)$ & $(.8418)$ & $(.8667)$ & $(.6253)$ \\
\hline Democracy & & .0056 & & .0350 \\
& & $(.0485)$ & & $(.0341)$ \\
\hline Stalemate & & $1.406^{* *}$ & & $1.545 * * *$ \\
& & $(.7376)$ & & $.50452)$ \\
\hline Post-Cold War & & & $1.7080^{* * *}$ & $2.9159^{* * *}$ \\
resolution & & & $(.6392)$ & $(.4785)$ \\
\hline Africa & & & -.0899 & -.0838 \\
& & & $(.8677)$ & $(.4297)$ \\
\hline Constant & $-3.613^{* * *}$ & $-2.538 * * *$ & $-3.2534^{* *}$ & -.7269 \\
& $(1.7620)$ & $(1.7473)$ & $(1.6732)$ & $(1.1497)$ \\
\hline & & & & \\
\hline Log likelihood & -83.552946 & -81.691651 & -79.669123 & -61.112585 \\
\hline Chi Square & 27.27 & 30.99 & 35.04 & 72.15 \\
Probability & 0.0001 & 0.0001 & 0.0000 & 0.0000 \\
Degrees of freedom & 5 & 7 & 6 & 9 \\
\hline Pseudo-R squared & 0.1403 & 0.1594 & 0.1803 & .3712 \\
\hline$* *$ p $<.05 * * * p<.01$ & & & & \\
\hline \hline
\end{tabular}


model does not indicate that a statistically significant relationship exists between the variable "democracy" and "maximum concessions." This indicates that the form of government does not affect the extent to which a state is willing to grant concessions.

Model 3, which replaces the alternative explanations with variables derived from the descriptive analysis in Chapter 5, indicates that the timing of negotiations does have an effect but that geography does not. The inductive argument that changes in the international structure (marked by the end of the Cold War) increase the willingness of states to grant more extensive concessions is supported by the strong and positive statistically significant relationship of “post-Cold War settlement” to “maximum concessions.” The variable “Africa," which is a product of the same inductive process and is intended to capture geographical variations in maximum concessions, it appears that whether or not a negotiated settlement is located in Africa does not have a statistically significant effect on the extent to which states grant concessions

Model 4, which is the most comprehensive of the models, combines the variables from each of the three previous models. This model replicates the findings of the previous models, with “guarantee” and "post-Cold War resolution” remaining significant. In general, this group of models shows a high degree of stability, which supports the validity of the findings because it demonstrates that the results are not sensitive to changes in the models and therefore the result of a spurious correlation. Stability is demonstrated in several ways. First, the statistical significance of each of the variables is consistent across each model - where statistical significance is demonstrated for a variable, it exists for all models. The same patterns also holds for variables that do not indicate a statistical significant relationship. Second, with the exception of "Deaths 
(logged)”, the signs of each of the coefficients remain steady regardless of statistical significance ${ }^{25}$. In the case of "deaths (logged)", which does change signs (positive in 2 models and negative in 2), the coefficient is extremely close to 0 and the changes are small. Third, the increase in the adjusted- $\mathrm{R}^{2}$ as additional variables are added indicates a corresponding increase in the portion of variation of "maximum concession" that is accounted for by the various models. Finally, the statistical significance of the loglikelihood indicates that each of the models has some explanatory power. In what follows, a more detailed examination of the statistical analysis of the utility of bargaining theory and alternative explanations is presented.

\section{Bargaining theory: perceptions of success}

According to bargaining theory, one of the primary causes of conflict is the misperception of the costs of fighting, which makes the identification of a bargaining space impossible. This research builds on that logic and contends that as fighting progresses, combatants gain more complete and more accurate information regarding the capabilities and resolve of their adversaries - what was private information at the start of the conflict becomes public - and the identification of a bargaining space becomes possible as combatants adjust their perceived expected utilities of fighting versus seeking a negotiated settlement. It follows, then, that states that are less successful on the battlefield will adjust its expectations downward and be willing to extend more generous concessions to the rebels. Costs, then, should be negatively related to concessions.

\footnotetext{
${ }^{25}$ Both deaths and duration appear in the models as the natural log of their measured value. This was done to reduce the extreme variation present in both of the variables, which resulted in a nearly normal distribution for each.
} 
This research uses two commonly used measures of costs as proxies for success the number of deaths sustained by the state and the duration of the conflict. The findings of the Tobit analysis indicate that the propositions developed herein from bargaining theory do not hold. With regards to the number of deaths sustained by the state - "Deaths logged" - two problems exist. First, in none of the 4 models are the coefficients statistically significant. Thus it would be unwise to draw any causal inferences from these results because “maximum concessions" and "Deaths (logged)” do not co-vary. Second, in two of the models - Model 2, containing alternative explanations and Model 3, the comprehensive model - the signs of the coefficients are opposite of that hypothesized, although the relationship is not statistically significant. ${ }^{26}$ In terms of statistical significance, the variable "Duration (logged)" fares even worse, as the sign is opposite the hypothesized direction in each model. .

\section{Bargaining theory: Incentives to cheat}

The second condition that, according to bargaining theory, makes the outbreak of fighting more likely is an incentive to disregard agreements, or as Walters (2002) puts it, an incentive to cheat. If this is a problem prior to the onset of conflict, then it follows that it would also present a problem in the conclusion of a negotiated settlement. One factor that may eliminate or decrease the propensity of adversaries to cheat is the

\footnotetext{
${ }^{26}$ If the coefficients for "Deaths (logged)" and "Duration (logged)" had been statistically significant, the transformation of the variables in terms of per unit responsiveness would have made a standard interpretation of the coefficients difficult. However, interpretation in terms of percent change would be relatively straightforward. Taking the coefficient for "Deaths (logged)," which is .0825, as an example, the interpretation would have been "For every 1\% increase in "Deaths (logged)," "Maximum concessions" would have increased by .0008 units.
} 
presence of an third party to observe or enforce the implementation of the terms of a negotiated settlement.

The variable "guarantee" denotes the presence of a third party to enforce a settlement. The results of the Tobit analysis indicate that efforts to decrease the incentives of the combatants to cheat does in fact increase the willingness of the state to grant more generous concessions to its rebel adversaries. Although the coefficients vary, in each of the four models, "guarantee" does exhibit a statistically significant relationship with "maximum concessions." Furthermore, in each of the models the coefficient for "guarantee” demonstrates an effect on "maximum concessions" at a very high level of significance $(\mathrm{p}<.01)$. In addition, the sign of the coefficient is in the hypothesized direction. From this, we can conclude that when a security guarantee is present, the maximum concessions granted by the states will increase, as hypothesized.

This result, then, provides confirmatory evidence for the tenets of bargaining theory. Determining the precise effect of a security guarantee on the maximum concessions offered by the state is, however, difficult for two reasons. First, the dependent variable "Maximum concessions" is an ordinal level variable and as such lacks the presence of set intervals between categories, which renders an interpretation of the coefficients based on either unit or percentage change nonsensical because the numerical concepts do not translate across units of observation. The second problem with exact interpretation is the variation of the coefficients across models. This research, then, will simply conclude that, as specified, removing incentives to cheat does in fact make states willing to extend greater concessions to its rebel adversaries. 


\section{Bargaining theory: Divisibility of the stakes}

The third condition specified by bargaining theory that makes conflict more likely is when the stakes over which the combatants are fighting are not easily subdivided and shared. According to Fearon (1995) and Lake (2003), issue divisibility is the easiest of the three conditions to overcome because of the possibility of issue linkage and payments, but can still prevent an obstacle to the resolution of disagreements short of fighting. If problems of issue divisibility can lead to the onset of conflict, then it follows that their presence will also make conflict more difficult to resolve. In terms of negotiated settlements, the presence of issue divisibility should lead to less generous concessions being granted by the state.

This research uses two indicators to denote the presence of indivisible issues conflicts in which the combatants are organized according to ethnic group and those over issues of territorial control. The results of the Tobit analysis presented above indicate that there is no direct relationship between either indicator of issue divisibility and the maximum concession granted by the state. In other words, neither the presence of combatants organized according to ethnic group nor territorial issues demonstrates a statistically significant relationship with the variable "maximum concessions.” Furthermore, only the variable “territory" - which denotes conflicts over territorial control - consistently demonstrates the expected sign, while the sign for "ethnic" consistently exhibits a positive sign. It should be noted, however, that the extremely small value of both coefficients (which are consistently near 0) fall within a 95\% percent confidence interval that includes positive as well as negative values. Thus, this research 
do not provide empirical support for the proposition made by bargaining theory that issue indivisibility will lead to less generous concession being made by the state.

Based on these empirical observations, it appears that bargaining theory, as specified in this research, at best provides only limited theoretical guidance in explaining the determinants of state concessions. Of those variables derived from this specification of the theory only one variable - "guarantee" - consistently demonstrates a statistically significant relationship. This observation indicates that there may in fact be a causal relationship between "guarantee” and "maximum concessions". Thus, some empirical support is provided for the use of bargaining theory as an explanation of the content of negotiated settlements.

In addition to bargaining theory, existing literature suggests that democratic peace theory and explanations of the resolution of civil war based on the presence of a hurting stalemate may provide additional insight. In addition, the descriptive analysis conducted in Chapter 5 also indicates that two inductively derived variables may be of value. The quantitative analysis of these hypothesized relationships is discussed below.

\section{Alternative explanations: Democratic peace theory}

Democratic peace theory suggests that democracies may be willing to grant more extensive concessions than non-democracies. For present purposes, two explanations are relevant. First, leaders in democracies are more closely tied to the public, who are more likely to oppose a civil war because they more directly endure the costs of conflict and so may prefer a quicker or less costly resolution. To appease the public, then, democratic leaders may be more willing to seek a negotiated resolution in order to minimize the price 
paid by the public. In addition, the democratic peace literature argues that leaders in a democracy may be more culturally disposed to compromise that their non-democratic counterparts. Democracies, then, may be willing to grant more extensive concessions to their adversaries than their non-democratic counterparts.

To account for variations in the levels of democracy exercised by the states, this research uses a combined score that integrates both authoritarian and democratic characteristics that is drawn from the Polity IV Project. This measure is applied to Models 2 and 4. Both models indicate that the degree to which the state exhibits democratic or authoritarian characteristics is not directly related to the maximum concession offered by the state. In both models, the coefficients are nearly zero and are not statistically significant, thereby indicating the lack of a direct causal relationship. The signs for the coefficient in each model are, however, in the expected direction (positive), although the 95\% confidence interval for each model does include negative values. Therefore, the empirical evidence on which this research is based does not support the contention that democracies will, in general, make more generous concessions to their rebel adversaries.

\section{Alternative explanations: Mutually hurting stalemate}

The literature also suggests that the conditions under which negotiations occur may be a factor in determining the extent of state concessions. This is based on the logic that a conflict is "ripe for resolution" when neither is able to achieve victory, a condition which produces a "mutually hurting stalemate." Since neither side is able to achieve an absolute victory, according to this line of thinking, each side will be more willing to enter 
into a compromise settlement. If this logic holds true, then states that encounter this condition should be willing to grant more extensive concessions in order to gain a resolution.

As with “democracy," this hypothesis is tested in Models 2 and 4, both of which build on the basic model suggested by bargaining theory. To indicate ripeness for resolution, this research codes civil wars according to whether or not a stalemate emerged between the adversaries. The results of the Tobit analysis presented above indicate that states granted more generous concessions when the combatants were evenly matched (as evidenced by the presence of a stalemate). In both of the models to which this variable was applied, the coefficients for "stalemate” are statistically significant at the $\mathrm{p}<.01$ level, indicating that we can be more than $99.9 \%$ certain that their values are not the result of random variation. Furthermore, in both of the models, the coefficients display the anticipated positive sign, indicating that a positive relationship exists between “guarantee” and “maximum concession.” From this, we can conclude that when combatants engaged in civil war reach a stalemate, any negotiated settlement that results will, in general, be more likely to contain greater concessions from the state than in those wars that did not produce such a standoff. This result, then, provides confirmatory evidence for the explanation produced by the “ripe for resolution” literature.

Thus, the existing literature on civil wars produces two theoretical explanations with testable hypotheses that pertain to the factors that influence state concessions. When combined with the theoretical model suggested by bargaining theory, it appears that there is no direct relationship between the type of state involved in the war and the type of concessions it will extent to the rebels. On the other hand, there is some support for 
explanations that contend that the conditions on the battlefield do directly affect the terms of settlement and that these explanations may in fact enhance the explanatory power of bargaining theory. One final group of explanatory variables remains to be evaluated those inductively produced by the descriptive analysis of trends and patterns in Chapter 5 .

\section{Trends and patterns: International political system}

In addition to the above variables that are derived from bargaining theory and existing explanations, the descriptive analysis conducted in the previous chapter indicates the presence of additional trends and patterns that may help to untangle the factors that influence the maximum concessions granted by states. Two of those variables - the effect of changes in the international political system (as evidenced by the conclusion of the Cold War) and the geographic location of the dispute (whether or not it is in Africa) are directly tested here. The purpose of this portion of the analysis is to determine whether or not the observed relationships hold up to additional scrutiny and to guide future efforts in this area of research.

The first factor to be addressed is that of the effect of the international political system on the content of negotiated settlements. It was observed that although fewer negotiated settlements occurred during the Cold War than after it, the annual rate at which civil wars increased dramatically 1989 (a date which roughly corresponds with the fall of the Soviet Union). This suggests that changes in the international political system that can be attributed to the end of the Cold War may directly affect the likelihood of a negotiated settlement. More relevant for present purposes, the descriptive analysis also indicates that the timing of a negotiated settlement may also directly affect the content of 
those settlements - the concessions granted by states, in other words. Generally speaking, any differences that may exist in the concessions granted by the state are at least possibly a result of the changes in the international political system brought about by the end of the highly competitive relationship between the two superpowers. This is plausible because one aspect of the competition between the US and the Soviet Union was the involvement of third powers, whether as competitive attempts by both to mitigate the influence of each other or by one superpower to extend its own interests. This leads to the non-directional hypothesis that changes in the international political system can be expected to affect the maximum concessions offered by the state.

The variable "post-Cold War" denotes whether a negotiated settlement was achieved prior to or after 1989. Based on the Tobit analysis, it does appear that the timing of a negotiated settlement does positively affect the maximum concession offered by the state, and that states were likely to grant greater concessions after the end of the Cold War than before. Thus, we can infer that changes in the international political system may in fact have a causal effect of the maximum concession offered by the state. More precisely, Model 3 and Model 4 both indicate the presence of a positive relationship between the variable "post-Cold War" and "maximum concession," both of which indicate a p-value of less than .01. These findings, of course, provide support for the contention that changes in the international political system affect the content of negotiated settlements. 


\section{Trends and Patterns: Geographic variation}

Another factor identified by the descriptive analysis of trends and patterns in

Chapter 5 was the influence of geography of the maximum concessions granted by states. The analysis indicated that Africa has the most onsets of civil war, the most negotiated settlements, and the largest percentage of negotiated settlements. In addition, Africa accounts for the largest percentage of power-sharing concessions as being the maximum concession granted by states, which may indicate the presence of regional variations. Several factors could account for these variations, including regional customs and political expectations, regional differences in types of government, the density of political or ethnically similar groups, or the distribution of resources. For present purposes, the more important issue is whether or not the observations drawn from an examination of the data hold up to scrutiny, which leads to the non-directional hypothesis that maximum concessions vary by the geographic region in which they are fought.

To account for regional variations in the maximum concession offered by states, this research focuses on whether or not the civil wars were fought in Africa. Therefore the claim being evaluated here is that civil wars in Africa may exhibit differences from civil wars fought outside of Africa. This variable was applied to Models 3 and 4. Based on the Tobit analysis of the data, it appears that geography does not directly affect the maximum concession offered by states. In both models, the variable “Africa” fails to achieve statistical significance. This indicates that maximum concessions in Africa do not vary significantly from those that occur in the remaining non-African regions of the world. In other words, the lack of a statistically significant relationship between "Africa” 
and "maximum concessions" suggests that the maximum concessions offered by states do not vary according to the region in which the wars are fought.

In sum, the purpose of this portion of the analysis has been to evaluate the effectiveness of bargaining theory as an explanation of the factors that influence that maximum concession offered by states to their rebel adversaries in civil wars. To do so, the relationship between those variables suggested by bargaining theory and the maximum concessions offered by states has been evaluated in several different specifications. Based on this evaluation, it appears that bargaining theory by itself provides some, but not alot of theoretical guidance in answering the question at hand. It appears that the existing literature and the trends and patterns observed in the data do, however, add explanatory power.

\section{Analyzing levels of concessions: The probit model}

Having addressed the factors that influence the type of concessions made by states, this research will now turn its attention to untangling the factors that influence the level of concession within each concessions type. Types of concessions at this stage are categorized according to whether or not they represent high or low levels of concession within each policy type. In what follows, the differences between the levels of each type of concession are briefly reviewed, followed by a presentation and discussion of the methods and results of the quantitative (in the case of policy and power-sharing concessions) and qualitative (for territorial concessions) analysis.

As discussed in more detail above, policy concessions, which address changes in decisions made by the state short of representation or jurisdiction issues, can be either 
low or high. Low level policy changes are those concessions that do not directly affect the political, social, or economic resources available to groups represented by the rebels and that are primarily symbolic in nature. High level policy concessions are those that expand the access of the constituents of the rebels to expanded political, social, or economic resources. Power-sharing concessions, which occur when the state concedes changes in the make-up or selection process of government officials, are similarly subdivided. Low level power-sharing concessions occur when the state grants the rebels only the opportunity to expand their decision-making authority, but are not guaranteed such a change. Conversely, high level power-sharing concessions are made when the state guarantees the rebel constituency a greater role in the decision-making process of the state. Finally, territorial concessions, which address the control of territory, were coded according to whether partial (a low level concession) or full (a high level concession) autonomy was granted by the state. No cases were documented in which full autonomy was granted by the state, so no high level territorial concessions appear in the dataset.

To analyze the factors that influence the level of concessions, probit analysis will be used. As before, to account for different theoretical arguments four models will be developed and tested. With regard to policy concessions, however, one key difference is present in the models. Because of the presence of nearly perfect collinearity between the level of policy concession and "territory,” which indicates the presence of territorial goals, the independent variable is dropped. The use of a probit model is justified because the analysis intends to differentiate between two outcomes - high and low level concessions within each concession type. Each of the four models is developed to assess 
the presence, strength, and direction between the dependent variable (whether the concession is high or low) and the theoretically specified variables independent variable.

\section{Levels of power-sharing concessions: An overview of the results}

In general, the results of the quantitative tests presented below indicate that with the exception of the effect of the number of deaths incurred by the state, bargaining theory does not accurately predict the level of power-sharing concessions granted by the state. In addition, neither the alternative explanations presented by the existing literature nor the factors identified by the descriptive analysis indicate the presence of the expected relationship. As indicated below, the number of deaths incurred by the state demonstrates a positive and statistically significant relationship with the level of concession offered by the state, which lends empirical support to the relationship suggested by bargaining theory. The remaining results, however, either indicate a lack of a statistically significant relationship or one that is opposite in direction from that suggested by bargaining theory. In fact, with regard to the effect of the duration of the conflict and the presence of a guarantee, a statistically significant relationship exists but it is in the opposite direction of that suggested by bargaining theory. Furthermore, the relationships suggested by alternative explanations and the descriptive analysis indicate that a statistically significant relationship does not exist between the level of powersharing concession granted by the state and explanatory variables, which means that we cannot be certain that the coefficients are not the result of random variation within the data. In what follows, a more detailed accounting of the results are presented. 
Levels of power-sharing concessions: The empirical results

As indicated by the Chi-squared test, which tests the proposition that the fully specified model is a better predictor of outcomes than a model consisting of only an intercept term, each model is statistically significant at the .05 level or above. This indicates that the variables in the model have some explanatory power of the variation in

\begin{tabular}{||l|l|l|l|l||}
\hline \multicolumn{5}{|c|}{ Table 6.3 } \\
\hline Probit results for power-sharing concessions \\
\hline Variable & Model 1 & Model 2 & Model 3 & Model 4 \\
\hline Deaths (logged) & $.5619^{*}$ & $.6997^{* *}$ &. $.6452^{* *}$ & $.8293^{* *}$ \\
& $(.2972)$ & $(.3268)$ & $(.3463)$ & $(.3643)$ \\
\hline Duration (logged) & $-.7227^{*}$ & $-.7875^{*}$ & $-.7952^{*}$ & -.6882 \\
& $(.4009)$ & $(.4456)$ & $(.4705)$ & $(.4306)$ \\
\hline Guarantee & $-2.105^{* *}$ & $-2.4302^{* *}$ & $-2.4648^{* *}$ & $-2.5688^{* *}$ \\
& $(.8238)$ & $(.9974)$ & $(1.0818)$ & $(1.0186)$ \\
\hline Ethnic & .3307 & .0272 & .3150 & .2816 \\
& $(1.030)$ & $(1.2303)$ & $(1.0219)$ & $(1.2281)$ \\
\hline Territory & .3383 & .8517 & 1.2517 & 1.0246 \\
& $(1.2790)$ & $(1.751)$ & $(1.0210)$ & $(1.9735)$ \\
\hline Democracy & & -.1426 & & -.1680 \\
& & $(.1422)$ & & $(.1265)$ \\
\hline Stalemate & & -.8706 & & -1.4624 \\
& & $(.8680)$ & & $(1.3066)$ \\
\hline Post-Cold War \\
resolution
\end{tabular}


the dependent variable. The exact level of significance, does, however, vary, with Model 2 (the basic model plus alternative explanations) faring the best and Model 3 (which adds the variables derived from the descriptive analysis to the basic model) performing the worst. This indicates that the hypothesis that a model containing only the intercept provides a better explanation of the outcome is a less than $5 \%$ chance for Models 1,2 and 4 and a less than $10 \%$ chance for Model 3.

Another feature of interest is the amount of variation in the dependent variable explained by the dependent variable. Loosely interpreted, the pseudo-R squared, which is the coefficient of determination, indicates the amount of variation in the outcome explained by the dependent variables varies for each model, as is to be expected. These values range from a high of 53\% for Model 4 to a low of 39\% for Model 1, indicating that Model 1 explains a relatively low portion of the variation in the outcome while Model 4 explains the most. This is not surprising, given that the reported pseudo- $\mathrm{R}$ squared is McFadden's R-squared, which increases as the number of variables in the model increase. Given this, a more informative comparison can be made between Model 2, which accounts for nearly $50 \%$ of the variation, and Model 3, with $42 \%$, which indicates that of these two models, Model 2 performs better because it explains a greater amount of variation in the dependent variable "maximum compromise". This discussion will now turn to an analysis of the individual variables.

As with the Tobit model utilized above, a direct and meaningful interpretation of the coefficients of the variables is problematic. This is so because the reported values are a ratio of the log-odds ratio are themselves difficult to interpret and because the dependent variable is ordinal, which means tat the difference between a high and low 
power-sharing concessions are not mathematically precise. However, the direction and statistical significance of the relationship between the independent variables and the dependent variable can be assessed.

\section{Bargaining theory: Perceptions of success}

As previously discussed, one of the primary contentions of bargaining theory is that combatants adjust their expected utility of war as they gain information regarding their perceived likelihood of success. Based on the contention that shorter wars and wars in which the state incurs fewer causalities indicate the likelihood of the state being successful, the hypotheses being tested here are that "deaths (logged)" and "duration (logged)" will be positively related - that is, high power-sharing concessions should be

more likely to occur as deaths and duration increase. In the case of "deaths (logged)," the results indicate that there is a positive and statistically significant relationship in each of the models, thereby indicating providing support to the contention made by bargaining theory that states are willing to extend more generous concession to the rebels when the costs of war are high.

When costs are measured in terms of the duration of the conflict, however, the results are contrary to what would be expected by bargaining theory. In three of the four models, a statistically significant relationship exists between "duration (logged)" and the occurrence of high level power-sharing concession, but is negative in all four of the cases. In other words, the state is less likely to grant a high level power-sharing concession when a war drags on. This contradicts the argument put forth by bargaining 
theory. Thus, when it comes to the costs of war and state power-sharing concession, the results are at best mixed.

\section{Bargaining theory: Incentives to cheat}

When it comes to incentives to cheat, bargaining theory contends that combatants will be less likely to enter into a negotiated settlement as long as their adversary is capable of ignoring the agreement. Alleviating such concerns should, according to bargaining theory, make a negotiated settlement more likely. Building on the hypothesis that concessions will be greater when a security guarantee is present, it follows that states should be willing to grant greater power-sharing concession when the incentive to cheat is removed. To measure the incentive to cheat, this research includes "guarantee" to denote the presence of an outside party to enforce the agreement.

As with the length of the conflict, the results contradict bargaining theory. The presence of a security guarantee demonstrates a statistically significant relationship to high power-sharing concessions, as bargaining theory suggests, but it is a negative relationship rather than a positive one. This indicates that, rather than being more likely to extended greater power-sharing concessions in the presence of a security guarantee, states are instead less likely to do so. Although the coefficients vary in each of the four models, each is consistently statistically significant at the .05 level of significance, which indicates the presence of only a small (5\%) likelihood that the results are based on random error with the data. Thus, the results of this research call into question the contention made by bargaining theory that states will be more likely to grant higher concessions when a security guarantee is present. 


\section{Bargaining theory: Divisibility of stakes}

Bargaining theory also weakly asserts that conflict is more likely when the gains are not easily subdivided. Just as the presence of indivisible issues may make more conflict more likely and more difficult to resolve, if bargaining theory is correct, then conflict fought over indivisible issue should lead to less generous concession being made by the state. Applied to power-sharing concession, this implies that low power-sharing concessions should be more likely than high ones when the conflict is fought over indivisible issues. Two variables were developed in this research to account for the presence of divisibility problems - conflicts in which the combatants aligned themselves according to ethnicity )denoted “ethnic”) and conflict fought over territorial control (“territory").

Based on the empirical observations on which this research is based, there is not a statistically significant relationship between issue indivisibility and the presence of a high power-sharing concession. When looking at the alignment of the combatants, in each of the models "ethnicity” fails to achieve statistical significance. Furthermore, the coefficients for "ethnicity” are all positive. In other words, the evidence indicates that states are more willing to grant high level power-sharing concessions when the combatants are organized along ethnic lines, although there is a more than acceptable chance the results are produced by random variation within the data. Thus, when taken at face value, these results run dispute the contention made by bargaining theory that indivisible issues will negatively effect the extent of concessions granted by the state. 
When looking at indivisibility from the perspective of control over territory, the results are similar. In each of the four models, none of the coefficients achieve statistical significance. Each of the coefficients is also positive, which indicates an increased likelihood of a high level power-sharing concession when the adversaries are fighting over the control of territory. Once again, this empirical evidence contradicts the contention made by bargaining theory that territorial conflicts will result in greater concessions. The empirical evidence, then, finds to the contrary of bargaining theory when issue indivisibility is present.

Thus, this research fails to produce empirical evidence in four of the five variables associated with bargaining theory. Only one - the number of deaths incurred by the state - appears to have a direct relationship with the degree of power-sharing concessions granted by the state. On two of the measures - the duration of the conflict and the presence of a third arty security guarantee - the evidence indicates the presence of a direct relationship that is opposite of that predicted by bargaining theory. And with regard to issue indivisibility, statistically the findings are inconclusive and any relationship that may exist appears to in the opposite direction of that predicted by bargaining theory.

\section{Alternative explanations: Democratic peace theory}

If the application of the literature that constitutes the democratic peace theory is correct in its contention the democracies are likely to grant greater concessions, then it logically follow that states that exhibit greater degrees of democracy will also be more likely to grant high level power-sharing concessions rather than low level ones. Based on 
an analysis of the relationship between the occurrence of high level concessions and “democracy,” however, the empirical evidence does not support this argument. As can be seen in the table above, in both Models 2 and 4 (the two models in which the variable appears) the coefficients indicate the presence of a negative relationship between the level of democracy and the presence of high level power-sharing concessions. In other words, this analysis indicates that more democratic societies are less likely to extend a greater decision-making role to their rebel adversaries than are less democratic or more authoritarian states. Once again, however, the coefficients to do not reach the accepted standards for statistical significance, which means that there is an unacceptably high likelihood that the results are a function of random error. Thus, this research indicates that democratic peace theory as developed and applied here at best does not demonstrate a causal relationship between the level of democracy exhibited by the state and the level of concessions granted to the rebels and at worst contradicts the direction of the relationship should it in fact exist.

\section{Alternative explanations: Mutually hurting stalemate}

Another factor proposed by the existing literature that addresses the extent of concessions is the conditions under which a negotiated settlement is sought. If, as discussed above, states are willing to extend greater concessions when is becomes clear that neither side is able to achieve a clear-cut victory, it follow that high level powersharing concessions will be more likely to occur when a conflict is "ripe for resolution," as indicated by the presence of a "mutually hurting stalemate." 
As with the tests of the variable "democracy," the coefficients of the variable "stalemate" indicate the presence of a negative relationship with the degree of powersharing concessions. This indicates that states are less likely to grant a high level powersharing concession when the combatants are evenly matched on the battlefield. However, once again there is reason to doubt that validity of this relationship, as statistical significance is not achieved for "stalemate" in either model. Thus, it appears that the evidence does not support the contention made by the existing literature that conflicts that are "ripe for resolution” are likely to grant greater power-sharing concessions.

\section{Trends and patterns: The international political system}

The descriptive analysis of trends and patterns within the dataset (Chapter 5) indicated the presence of changes in both the frequency with which negotiated settlements occurred and the content of those settlements. This analysis indicated that states granted greater concessions to their rebels adversaries following the end of the Cold War. In order to determine whether or not this observed relationship hold up to the enhanced scrutiny of inferential statistics, the variable "post-Cold War" settlement was developed to distinguish those wars that were resolved after 1989. This variable is included in Models 3 and 4 in order to determine the extent and direction of any relationship.

Contrary to the observations drawn in Chapter 5, which indicate that states were more likely to grant power-sharing concessions after the end of the Cold War than before, the results of this research indicates that when controlling for the influence of other factors, states are actually less likely to grant the rebels increased influence in political 
decision-making. As demonstrated in the table above, the relationship between "postCold War” and the likelihood of the state extending a high level power-sharing concession is negative. This indicates that states are less likely to extend high level power-sharing concessions after the Cold War than they were during it. However, the coefficient of the variable fails to achieve statistical significance, meaning that we cannot be very certain that the relationship does in fact exist and is not due to random variation within the data. Therefore, the inferential statistical analysis calls into question the conclusion that greater concessions are more prevalent in the post-Cold War period, while the lack of statistical significance is contrary to the contention that the shift from a multi-polar international political system affects the content of negotiated settlements.

\section{Trends and patterns: Geographic variation}

Another factor identified in Chapter 5 that appears to have an effect on the content of negotiated settlements is the location in which the war was fought. Specifically, it was shown that Africa accounts for the largest percentage of negotiated settlements in which power-sharing concessions represent the maximum concession granted. Logically, this raises the possibility that states in Africa are more likely to grant high level powersharing concessions than low level ones.

To account for the effect of geographic variation in the content of power-sharing concessions, the variable "Africa," which indicates whether a conflict was in Africa or not, was included in Models 3 and 4. The results of this analysis are mixed and questionable. First off, the problem of statistical significance again makes it difficult to determine whether or not a direct relationship does actually exist between the level of 
power-sharing concession and geographic area. Furthermore. A comparison of Models 3 and 4 cloud the issue by returning contradictory results. The coefficient for "Africa" indicates the presence of a negative relationship, which implies that high level powersharing concession are less likely to occur in Africa than in other parts of the world. Conversely, in Model 4 the coefficient is positive, thereby indicating an increased likelihood of such a concession. Therefore, this analysis cannot support the contention that the level of power-sharing concession vary with geography.

\section{Levels of policy concessions: A dissection of the models}

The next concession type to be addressed are those concessions that represent a one time concession made by the state to the rebels. These policy concessions are considered to be the least severe type of concession because they represent only a pointin-time concession by the state, whereas power-sharing and territorial concession permanently expand the decision-making role of the rebels with the state. These represent "one-shot" concessions because they do not increase the long term influence of the rebels with the decision-making process. In essence, policy concessions are those that fall short of power-sharing and territorial concessions. Policy concessions that represent only symbolic changes are considered low level policy concession, whereas high level policy concessions expand the rebels' access to political, social, or economic resources which expand the rebel's access to political, social, or economic resources.

The quantitative analysis of the determinants of the likelihood of high versus low levels of policy concession also utilized a probit model. As before, four models containing various specifications of theoretically derived variables were tested. In this 
case, however, each combination proved to be an inadequate explanation of the factors that influence the state's choice between high and low level policy concessions. Each of the four models failed to achieve statistical significance, as indicated by results of the likelihood ratio test. This test determines whether the specified model has explanatory power. To do so, a constrained model in which all the coefficients of the model are set to 0 is estimated. In practice, this creates a model consisting of a dependent variable and an intercept term and produces the hypothesis that all the coefficients in the model equal 0.

\begin{tabular}{|c|c|c|c|c|}
\hline \multicolumn{5}{|c|}{$\begin{array}{c}\text { Table } 6.4 \\
\text { Probit results for policy co }\end{array}$} \\
\hline Variable & Model 1 & Model 2 & Model 3 & Model 4 \\
\hline Deaths (logged) & $\begin{array}{l}.3829 \\
(.2943) \\
\end{array}$ & $\begin{array}{l}.25581 \\
(.3379) \\
\end{array}$ & $\begin{array}{l}.4063 \\
(.3115) \\
\end{array}$ & $\begin{array}{l}.5880 \\
(.5511) \\
\end{array}$ \\
\hline Duration (logged) & $\begin{array}{l}.8161 \\
(.5746)\end{array}$ & $\begin{array}{l}.9189 \\
(.6534)\end{array}$ & $\begin{array}{l}1.0737 \\
(.7668)\end{array}$ & $\begin{array}{l}1.4338 \\
(1.1575)\end{array}$ \\
\hline Guarantee & $\begin{array}{l}-1.1632 \\
(.9462)\end{array}$ & $\begin{array}{l}-1.100 \\
(1.0596)\end{array}$ & $\begin{array}{l}-1.135 \\
(1.1904)\end{array}$ & $\begin{array}{l}-1.8458 \\
(1.7904)\end{array}$ \\
\hline Ethnic & $\begin{array}{l}1.4817 \\
(1.0895)\end{array}$ & $\begin{array}{l}1.6201 \\
(1.1536)\end{array}$ & $\begin{array}{l}1.7752 \\
(1.1986)\end{array}$ & $\begin{array}{l}2.3660 \\
(1.6246)\end{array}$ \\
\hline Democracy & & $\begin{array}{l}-.0300 \\
(.0676)\end{array}$ & & $\begin{array}{l}.0814 \\
(.1360)\end{array}$ \\
\hline Stalemate & & $\begin{array}{l}.5985 \\
(.9702)\end{array}$ & & $\begin{array}{l}.1635 \\
(1.0906)\end{array}$ \\
\hline $\begin{array}{l}\text { Post-Cold War } \\
\text { resolution }\end{array}$ & & & $\begin{array}{l}.3044 \\
(1.0638)\end{array}$ & $\begin{array}{l}1.1170 \\
(1.6936)\end{array}$ \\
\hline Africa & & & $\begin{array}{l}1.0349 \\
(.9273)\end{array}$ & $\begin{array}{l}1.3784 \\
(1.1796)\end{array}$ \\
\hline Constant & $\begin{array}{l}-6.7552 \\
(4.2108) \\
\end{array}$ & $\begin{array}{l}-6.1786 \\
(4.5023) \\
\end{array}$ & $\begin{array}{l}-8.8611 \\
(5.5006)\end{array}$ & $\begin{array}{l}-12.8522 \\
(10.0356) \\
\end{array}$ \\
\hline Log likelihood & -8.8702 & -8.6186 & -7.9675 & -7.6864 \\
\hline $\begin{array}{l}\text { Likelihood ratio test } \\
\text { Chi Square } \\
\text { Probability } \\
\text { Degrees of freedom }\end{array}$ & $\begin{array}{l}4.75 \\
.3136 \\
4 \\
\end{array}$ & $\begin{array}{l}5.26 \\
.5114 \\
6 \\
\end{array}$ & $\begin{array}{l}6.56 \\
.3636 \\
6 \\
\end{array}$ & $\begin{array}{l}7.12 \\
.5237 \\
.3166 \\
\end{array}$ \\
\hline Pseudo-R squared & .2113 & .2337 & .2916 & \\
\hline Notes: $\begin{aligned} \mathrm{n}=20 \\
\\
{ }^{*} \mathrm{p}<.10, * * \mathrm{p}<.05\end{aligned}$ & $* * * \mathrm{p}<.01$ & & & \\
\hline
\end{tabular}


If this constrained model is rejected, the conclusion that the fully specified model as calculated provides a better explanation than a constrained model. In each of the tests conducted, the full model fails to achieve statistical significance. This means that we cannot be certain that the variables in the models do in fact have an effect on the dependent variable - the likelihood of a high level policy concession. Therefore, the results of these statistical tests are at best inconclusive and at worst misleading. This discussion, then, will turn to an examination of the model.

Of the many explanations that exist for the failure of this group of models, two likely candidates will be addressed. One possible explanation discussed below focuses on the theoretical constructs on which the models are based. It is entirely possible that the application of the theories developed in this research strayed too far from their original intent - which is to explain either international conflict or the resolution that results in civil wars. Because these theories were not intended to explain state concessions, it is at least possible that the use of these theories represents model misspecification. In other words, it may be that the variables identified are not in fact related to the level of policy concessions granted by the state. Another possible explanation addresses the patterns contained within the data. Given the complexity of the determinants of state concessions that end civil wars, another possible explanation is that the data are not sensitive enough to adequately represent real-world patterns. In this case, causal relationships between the dependent variable and some or all of the independent variables may exist, but a high degree of variation clouds the relationship. Each of these potential explanations is developed in more detail below. 
To date, an expansive amount of literature has been developed that addresses international conflict and civil war. The bulk of this research, however, focuses on the onset and resolution of these very different types of conflict. The purpose of this research has been to focus exclusively on a very precise type of outcome - state concessions within civil wars. Given that the theories on which this research is based represent a significant portion of the accumulated knowledge of political science community, it is plausible that the theories that have been developed to explain the onset and resolution of conflict are equally applicable to developing an explanation of the process by which states decide whether or not to grant policy concessions and, if so, to what extent. However, it is equally justifiable that this attempt represents a case in which the theories are too extremely transformed from their original intent. Just because a theoretical explanation and a set of variables have been demonstrated an ability to understand the onset and resolution of conflict does not necessarily mean that the same relationships can be expected to be observed when examining the choice between high and low policy concessions. It could be the case that the theories on which this research rests does not adequately explain this choice. If the application of the theory is incorrect, then it follows that the theoretically identified variables will not demonstrate the hypothesized relationship. The remedy to this problem is, of course, a different theoretical specification of the models. If this is in fact the case, then the value of this research is that it has demonstrated the inapplicability of these theories to the task at hand.

It is, however, equally plausible that the theoretical models do have explanatory power. If the above explanation for the failure of the models to achieve statistical significance is in fact incorrect and the theoretical models do in fact model the real world, 
the question then becomes - why don't the statistical analysis reflect the real-world relationships between the variables? The most direct answer to this question lies in the statistical processes on which this research is based. As previously mentioned, the likelihood ratio test assesses the chance that the fully specified statistical model outperforms a constrained model. The constrained model is one in which all the coefficients are held to 0 , which in practice produces a model containing only a dependent variable and an intercept term. In the case of the four models presented here, statistical significance is not achieved, which indicates that the fully specified models do not perform any better than the constrained model in explaining the relationship between the dependent variable and the independent variables. A closer examination of the models indicates that none of the variables in the fully specified models achieve statistical significance. This does not mean that there is no relationship, but only that we cannot say with a degree of certainty that a relationship exists. In other words, the results are indeterminant in that we can not say with a high degree of certainty that the relationship exists, just as we cannot say that it does not exist. When the coefficients do not reach accepted norms of statistical significance (that the chance of the results being an outcome of random variation within the data is less than 1 in 20), they are statistically equivalent to 0 . This means that each of the fully specified models (where no coefficients reach statistical significance) essentially represents a model where the coefficients of all the independent variables are 0 . In other words, each of the fully specified models is the same as its constrained model. It becomes clear, then, that each fully specified model cannot outperform its corresponding constrained model. 
The issue, then, is not necessarily whether or not a relationship exists, but whether or not we can observe any relationship that may exist given the limits of the data. As indicated in the table above, the standard error of the estimates for each of the coefficients is relatively large. This decreases the likelihood that a statistically significant relationship results even if a relationship is actually present. Maximum likelihood estimation procedures, where are used to estimate the parameters of a probit model, calculates the standard error of the estimate. This descriptive statistic, which is the square root of the variance of the estimate, indicates the degree of dispersion of the set of estimated values for each coefficient. When the standard error is high relative to the value of the mean, it indicates a high degree of variation within the set of estimations for that coefficient. This means that we are less likely to observe any relationship that exists within the data.

To explain, MLE estimation procedures use an algorithm to conduct a specification search to determine the combination of coefficients that is most likely to produce the data. In doing so, a set of values for each coefficient is produced. The variance of this set of values is produced, from which the standard error is calculated. When there is a high degree of variation with the set of estimated coefficients, a large standard error results. This does not mean that no relationship exists, but only that any relationship that does exist is difficult to identify. Thus, when the standard error of any estimate is high, we are less confident that the relationship does in fact exist. This uncertainty is most directly observed in the computation of hypothesis testing, which is done to determine whether or not a certain level of statistical significance (i.e. certainty) is achieved. 
In hypothesis testing, the test statistic used is the ratio of the coefficient to the standard error. As the size of the standard error increases (the further from 0 it is, in other words) the more certain we can be that the coefficient is in fact different than 0 . As the size of the coefficient relative to the value of the standard error increases, the degree to which we can be confident in our results increases. However, when the standard error is large (when there is a high degree of variation in the set of estimated values for a given coefficient, in other words) relative to the size of the coefficient, we become less certain in our results. The low level of statistical confidence, however, does not suggest that no relationship exists, but only that it is difficult to distinguish between the null hypothesis (that the coefficient is equal to 0 ) and the alternative (that it is not equal to 0 ).

In each of the models being addressed here, the size of the standard error relative to the size of the estimated coefficients is rather large and, in some cases, exceeds the value of the coefficient itself. As a result none of the individual coefficients in the models reach standard levels of statistical significance. This occurs because we cannot, with a high degree of certainty, distinguish between 0 and the coefficient produced by the probit model. This produces a model in which all of the coefficients are 0 , which in practice produces exactly the same constrained model tested in the likelihood ratio test. Therefore it is not possible for us to reject the null hypothesis of the likelihood ratio test that the full specified model does not perform better than the constrained one. These results, then, indicate that the models do not adequately identify the presence of a relationship, which is different than demonstrating the absence of the relationship. The theoretically derived models presented above, then, may in fact provide correct explanations. 


\section{Chapter 7: Qualitative analysis of territorial concessions}

Only three civil wars in this study resulted in a state granting territorial concessions to its adversary - Sudan (1963-1973), the Philippines (1972-1996), and Bosnia-Herzegovina (1992-1995). This outcome represents common ground and an area of mutual support for the proponents of both bargaining theory and other international relations theorists. When viewed through the lense of bargaining theory, the near-total lack of territorial concessions provides clear and direct support for the contention commonly found in international relations literature that states value territory above all else. This is so because the logic of bargaining theory dictates that states will grant concessions they hold in great value only when the circumstances are extreme. If the contention that states value territory above all else is taken at face value, then the lack of territorial concessions itself lends direct support to bargaining theory. ${ }^{27}$

The relative lack of territorial concessions does, however, present a problem. As a result of the few occurrences and the lack of variation in the levels of these concessions (all are low), quantitative analysis of territorial concessions is simply not an option.

\footnotetext{
${ }^{27}$ This point borders on being a tautology. The point, however, is not to make an argument of causality, but merely to point out the common ground between two theoretical perspectives.
} 
Therefore, these three cases will be discussed in qualitative narratives intended to emphasis the process by which the states decided to grant territorial concessions. The purpose of these narratives is twofold. First, each narrative will be utilized to highlighting the process by which Sudan, the Philippines, and Bosnia-Herzegovina decided to extend territorial concessions as a means of ending their respective civil wars. Second, each will be used to determine the extent to which bargaining theory, the alternative explanations proposed by existing literature, and the variables identified by the descriptive analysis identify general causal factors that compel the abdication of territorial sovereignty by a state. Compared to the quantitative analysis approach utilized above, the benefit of qualitative analysis is that it allows for a detailed examination of the historical record to identify the factors that influenced the states’ decision to grant territorial concessions. The downside to this approach is that the extent to which these findings is, at best, severely limited because each of the three cases represents what is essentially a unique event. The cases of Sudan (1963-1973), the Philippines (19721996), and Bosnia-Herzegovina (1992-1995) are discussed below.

\section{Sudan}

Despite its contentious success and eventual collapse, ${ }^{28}$ the Addis Ababa agreement that brought the first Sudanese civil war to an end is an informative case in that it highlights many of successes and failures of the theoretical conjectures being

\footnotetext{
${ }^{28}$ The agreement was implemented and led to the establishment of the High Executive Council in Sudan in1972. The Council proposed a new constitution in line with the terms of the Addis Ababa Agreement, which was adopted in 1973. The southern region of Sudan, which had been granted autonomy in the peace settlement, went to the polls and elected a Regional People's Assembly in November of 1973, which was followed by the election of a country-wide National Assembly in April of 1974. Conflict diminished, but did not disappear. The Addis Ababa agreement was widely seen as failed when, in June 1983, the country was re-divided into three smaller areas and, in September of that year, Islamic law was established. (Europa 1990, p. 2378)
} 
tested. In terms of the peace process leading to the acceptance of the Addis Ababa Agreement, Sudan represents what has been described by some scholars as being “a rather unique process” (Rothchild and Hartzell 1993, p. 63). As such, it presents a special case in an effort to determine the factors that influence the concessions granted by states, but one that serves to illuminate the difficulties of developing a systematic theory of the process.

Sudan is a country whose history and complex demographics make it ripe for identity-based conflict (Deng 1995, p. 78), a contention that is upheld by its long history of civil unrest and domination by external powers. Geographically, Sudan is a large country whose borders overlap Northern and Sub-Saharan Africa, thereby creating boundaries that include both Northerners, who are predominantly Muslim and live in a hot and arid climate, and Southerners, whose culture and religious views more closely approximate Sub-Saharan animist and Christian religious views and who reside in a lush and fertile equatorial climate (Brogan 1998) ${ }^{29}$. The resulting ethnic divisions are sharpened by the relative prosperity of the Northern Sudanese (brought about, in part, by the British "Southern Policy," which attempted to promote the interest of the Southerners) and the historically common tendency of the Northern-influenced government to try to extend its cultural, religious, and political influence to its southern citizenry (Deng 1995, pp. 78-81; Rothchild and Hartzell 1993, pp. 64-68).

Historically, Sudan’s modern history of civil war and domestic unrest traces its roots back to 1819, when the country first came under Egyptian rule. The link with

\footnotetext{
${ }^{29}$ Rothchild (1997, p. 214-215) describes the categorization of the Sudanese as being either "Southern" or "Northern" as being an "oversimplification that greatly distorts reality" and reflective of "subjective and symbolic factors at least as much as objective reality." In part, this criticism of the commonly-used terminology is based on a more detailed analysis of the ethnicity of the inhabitants of the two regions.
} 
Egypt quickly drew Sudan into colonial politics when, in the early 1870s, Egypt became a British colony (Brogan 1998, Europa 1990). Sudan became a pawn in the colonial great power rivalry between Britain and France, although neither side a strong strategic interest in the country (Brogan 1998). Despite the lack of strategic importance of Sudan to either great power, competition over Sudan was the focal point of a rivalry that nearly led to a clash between the European powers. In an effort intended to simultaneously extend British influence at the expense of Egypt, to put down a Sudanese uprising, and to “frustrate the French,” British and French forces faced-off at Fashoda in 1898. The clash ended without bloodshed when a force of 120 Africans led by 8 French officers spent two years marching across Africa only to be told to "politely but firmly told to go home" by British forces. (Brogan 1998, p. 105).

Civil war in this African state begins similarly to many African civil wars - with a failed political independence. Talks beginning in 1953, which included representatives for northern interests but explicitly excluded a southern voice, placed both Britain and Egypt in the position of competing for the loyalty of the northern parties (Brogan 1998). In 1954, Britain and, under British pressure, Egypt began the process that brought about political independence for Sudan as a parliamentary republic in 1956 (Europa 1990, p. 3960). Southern spokespersons called for a federal system that would protection the culturally distinct South from Northern Arab and Islamic pressures but were continually ignored (Deng 1995, Rothchild and Hartzell 1993). For example, when a committee was appointed by the Legislative Assembly in 1956 to draft a constitution, only three of the forty-six members were from southern Sudan and, not surprisingly, those three voices 
were overwhelmed when they the reiterated demands for constitutional protections for the south (Deng 1995).

Political troubles soon combined with ethnic tensions when General Ibrahim Abboud led a military coup in 1958 that overthrew the British-installed civilian (Deng 1995, pp. 80-81). A Northerner, the general immediately began a campaign to eliminate potential challengers and embarked on a policy of Arabization and Islamization in the south, which resulted in post-colonial Sudan being primed for civil war by the desire northern leaders to force the assimilation of the south and the insistence of the south on the presence of a dual identity maintained through federalism (Deng 1985). When southern demands continued to be ignored, a separatist revolt that forced the issue of national identity was sparked (Rothchild and Harzell 1993). By 1963, the rebellious southerners had organized under the banner of Anya Nya (meaning "snake venom" in one of the southern dialects), a resistance movement whose goal was political independence and who received external support from Dinka tribes of the south internally and by Congolese rebels and the governments of Ethiopia and Israel externally (Brogan 1998). An intense and bloody war resulted, in which the northern army, despite its better training and superior arming, found itself unable to quell the rebels because of the expansiveness of the region (Brogan 1998, p. 106). Estimates of the number of deaths range widely, from a low of 250,000 (Correlates of War) to a high of 400,00 (Brogan 1998).

The tide turned, however, with regime change. In response to widespread rioting and social discontent, the Abbud government relinquished control and turned power over civilians under the leadership of Prime Minister Sir el-Khatim el-Khalifah, who relaxed 
tensions and invited southerners to a Round Table Conference in Khartoum. At this time, several grievances were aired by the Southerners, with proposed remedies including a federal system uniting the two disparate regions, a process through which the Sudanese people chose a collective identity, and separation into distinct political entities (Deng 1995). Although none of the initiatives were implemented, the proposed federal system ultimately served as the foundation for the 1972 Addis Ababas Agreement (Brogan 1998, Rothchild and Hartzell 1995). When a May 1969 coup brought another general, Jaafer Nimeiri, to power, movement towards reconciliation continued (Deng 1995). In contrast to Abbud, General Nimeiri, who was associated with the Communist party and advocated a socialist agenda for Sudan, was more inclined to pursue peace, and ultimately decided to bring the war to an end (Brogan 1998).

In June of 1969, Nimeiri advocated a set of initiatives that drew on the propositions of the Round Table Conference and included both territorial and policy concessions that would eventually produce a viable agreement and regional autonomy (Rothchild and Hartzell 1995). Concession offered by the state included amnesty for the southern rebels; the creation of programs to improve the social, economic, and cultural affairs of the south; and the creation of a Ministry of Southern Affairs (Brogan 1998).

Over the next several years, Nimieri continued to seek peace with the secessionist rebels, a process that ultimately produced the Addis Ababa Agreement of 1973. This agreement (temporarily) brought to a close decades of conflict that characterized postindependent Sudan. In addition to implementing the proposals made by the Round Table Conference, this agreement combined three southern provinces into a single entity and established a High Executive Council and People’s Regional Assembly with jurisdiction 
over southern affairs in Juba (Brogan 1998). According to the text of the 1972

agreement, the authority of the Regional Assembly included maintaining public order and regional security, levying taxes and duties, and exercising independent budgetary authority. The result was a system of government in which the central government maintained control over defense issues and foreign affairs, but otherwise left the south with a high degree of autonomy (Brogan 1998). In other words, the government of Sudan granted low-level territorial concessions in the form of autonomy to its rebel adversaries.

\section{Why concessions?}

Why did Nimeiri and other Northerners agree to territorial concessions that restricted northern access to the south and divided the state into two parts, especially when their predecessors refused to do so? The answer to this question of course involves a combination of interdependent factors. As previously discussed, the decision of what kind of concessions to extend is contingent on the decision by the parties to seek a negotiated resolution in the first place. This analysis will therefore begin with an overview of the factors that made negotiations possible, then move on to a discussion of the terms of settlement with an emphasis on explaining why Sudan choose to extend territorial concessions .

According to Rothchild and Hartzell (1993) and an extension of that work by Rothchild (1997), five conditions made the Sudanese environment favorable for a negotiated settlement: (1) a clearly identifiable leadership was in place on both sides; (2) the conflict had evolved into a stalemate in which neither side was able to gain the upper- 
hand; (3) leaders on both sides were politically motivated to seek a resolution; (4)

external pressure to resolve the dispute was being applied; and (5) a mediator had stepped forward to help the adversaries reach a mutually acceptable resolution. Each of these is discussed in more detail below.

The first precondition - the presence of a clearly identifiable leadership representing both sides - is, of course, necessary for fruitful negotiations to begin. Both sides of the table must be occupied by representatives who are able to speak on behalf of those they represent and to commit on their behalf. Although initial proposals to negotiate were opposed by members of the Nimeiri regime, several top leaders resigned to protest the move to resolve the conflict. Rather than forestalling negotiations, as intended, the resignations enable Nimeiri to develop a cohesive front in support of negotiations within his regime (Rothchild and Hartzell 1993). In addition, his willingness to act decisively in the face of opposition further enabled his position, as did his ability to demonstrate his power and popularity through a referendum after overcoming a 3-day loss of power at the hands of communists in 1971 (Deng 1995, pp. 90-91).

On the southern side, a similar difficulty was overcome. Although facing strong differences of opinion, the disparate groups of rebels were willing to loosely ally themselves under the leadership of the Southern Sudan Liberation Movement and General Joseph Lagu (Rothchild and Hartzell 1993). He, in turn, was able to overcome the split between those who were willing to accept a settlement and those that advocated fighting for full independence and ultimately serve as the southern representatives in talks with the government (Rothchild and Hartzell 1993, Rothchild 1997). The result was a 
necessary first step towards negotiations - each side managed to overcome internal difference to choose leaders who were able to negotiate on their behalf.

Second, given its limited resources and questionable hold on power, the government of Sudan faced a difficult task with increasing costs - eliminating the rebels or forcing a capitulation. This put the government in a position that "made it difficult, if not impossible, for the government to win an outright military victory over the South” (Rothchild 1997, p. 219). This produced a stalemate in which "neither the Sudanese nor the SSLM possessed, or seemed likely to muster, the resources necessary to escalate itself out of an impasse at an acceptable cost” (Rothchild 1997, p. 219). The presence of a stalemate, in which neither side was able to achieve its goals and both incurred a variety of losses, produced a situation that predisposed the opposing leaders to seek a mutually acceptable compromise, even though by doing so neither side would be able to fully achieve their goals (Rothchild and Hartzell 1993).

Third, both Nimeiri and Lagu were politically predisposed to a negotiated settlement (Rothchild 1997). For Nimeiri, bringing the conflict to a close was politically necessary in order for him to achieve his greater goals. Having alienated supporters on both sides of the political spectrum, Nimeiri had little choice but to seek out the center, which necessitated making overtures to the south (Brogan 1998). In addition, Nimeiri was faced with the likelihood that the war would continue to be a drain on the resources of Sudan, a situation that could ultimately lead to his downfall. On the southern side, Lagu also viewed military conquest as unlikely and was therefore determined to seek a negotiated settlement (Deng 1997, p. 221). Having been able to pull together the independent factions that constituted the southern rebellion under his political and 
military leadership, Lagu was able to embark on what he saw as his best option given the limited armaments and training available to the rebels (Rothchild and Hartzell 1993). Thus, while leaders on both sides had the option of pursuing their goals in whole, each also had the ability and the motivation to seek a compromise solution.

Fourth, the conflict drew the attention and involvement of two regional actors Ethiopa and Uganda, both of whom had a stake in the outcome of the conflict (Rothchild 1997, p. 222). Rather than playing a proactive role by encouraging peace, however, decisions made by both of the neighboring countries indirectly pressured the government and rebels of Sudan to seek peace (Rothchild and Hartzell, 1993). Ethiopia's own secessionist movement was intricately entangled in the Sudanese civil war. Ethiopian rebels used neighboring Sudan as a conduit for the smuggling of arms and as a place of refuge, a move which prompted Emperor Haile Selassie to return the favor by allowing support to flow through Ethiopia to the Sudanese rebels. This game of tit-for-tat, however, turned cooperative when, in 1971, Ethiopia and Sudan agreed to stop aiding the rebellious factions in each others country (Rothcild 1997, p. 223). The result of this was to apply pressure Nimeiry regime and the rebels to seek a negotiated settlement. In the case of Uganda, the Sudanese rebels gained the support of Idi Amin, who had recently overthrown the president of Uganda, Milton Obote. Supporters of President Obote, who were preparing for an attempt to restore the president, received aid and support from Sudanese troops. In return, Amin allowed supplies destined for Anya Nya to pass through Uganda. However, in 1971 Uganda and Sudan mutually agreed to cease supporting each others rebels. The effect of this agreement was to eliminate an important 
source of supplies for the Sudanese rebels, which thereby increased the difficulty of the strategic position.

The final precondition addressed by Rothchild and Hartzell (1993) and Rothchild (1997) was the presence of an outside mediator. Although not viewed as a necessary condition for fruitful negotiations, the presence of a third party to facilitate communications between parties and to point out opportunities is generally associated with an increase in the likelihood of success (Walter 2002). In the Sudanese conflict, two mediators were available: the World Council of Churches (WCC) and the All Africa Conference of Churches (AACC) (Rothchild and Hartzell 1993). Both parties, which had a history of involvement in relief efforts and goodwill missions, were able "to assess the implications of changes in leadership, the emergence of identifiable bargaining parties, and other events as they took place and make the most of opportune moments in order to advance the negotiation process" (Rothchild and Hartzell 1993, p. 77).

Taken together, each of these five factors contributes to what Rothchild and Hartzell (1993) and Rothchild (1997) term “favorable preconditions” to successful negotiations. As with most civil wars, the first Sudanese conflict represents a complex web of causes that individually and collectively make such conflicts recalcitrant and difficult to resolve. Added to the mix of domestic rivalries, scarce resources, and interested third parties are the territorial demands made by the rebels and the reluctance of any state to cede control over people, resources, and territory. Given these difficulties, it is somewhat surprising that talks actually produced a settlement that was acceptable to both parties. The discussion, then, will turn to the factors that made an agreement possible. 


\section{Why territorial concessions?}

Having decided to pursue a negotiated settlement, why did the government of Sudan decide to, for all practical purposes, abdicate its sovereignty over a piece of its territory? To address this question, three explanatory factors are developed below. The first stems form the nature of the conflict itself, the second addresses the decision makers, and the third draws on Walter's (1992) credible commitment theory and directly addresses bargaining theory.

First and foremost, the conflict was at its roots was based on the ethnic and cultural differences between was considered the Arab north and the African south. The dispute was a complex one in which "class, culture, ethnicity and region in Sudan all tended to coincide and to reinforce one another” (Rothchild and Hartzell 1993, p. 67, original italics removed). Southern rebels were unwilling to relinquish claims for some degree of independence, yet the government was unable to defeat them. Given the inability of the Sudanese government to conquer the rebels (or at least its unwillingness to expend the necessary resources to do so), Sudanese leaders were forced to choose between two options: continue to fight, and thereby continuing to expend resources and incur costs or make territorial concessions to appease their adversaries. Had the government of Sudan made concessions that feel short of regional control of the south by Southerners, it is unlikely that the rebels would have acquiesced considering their demonstrated commitment. This is evident because, by the time the Addis Ababa Agreement was concluded in 1971, dissatisfied southerners and rebel groups had been protesting their treatment by the north since before independence and appeared unlikely 
to acquiesce. Territorial concessions, it seems, were necessary if the rebels were to be appeased. Therefore, one part of the explanation of why Sudan relinquished direct territorial control is that it offered the government a means by which to resolve the conflict and remove itself from civil war.

Secondly, the stalemate that emerged between the two adversaries put the rebels in the position of being able to continue their struggle. For political and strategic reasons, the ability of the rebels to withstand the Sudanese army effectively removed (or at least made unattractive) the state's option of continuing what appeared to be an unending fight. Starting from a small band of malcontents, under the leadership of Lagu, the southern forces (in particular the Anya Nya) demonstrated their ability to withstand the state's forces. Rather than facing certain defeat, the rebels had grown stronger over the course of the conflict (growing to include between 10,000 and 12,000 troops), gained domestic support, and even drawn international attention to their cause (Rothchild and Hartzell 1993, pp. 73-74). Although there is reason to question the likelihood that they would succeed in defeating that Sudanese army, the rebels were able to gain a position that enabled them to hold off the state and force it to expend already limited resources. The state made territorial concessions, then, for two reasons: (1) the opposition clearly demonstrated that those were the only type of concessions that were acceptable; and (2) granting such concessions, although costly, enabled the government of Sudan to bring an end to the conflict.

Third, domestic politics and leadership choices played an important role. Not only was regime change required to reorient the government of Sudan to consider seeking peace with the rebels, but the need for domestic support played an important role. 
Opposition to a peace agreement continued to be present in the government after Nimeiri took control, but for domestic political reasons he was motivated to ignore the opposition of anti-settlement factions and seek an agreement. According to Deng (1995, p. 90),

Nimeiri had alienated both the right and the left and was building on the support in the center, which his advisors suggested could include the South as the strongest alternative political and military power base. Nimeiri was persuaded of this against the opinion his military advisors and senior officers, some of whom resigned in protest from the Revolutionary Command Council, to the executive authority within the regime.

Thus, in this case, domestic political considerations clearly play an important role, a variable that is overlooked in the quantitative analysis above.

This is a factor that extends beyond the leadership level to include the makeup of the negotiating team as well. The choice of Abel Alier as the southern representative within the government was critical to the success of the negotiations (Deng 1995, p. 91). Alier's appointment as the leader of the Sudanese negotiating team injected the deliberations of "a southerner whose modesty, loyalty, and commitment to a peaceful resolution of the conflict had been tested” (Deng 1995, p. 91). His role was considered crucial in many respects because "it was taken as a positive sign of the government's seriousness of purpose,” and because his proposals for regional autonomy "became the basis for the final accord” (Rothchild and Hartzell 1993, p. 71).

On the other side of the table leadership played an important role as well. The ability of General Lagu to assume the position of military and political leader enabled him to convince various rebel factions that a united front was necessary and that the need to reach a negotiated settlement was inevitable. Doing so enabled him to negotiate an effective agreement with the state. "Once Lagu consolidated his position of political and military leadership with Southern ranks, he was able to overcome the reluctance of some 
of his commanders to begin negotiations and to respond positively to government overtures (Rothchild and Hartzell 1993, p. 71)

What, then, does this tell us about the applicability of bargaining theory as an explanation of the concessions made by states in a state of civil war? This analysis contends that bargaining theory does in fact provide theoretical guidance for understanding the decision to grant low level territorial concessions, albeit indirectly. Several of the factors proposed by bargaining theory and alternative explanations do appear to have influenced the decisions made by the government of Sudan, while others are overlooked.

Clearly one of the primary factors that brought about the possibility of territorial concession was the leadership of both the state and the rebels. The choice of leadership, however, is not a factor that enters into the decision-making calculus of bargaining theory. It does seem reasonable to expect some leaders to be more open to the prospect of bargaining (to be risk averse, in other words) than others. This would indicate that the degree to which the factors proposed by bargaining theory influence the human decisionmakers is not uniform. Willingness of the leadership to bargain, then, is a factor that may influence both the decision to negotiate and the concessions offered by the state that is overlooked by bargaining theory.

One of the primary factors that, according to bargaining theory, influences the terms of settlement is the misperception of the costs of fighting. Although the costs of the conflict do not appear to directly influence the decision to grant territorial concessions, it does appear that the inability or unwillingness of the Sudanese government to devote the necessary resources necessary to achieve a capitulation put it in 
the position of facing a long-tern conflict or having to grant concessions. Given the demonstrated resolve of the rebels and their reluctance to accept anything short of partial autonomy, costs, then, indirectly put the state in the position choosing between fighting or granting autonomy. Had the state been able or willing to devote the resources necessary to achieve capitulation, the outcome may have been different. Therefore, it seems reasonable to conclude that while costs the costs of fighting did not directly determine the terms of settlement, they did increase the likelihood of a negotiated settlement, the only form of which that was acceptable to the rebels (and therefore the only effective type) was territorial concessions.

Bargaining theory also contends that an incentive to cheat decreases the willingness of a state to extend concessions. As Walter (2002) contends, one possible way to overcome this problem is through the promise of enforcement by a third party to enforce the agreement or to ensure the security of the combatants once they lay down their arms. When such a security guarantee is present, bargaining theory contends that state concessions will be greater. In the case of Addis Ababa Agreement, such a promise was in place, although it was a relatively weak one ${ }^{30}$. Ethiopian Emporer Haile Selassie offered the guarantee of his government to the security of the Sudanese rebels would be protected and, furthermore, personally pledged that “Anya Nya returnees would not suffer reprisals” (Walter 2002, p. 97). Thus, through Selassie’s promise, the security of the rebels was ensured and the threat of broken promises was significantly reduced by the backing of a regional power. In effect, the agreement was made that much more attractive to the rebels. This case, then, appears to corroborate the contention made by bargaining theory.

${ }^{30}$ Walter (2002, p. 97) points out that the Somali guarantee was the weakest one of fourteen in her study. 
The third factor proposed by bargaining theory that may affect the outcome of negotiations - that conflicts over indivisible stakes are more difficult to resolve - are present in two forms. Both serve as the basis for hostilities in this conflict. The primary issue over which this civil war was fought was, of course, territorial control. Furthermore, the combatants on each side were organized along ethnic lines. Both of these factors represent what are considered by bargaining theory (as developed for the purposes of this research) to be indivisible stakes. In this case, however, the difficulties presented by these indivisible stakes were overcome, albeit at high costs to both sides. In fact, the organization of combatants along ethnic lines may have actually increased the likelihood of a negotiated settlement, albeit indirectly. As discussed above, one of the preconditions that lead to successful negotiations was the presence of a clearly identified leadership on both sides. Although discontent regarding the decision to negotiate was present at first, both Nimeiri and Lagu were able to develop a fairly high degree of consensus within their respective ethnic constituencies. In this case, it appears that the negotiation process was made easier by the uniform composition of the groups, which were ethnically homogenous and therefore more cohesive. Because each side was (to a high degree) in agreement, little intra-side debate or opposition was present, which made a territorial concession an acceptable way in which to resolve the conflict.

With regard to the explanations developed from the existing literature, the presence of a stalemate clearly had a strong impact on the content of the negotiated settlement. As discussed above, the inability of either party to marshal the required strength to decisively defeat its opponent brought about a situation in which both sides were compelled to seek a compromise solution or face the continuation of a long-term 
struggle. This, of course, made the likelihood of a negotiated settlement possible given the inability of either side to defeat the other produced a limited the range of choices, all of which entailed making a compromise in order to end the war. Given that the issue was territorial control, it follows that the stalemate significantly increased the chances of the highest level of concessions because if victory was seen as a possibility in the future, the state may have been more willing to fight the rebels to their defeat.

The level of democracy, on the other hand, appears to have played at best a limited role. The decision by Nimieri to seek a negotiated settlement by offering autonomy was, in part, the result of his need to gain domestic political support. The historical record, however, strongly suggests that Nimeiri was acting in his own best interests and not responding to the demands of the populace, as the democratic peace literature suggests.

The remaining variables addressed in the quantitative analysis above that account for the timing and location of the negotiated settlement specifically address the likelihood of state concessions relative to other times and places. Of course such a comparison cannot be made based on a single case. Therefore, this analysis will only make two observations. First, this case represents the sole territorial concession in Africa (and only one of three globally). And second, the concessions occurred during the Cold War, which is statistically unusual in that a dramatic increase in the rate of negotiated settlements followed the end of the Cold War. It should be noted, however, that unlike many other civil wars occurring during the Cold War, the superpower rivalry had little if any direct effect on the course of the conflict. 
In sum, the completion of the Addis Ababa Agreement in 1972 represents an unusual case of a negotiated settlement in that the political and military condition predisposed the conflict to a resolution at the bargaining table. In most cases of civil war, the conditions are much less likely to bring about a negotiated settlement. This case, then, sets a low standard for theory testing. For the purposes of illustration, though, such a case is useful for identifying the process by which the terms of settlement are determined. Its uniqueness, though, makes drawing generalizations difficult. The discussion now turns to the case of territorial concessions in the Philippines (1972-1996).

\section{The Philippines}

On September 2, 1996, major strides towards peace were taken to end the civil war in the Philippines when the Final Peace Agreement was signed by representatives for the government and the Moro National Liberation Front, one of several groups fighting for greater political independence for the Moro. Success, however, was limited because several other Moro groups continue to fight. Although racially and linguistically similar to the "Filipino majority," the Moro are united by a historical connection to the Moors of Spain and their Muslim religion. The resulting peace, however, was only partial as a result of the many groups claiming to represent the Moros.

\section{The onset of war}

The history of the Moro people, which predates conquest of the Philippines by the Spanish in 1565 and transcends rule by the United States and occupation by the Japanese, is one marked by continual claims for autonomy for the island of Mindanao and the Sulu 
archipelago (Brogan 1998, Uppsala Conflict Database). Although effectively under control under American rule, tensions in the newly independent Philippines grew with the continued migration of predominantly Catholic Filipinos into the region (Muslim and Cagoco-Guiam, 2003). By the late 1960s, tensions increased dramatically as the Moro became frustrated by the challenges brought about by Christian Philippine migration into the area. Although they accounted for roughly 75 percent of the population of Mindanao at the turn of the century, the influx of outsiders reduced their proportion to approximately 25 percent of the population of Mindanao by the late 1960s (Uppsala Conflict Database). The most productive agricultural lands were taken over and natural resources were extracted with the Moro seeing little in return (Muslim and CagocoGuiam, 2003). Because of the loss of land, as well as the resulting increase in competition for natural resources and the loss of cultural identity, the Moro reiterated demands for greater autonomy to the government and did so with force by shifting into a state of open rebellion (Muslim and Cagoco-Guiam, 2003).

In September 1972, the long-simmering conflict reached new heights as President Ferdinand Marcos declared martial law in the region as a response to widespread communal violence (Brogan 1998). The move sparked the creation of the Moro National Liberation Front (MNLF), a secular movement that traces its origins to the Muslim Independence Movement (MIM) that organized along tribal lines press claims for independence in response to the killing of 28 rebellious recruits (MAR: Assessment for the Moros in the Philippines). One month later, the MFLN moved to the forefront of the Moro movement by launching the first organized Moro counter-offensive against the 
government and, by 1975, had established itself as a popular movement representing the interest of the Moro people (Uppsala Conflict Database).

Marcos responded with a two-pronged approach by simultaneous seeking socioeconomic reform while at the same time suppressing Muslim agitation by instituting martial law (Brogan 1998). These reforms included the reconstruction of devastated land, initiatives intended to support Moro investment and development activities, resettlement assistants for refuges, and the provision of social welfare programs but are unsuccessful at reducing tensions. Martial law sparked a widespread Moro revolt and the conflict quickly broadened into full-scale civil war in which incurred by both sides (Muslim and Cagoco-Guiam, 2003).

The MNLF was very successful at attracting support internally and externally, but faced dedicated opposition by government forces. By 1974, between 50,000 and 60,000 rebels had been recruited and placed in fighting positions, while external military support flowed through Malaysia from Libya and the Organization of the Islamic Conference (OIC) provided political support (Brogan 1998). In response, the Armed Forces of the Philippines (AFP) reorganized itself to counter the growing strength of the Moro rebels (consisting of the MFLN and several associated factions) by creating the Central Mindanao Command and the Southern Command (Stankovitch 2003). The government forces launch a full-scale attack in February of 1974, being particularly effective by imposing between 500 and 2,000 deaths in a two-day siege of the southern town of Jolo (Muslim and Cagoco-Guiam, 2003). The fighting between the two adversarial groups soon produced a stalemate (Stankovitch 2003). 


\section{A failed peace}

In an effort to bring about a resolution, President Marcos initiated efforts to begin negotiations by holding direct talks with MNFL Chairman Nur Misuari and MNLF leaders in the field (Brogan 1998). In addition to the stalemate, Marcos was facing international pressure from the Organization of Islamic Conferences and oil producing Muslim states, who were threatening an embargo in support of their religious brethren (MAR: Assessment for the Moros in the Philippines). To improve his image abroad, Marcos began a public relations campaign to court support in the Muslim world that included establishing or improving relations in twenty Muslim countries, sending Imelda Marcos as a special emissary to Libya, and establishing social and cultural exchanges with Egypt (Muslim and Cagoco-Guiam 2003, Stankovitch 2003). In addition, the president also made overtures to the Non-Aligned Foreign Ministers Meeting. His efforts paid off, as the OIC pressured the MNLF to decrease its demands from full independence to autonomy (Muslim and Cagoco-Guiam 2003).

Conducted under the auspices of the OIC with final negotiations taking place in Libya, the Tripoli Agreement was signed by representatives of the Philippine government and the MFLN on December 23, 1976 (MAR: Assessment for the Moros in the Philippines). According to the text of The Tripoli Agreement, the Republic of the Government of the Philippines: agreed to grant autonomy to thirteen southern provinces and southern nine cities; permitted the southern provinces to establish their own judicial (based on Islamic law), executive, legislative systems; and to allow the provinces to establish their own security force (Tripoli Agreement 1976). As a safeguard, the government insisted that the agreement empower it to take the necessary steps to 
implement the agreement (Stankovitch 2003). Additional concessions from the state came in the form of amnesty being granted to the rebels and guaranteed positions within the government for rebel leaders to allow them to surrender while saving face, which occurred in talks leading up to the negotiations (Stankovitch 2003).

Support for the reduction of demands was contentious within the MNLF. While some MNLF leaders surrendered their arms to accept government posts, others, including Chairman Misuari (the signing representative of the Moro) continued to seek full political independence for the Moro region (Muslim and Cagoco-Guiam 2003). As a result, two splinter groups - the Moro Islamic Liberation Front (MILF) and the Moro National Liberation Front Reformed - emerged and continued to independently seek greater reforms (Uppsala Conflict Database).

The implementation of the accord, however, was less than perfect. Both the MFLN on the government began to accuse each other of insincerity and deceptive practices (Muslim and Cagoco-Guiam 2003). Marcos implemented reforms that established two regional governments, but did not take the steps necessary to implement autonomous rule (Muslim and Cagoco-Guiam 2003). Peace was short-lived and the conflict resumed within months, although sporadic talks continued.

Leadership changes in the government of the Philippines, however, eventually turn the tide back towards peace. By the mid-1980s, the strength of the long-simmering communist insurgency gained strength, ultimately leading to the removal of Marcos from office. Facing intense military attacks, legal challenges, and popular discontent, Marcos called for elections and is challenged by Corazon Aquino (Brogan 1998). Although he declares himself the winner (as result of what many considered to be a fraudulent vote 
count), his victory was short-lived and he ultimately is forced to resign in the aftermath of a failed coup attempt (Brogan 1998). Corazon Aquino claimed the presidency and proposed widespread reforms, including a new constitution, regional autonomy for the Moro, and a ceasefire (Muslim and Cagoco-Guiam 2003). The MNLF agreed to meet at the negotiating table and, despite challenges from the MILF, soon gained recognition from the government to speak on behalf of the Moro. Talks between the government and the MNLF, which were accompanied by attacks by the MILF, continued into 1997, but eventually broke down when the government unilaterally imposed autonomy despite MNLF and MILF objections (MAR: Assessment for the Moros in the Philippines). In 1987, the Philippine Congress passed legislation allowing the disenchanted areas to engage in a plebiscite to determine the status of the disputed territories, but only four regions accepted the conditions Uppsala Conflict Database). The effort, however, was opposed by both the MNLF and the MILF because it was too limited and because they were not given the opportunity to participate.

Open conflict continued a various levels of intensity until 1992, when political change once again and brought about the possibility of peace. Fidel Ramos was elected president in February and immediately began to seek a resolution to the decades-old conflict (Muslim and Cagoco-Guiam 2003). Ramos took initial steps to garner international support for a permanent resolution when, as a candidate, he met with Libyan leader Colonel Muammar Qaddafi (Stankovitch 2003). Upon his election, Ramos immediately called for peace and appointed a presidential commission to develop a program to offer amnesty to the rebels to begin negotiations. In October, representatives of the new government met with the MNLF in preliminary negotiations. A ceasefire was 
adopted in 1993 and, although they did not directly take part in the talks, the MILF agreed not to oppose the peace process (Muslim and Cagoco-Guiam 2003). On September 2, 1996, the Final Peace Agreement was signed with the intention of implementing the terms of the 1976 Tripoli Agreement. Although the MILF did not participate, the agreement was largely successful and formed the groundwork for future talks between the MILF and the Government of the Republic of the Philippines.

\section{Why territorial concessions?}

The territorial concessions contained in the Tripoli Agreement and implemented by the Final Peace of Agreement of 1996 represent the outcome of a decades-long process that is marked by starts and stops. Clearly the process by which the terms of the agreement were accepted by the warring parties does not represent a smooth or linear process. In fact, in many ways it exemplifies the difficulties of reaching and implementing such an agreement. Nor was it a peaceful process. Although the level of violence varied considerably, it was at time of the agreement very heated and cumulatively very costly to both sides. Government estimates place the number of deaths at approximately 120,000 people, with more than a million left homeless and at the height of the conflict in the 1970s, over 75 percent of the government's troops were deployed to address the unrest (Uppsala Conflict Database). Adding to the cost was the length of the conflict - approximately three decades. Nor was the Final Agreement the end of the story. To this day, occasional acts of violence occur between the Moro and their Christian neighbors, albeit at a significantly diminished level, despite a series of agreements being adopted between the MILF (Stankovitch 2003). 
Why then did the Government of the Republic of the Philippines agree to give up control over a resource rich part of its country? The simple answer is, of course, to gain peace. A more complete answer, however, is presented below. In what follows, four factors leading to lasting territorial concessions are addressed: the determination of the rebels; the presence of a stalemate; the willingness of leaders on both sides to resolve the dispute; and the presence of third parties.

The first factor that contributed to the willingness of the government of the Philippines to make concessions appears to be the demonstrated commitment of the rebels. Moro claims for territorial independence extend back to the beginnings of Spanish rule in the mid- $16^{\text {th }}$ century (Muslim and Cagoco-Guiam 2003). Claims for Moro independence were pressed against the US government during the colonial period, which culminated with an unfulfilled request for Moro autonomy when the Philippines were granted independence. So, by the time the independence of the Government of the Republic of the Philippines was granted by the US in 1946, a long history had been established. By the late 1960s, tension had increased in response to inward migration of Philippine Christians and armed struggle organized under the leadership of the MNLF resulted (Muslim and Cagoco-Guiam 2003). In this respect the Moro claims for self-rule presented the government of the Philippines as a problem that was not likely to "go away" on its own. In fact, several attempts were made by the government to appease the Moro and their leadership prior to both the Tripoli Agreement and the Final Peace Agreement. Nearly three decades of violence, however, demonstrates the unwillingness of the rebels to be swayed and the inefficacy of a military solution. This left the state with two options - defeat or appease its adversary. 
Government forces, however, were unable to defeat its enemy and by 1974 the conflict had produced a stalemate (Stankovitch 2003). The onset of a stalemate marks a turning point in the armed conflict - because neither side was able to achieve its goals on the battlefield they turn to the negotiating table. The Tripoli Agreement marks a significant milestone towards peace, but one that does not prove to be immediately successful. Two factors diminished the successfulness of the Tripoli Accords. First, the downgrading of demands from independence to autonomy produced dissention within the ranks of the Moro. The result was the fractionalization of the movement, which ultimately forced the government with deal with demands from different, yet related, groups. Second, the Accords provided little detail about what was meant by autonomy and how it was to be established. As a result, different interpretations of the document made implementation difficult. In many respects, attempts to implement the accord resembled a continuation of the bargaining process as each side made demands of its adversaries. The vagueness of the document provided leaders of each side with political ammunition to continue to seek their ultimate goals. Reaching an agreement, then, does not necessarily indicate the resolution of a dispute.

Final implementation did not occur until the government had demonstrated its willingness to seek a settlement acceptable to the rebels and the rebels had indicated their willingness to live by such an agreement. The rise of Corazon Aquino to the presidency brought to power a leader who was willing to ensure regional autonomy for the Moro that would be constitutionally guaranteed. While considered a step in the right direction, the changes were also viewed as insufficient by the rebels. The establishment of a ceasefire and the return of Misuari to the Philippines, however, seem to indicate a willingness on 
the part of the MNLF to seek a resolution. Talks under Aquino, however, were not productive and marked by frequent episodes of violence, a factor that did not change until the election of President Ramos to the Philippine presidency.

To Ramos, peace was the focal point of his administration. In contrast to initiatives under Aquino, Ramos addressed the specific demands of the Moro and the MNLF. This included adopting the principles of the Tripoli Agreement and granting the Moro the ability to address the political, social and economic inequalities of the region (Muslim and Cagoco-Guiam 2003). Doing so, however, only appeased the MFLN faction of the Moro. The government, then, had to also accept the presence of other rebel groups with unresolved demands on the same issue. Therefore, a necessary step toward territorial concessions was the presence of a leader willing to meet the demands of the rebels.

Finally, the presence of third parties made important contributions to the context of the negotiation process in several ways. First, the Islamic oil-producing states who sympathized with the marginalization of the fellow Muslim played a coercive role (Santos 1999). When it appeared that the Marcos regime was unwilling to seek a negotiated settlement, the threat of an oil embargo added to the potential costs that would be incurred should the government decide to continue to fight. Of course, Marcos was able to minimize these potential costs by successfully embarking on a foreign policy that improved his image and bargaining position in the Muslim world (Stankovitch 2003). Second, both the Organization of Islamic Conference and the government of Libya helped keep the negotiations on track through the provision of good offices (Santos 1999). By doing so, they were able to step in propel talks forward when necessary. 
Third, the OIC was also instrumental in encouraging the Moro to accept autonomy as an acceptable resolution (Santos 1999). Thus, the involvement of third parties played a supporting role to what concluded as a successful resolution of a territorial dispute.

In sum, claims for an independent Mindanao ultimately extracted territorial concessions from the Government of the Republic of the Philippines. The process by which a resolution was achieved, however, was a complex one that evolved over time. It was a process that can also be viewed as being only partially successful because it did not represent an entire solution, but one acceptable to only a subset of the disaffected Moro. It does, however, highlight the role of increasing costs to the state as a factor that affects the context of the decision to make concessions, but not necessarily the concessions themselves. Finally, it emphasizes the importance of a stalemate as a necessary precondition for talks to occur. In what follows, the Dayton Peace Accord is discussed.

\section{Bosnia (1992-1995)}

The negotiation process that formally brought an end to the Bosnian civil war (1992-1995) is one that bears little resemblance to that of the Sudanese and Philippine peace processes. Entered into force with the signatures of Alijia Izectbegovic of Bosnia, Franjo Tudjman of Croatia, and Slobodan Milosevic of Serbia in Paris on December 14, 1995, what is commonly known as the Dayton Peace Accords was the result of 21 days of intense negotiations in Dayton, Ohio (Brogan 1998). The terms of the agreement, which includes territorial, power-sharing, and policy concessions, effectively subdivides the former Yugoslav Republic into two separate political entities - the Federation of Bosnia-Herzegovina and the Serb Republic of Bosnia - each of which maintains a high 
degree of independence (Europa 1998). However, the motivation to conclude such an agreement did not come from the combatants themselves. Instead, as discussed below, the accord represents the enormous and concerted effort on the part of the international community to end a campaign of ethnic cleansing and protect the strategic interests of the world powers more so than it does the efforts or desires of the combatants themselves.

Studying the terms of this agreement is informative for several reasons. First, since it represents the first ethnic secessionist movement in the aftermath of the Cold War, it may provide guidance for understanding the process by which other post-Cold War agreements are made (Saideman 2001). Second, the complex interplay of domestic politics and ethnic identity can further inform our understanding of the role of identity politics in civil wars generally and those that end in territorial concessions specifically. Third, this case highlights the role that the international community can play in the resolution of civil wars and so may provide lessons to policymakers.

\section{The Bosnian civil war}

The war that has been described as "the worst outbreak of violence in Europe since World War II” (Kaufman 2001, p. 165) is a conflict whose roots can be traced back to the Roman Empire (Brogan 1998, p. 439). A conglomeration of 6 independent republics - the republic of Serbia, Croatia, Bosnia-Herzegovina, Slovenia, Macedonia, and Montenegro, with Serbia consisting of the two autonomous regions of Kosovo and Montenegro - the pre-civil war Republic of Yugoslavia enjoyed a relatively peaceful and prosperous period from the end of the World War period until the death of its wartime resistance leader Joseph Broz Tito. Under Tito, the political structure of Yugoslavia was 
highly decentralized along ethnic lines, a characteristic that increased in importance during the 1960s and 1970s and contributes to the ethnic problem of the 1990s (Snyder 2000). Following the death of Tito, who had been the primary restraint of ethnic and ideological tensions, a period of economic decline combined with uneven development among the republics made the country ripe for conflict (Saideman 2001, p. 105).

Historically, the roots of the modern conflict can be traced back to ethnic rivalries flamed by a competition among political leaders (Saideman 2001). In particular, modern ethnic tensions are commonly attributed to the actions of Slobodan Milosevic, who appealed to the minority Serb's sense of national identity as a means by which to defeat political challengers in the Communist Party and demanded that Kosovo and Vojvodina lose their autonomous status. Tension turned into open hostility between the ethnic groups when, in June 1991, Slovenia and Croatia declared their independence, thereby creating a permanent split in the Yugoslav republic (Brogan 1998). The response of the now Serb dominated Yugoslav army (and controlled by Milosevic) was a failed attempt to force the separatists to reconsider by invading Slovenia. Fighting almost immediately spread to Croatia, where federal forces were more successful and able to impose order and, ostensibly, 'protect' the Serb minority that resided there. Order, however, was quickly replaced by mass execution and ethnically motivated killings of Croats.

The reaction of the international community was, at this point, limited and avoided the use of force (Foyle 2005). The United Nations - in response to US pressure - immediately imposed an arms embargo on all of the former territories of Yugoslavia in hopes of preventing escalation, an action which ultimately served to protect the advantage of the better-armed Serbs (Brogan 1998, pp. 448 - 449). Soon after, the 
United Nations Protection Force (UNPROFOR) was established to implement a USsponsored ceasefire agreement (Foyle 2005). By March of 1992 ethnic conflict had expanded as Bosnian Serbs, who feared being dominated by Bosnian Muslims, armed themselves and fought to include their region in the newly formed partnership between Serbia and Montenegro, the Federal Republic of Yugoslavia (Kaufman 2001). Such a move, however, was equally threatening to Bosnian Muslims, who would lose their status as the largest ethnic group.

Fueled by recognition of an independent Bosnia from the European powers and the US, Muslims and Croats in the country stepped up their efforts, only to be overwhelmed by Serbian-backed militias. The conflict quickly turned from one for control to one of ethnic cleansing as Bosnian Serbs turned against their former neighbors (Saideman 2001). In an effort to remain neutral, the UN maintained a strict role as observers, although the Security Council did impose economic sanctions and an arms embargo against Serbia in 1992 and worked to ensure the supply of food and medicine for Bosnian Muslims (Foyle 2005). Official and public international attention increased in response to events such as the publication of images of a Serb attack on the marketplace in Sarajevo, Serb attacks on UN protected safe havens, and attacks on UN peacekeepers.

\section{Compelled to negotiate}

The extreme aggressiveness of the Serbs ultimately prompted a reaction from the West, which eventually led to a negotiated settlement. In response to the attack on the Sarajevo marketplace, the US, which had viewed the conflict as a regional problem that 
was ancillary to its strategic interests, responded by pressuring its North American Treaty Organization (NATO) allies to issue an ultimatum to the Serbs to force an end to the attacks on the Bosnian capitol or face air strikes from NATO forces (Foyle 2005). The move was successful in that Serb forces withdrew from Sarajevo, but it failed to deter the continued attack of the Serbs on their ethnic adversaries as well as UN peacekeepers. Soon thereafter, the US increased the level of its direct involvement by encouraging the Muslims and Croats to join forces against their mutual adversary, a move which produced a defensive pact but not one that gave the Muslims and Croats the necessary strength to defend themselves.

Within the US and the international community, support grew for some type of response. Public support for the direct involvement of US troops, however, was minimal. Clinton, who was motivated by campaign promises and public statements to pursue a resolution and was concerned by the effect that the lack of US action was having on its international reputation, engaged his advisors to develop a solution to the predicament (Foyle 2005). In July of 1995, the Serbs rejected a proposal by European Union representative Cyrus Vance that would have reduced their territorial holdings from nearly 70 to 49 percent of the country (Brogan 1998, pp. 449-450). Multilateral efforts by the US, Russia, Germany, Britain, and France to resolve the conflict offering to end all sanctions in place against Serbia in exchange for Serb recognition of boundaries of Bosnia and Croatia were rejected as well (Foyle 2005).

Tensions within the NATO alliance grew as European powers pushed for the US to allow UNPROFOR to expand its use of force or to replace European troops with American forces. The American president, however, was reluctant to put troops on the 
ground out of a fear of public opposition and concerns levied by his advisors (particularly Joint Chiefs of Staff chairman Colin Powell) regarding the lack of clear objectives and open-ended time frame (Foyle 2005). After intense deliberations, the Clinton administration adopted an "endgame strategy" that ultimately became known as "lift and strike” as a means by which to compel the Bosnian Serbs to seek a negotiated settlement to the conflict (Foyle 2005, p. 19). Presented to European leaders by National Security Advisor Anthony Lake, "the policy offered carrots and sticks: the Bosnian Serbs would face extensive bombing if they refused to negotiate; the United States would unilaterally lift the arms embargo but would then disengage from the region if the Muslims refused to negotiate a settlement. In addition, Western economic sanctions would be lifted against Yugoslavia if it recognized the independence of Bosnia, Croatia, and Macedonia” whereas "regional economic assistance would follow an agreement (Foyle 2005, p. 19). Pressure on the adversaries increased when the US Senate approved a resolution ending the arms embargo against, a measure which was adopted in quick succession by the US House of Representatives.

International pressure on the combatants increased when Serb forces attacked the UN-designated "safe area" at Srebrenica, one of six that had been established two years earlier to provide refuge for Bosnian Muslims, in an attack that resulted in the death of 8,000 men and boys (Brogan 1998, pp 450-451). In response, NATO forces led by the US targeted a variety of Serbian military installations throughout Bosnia in a bombing campaign that lasted from the end of August through October 1995, which opened the way for a Muslim-Croat offensive. Having been able to gain access to armaments from abroad (particularly from Middle East Muslims) in spite of the arms embargo, the 
Muslim-Croat forces were effective in regaining territory and quickly recaptured 1300 square miles before the UN and NATO demanded a halt to the offensive (Brogan 1998, pp 450-451). Under intense pressure from the international community, the leaders of the three adversarial groups agreed to meet in Dayton, Ohio, to seek a negotiated settlement.

Under the watchful eyes of the representatives of the US, Britain, France, Germany, Russia, and a representative from the EU, the parties negotiated and itialed an agreement (which included eleven annexes in addition to the main agreement) on November 21 and signed the document into force in Paris on December 14, 1995 (Kaufman 2001). In doing so, the signatories adopted a complex agreement that that included territorial, power-sharing, and policy concessions; instituted a ceasefire; invited a NATO force to implement the terms of settlement; established a timetable for elections; committed the parties to the adoption of a new constitution for the newly created Republic of Bosnia and Herzegovina; established the boundaries of the Federation of Bosnia and Herzegovina and the Serb Republic of Bosnia (The Dayton Accords, 1995).

\section{Why territorial concessions?}

The territorial concessions contained within the Dayton Accords represent the outcome of what can (once again) best be described as a unique process. To begin with, the onset of ethnic rivalries was trigged by the actions and statements of political leaders jockeying for power, a condition attributed to the lack of a dominant ethnic majority in any of the decentralized regions within the former Yugoslavia (Kaufman 2001). Second, the onset of violence was triggered by appeals to ethnic divisions which ultimately 
brought about the dissolution of the state. Because of this, any resolution required an additional element - the development of a new state structure, which in this case involved two highly decentralized and ethnically homogenous political entities replacing the previous five (Saideman 2001). Third, the pre-existing high degree of ethnic followed by savage conflict and massive numbers of relocations (internally and externally) forced the parties to address the additional problem of relocation (Brogan 1998). Clearly each of these factors contributed to an environment in which a negotiated settlement was highly unlikely to be successful. In fact, the actions of the adversaries point directly to a goal of not only capitulation, but of genocidal elimination of its adversaries.

Why, then, did territorial concessions emerge as the solution? In contrast to the process by which territorial concession were developed in Sudan and the Philippines, where domestic pressures existed for both sides to seek a resolution by expanding their own bargaining space to include the demands of their adversaries. In this case the entire negotiated settlement can be directly attributed to external pressures plied by the US, the various European powers, Russia, NATO, and the UN. In fact, a strong argument can be made that the territorial concessions were a direct result of campaign promises made by US president Bill Clinton, who was under public pressure to follow through on his criticisms of US policy under George Bush (see, for example, Foyle 2005). Had the US not adopted its policy of "lift and strike," thereby pressuring the three adversaries to seek a negotiated settlement, and had the European powers and Russia not considered an intervention to be in their best interests, it is highly likely that the Bosnian civil war would have continued until at least one side had been eliminated. External political decisions, then, and not any of the covariates of state concessions addressed by 
bargaining theory or the existing literature brought about territorial concessions in the case of Bosnia.

\section{Conclusions: Factors that affect the likelihood of territorial concessions}

International relations theory consistently claims that territory is of utmost importance to states. The evidenced garnered from the negotiated settlement of civil wars corroborates this view. Only three civil wars resulted in increases in autonomy (a low-level territorial concession), while in no cases did the state give up its sovereignty. Given the small number of civil wars in which territorial concessions are granted, it is difficult (if not impossible) to generalize observations from the evidence. However, the three cases discussed above do point to some commonalities, as discussed below.

First, each of the cases above points to the importance of a stalemate as a necessary precursor to territorial concessions. The necessity of a stalemate is in keeping with both bargaining theory and Zartman’s condition that a "mutually hurting stalemate" is necessary for a negotiated settlement to occur. With regard to bargaining theory, the basic logic is that combatants will make concessions only when the utility of doing so exceeds that of not doing so. This implies that states will make large concessions only rarely and only out of necessity. Based on this logic, we can expect states to be willing to accept relatively high costs prior to giving up territory and to only make territorial concessions when it is absolutely necessary to do so. In the each of the three cases addressed above, the presence of a stalemate indicated the inability of the state to impose it will on its adversary. It also indicates the ability and willingness of the rebels to continue fighting. As a result, the states were faced with a choice: continue fighting 
(without success) or make a territorial concession. In order to avoid continued warfare, Sudan, the Philippines, and Bosnia were each forced to give up they cherish the most land.

The presence of a stalemate in each of these cases also supports Zartman's contention that negotiated settlements will occur only when neither side is able to achieve their goals militarily and both sides incur costs by failing to resolve their differences. Here Zartman focuses on the condition under which negotiates settlements are more or less likely to occur. This research adds to that by extending the logic to the terms of settlement. If combatants are willing to enter into a negotiated settlement only when the above two conditions hold, then by extension we should expect large concessions to occur only when the incurred costs are high. The above cases support such a contention.

Second, the evidence suggests that international actors and third parties can play an important role in the decision to grant enhanced territorial independence, but that their effect varies widely. The role played by third parties in these three cases does, of course, vary considerably. In Sudan and the Philippines, outside parties played a role that can best be described as supporting. In the case of Sudan, Ethiopian Emperor Selassie encouraged a settlement and personally pledged to enforce the agreement. In this sense, his role, while important to the resolution of hostilities was limited in that it was not coercive to either side. A similar role was played by Libya in the Philippine resolution. In contrast, though, the OIC played a coercive role by threatening to limited oil exports to the Philippines, a move which would have had direct economic effects and increased the costs of the war to the Philippine government. In other words, the OIC not only encouraged a settlement, but used its influence to bring it about by altering the 
preferences of the Philippine government. Finally, in the Bosnia case, outside actors (the US, the UN, and European powers), not only encouraged territorial concessions, but compelled Bosnia to make them. This case represents the most extreme degree of influence in these three cases. However, had the outsiders not acted, it is likely that, rather than giving up territory, the combatants would have continued fighting until one side or the other was eliminated. So in the Bosnian cases, the role of outside actors can easily be cited as a cause of, and not just a contributing factor to, territorial concessions.

The third common factor in each of these cases goes directly to he individual level of analysis. In each of these cases, the likelihood of a negotiated settlement and the willingness to extend territorial compromises is strongly influenced by leadership. This indicates that the human decision-making process (which bargaining theory fails to consider) is at least as important as systemic conditions (which bargaining theory emphasizes). This indicates that the preferences of states cannot be viewed as simply the product of raw mathematical calculations because in each of these three cases who was in charge was an important contributing factor to both the decision to settle and the decision to offer territory as a part of that settlement.

In sum, the small number of cases makes it difficult to make generalizations about the factors that influence a state's decision to offer territorial concessions to end civil war. However, some common factors emerge - the presence of a stalemate, the involvement of external third parties, and a leadership willing to give up territory. Based on these observations, it seems reasonable to view these conditions as precursors to territorial compromise, albeit cautiously. 


\section{Chapter 8: Summary and conclusion}

The purpose of this research is to identify the factors that influence the concessions made by states to the rebels to end a civil war. As such, its emphasizes the resolution of the underlying political disputes that produce militarized conflict within a state. By doing so, this research intends to contribute to our understanding of civil wars as a political event by highlighting the link between militarized conflict and the resolution of underlying political disagreements. It therefore addresses a topic that is of interest to a wide variety of scholarly communities, including civil war specialists, international relations theorists, peace study scholars, area specialists, and policymakers. Despite the substantial amounts of research dedicated to understanding civil wars as both a political and military event, it also addresses a facet of civil wars that, to date, has received little (if any) scholarly attention.

Understanding the determinants of the concessions states make to end a civil war makes several important contributions to the field of political science. First, this research expands our existing understanding of the conduct and resolution of civil wars. It does so 
by shifting the emphasis of the study of civil wars from when a negotiated a negotiated settlement is likely to occur to how the terms of settlement on which a settlement is based are determined. Second, it provides insight into the process by which battlefield successes or failures are translated into political accommodations between competing adversaries. As such, it goes directly to the heart of the matter of the resolution of civil wars by emphasizing the resolution of the underlying political disagreement. Finally, it highlights the extent to which states will make political concessions to appease their rebel adversaries. If we are to truly understand civil wars as a political phenomenon, each of these represent important contribution.

In what follows, the central arguments and assumptions that form the basis of this research are addressed. This is followed by a recapping of the results of the empirical analysis. Finally, the basic conclusions of this research are summarized.

\section{The argument revisited}

In order to develop an explanation of the factors that influence the concessions made by states involved in civil war, this research builds on the logic of bargaining theory, but integrates explanations present in the existing literature and from variables that were inductively derived from an examination of the dataset. Bargaining theory, which draws from and extends rationalist theories of conflict, contends that conflict occurs when two actors involved in a dispute are unable to successfully identify a bargaining space, or a set of possible resolutions that are acceptable to both parties. In this sense, bargaining theory views conflict as a breakdown or failure because both sides would be better off if they were able to resolve the conflict short of fighting. Bargaining 
theory contends that this breakdown occurs when at least one of three conditions are present: private information, an incentive to cheat, and indivisible stakes. This research applies bargaining theory in reverse by arguing that if conflict is likely to occur when these conditions are present, then combatants should be able to identify a bargaining space when the conditions are addressed. If this is so, then peace should result when the preconditions for war are addressed and the resulting terms of settlement (measured as state concessions) should reflect the ability of adversaries to gain concessions from each other.

In addition, this research integrates two additional sources of explanations. First, it draws from existing literature to identify alternative explanations for state concessions. This produces two factors that may influence concessions made by state: the level of democracy of the state and the presence of a stalemate. The level of democracy, the democratic peace literature agues, should positively affect the maximum concessions offered by the state because of cultural and structural pressures to resolve conflicts quickly and with a minimum of costs. Similarly the presence of a stalemate should make the state more willing to grant greater concessions because it represents the opportunity to end the fighting and gain some (but not all) of its goals. The second source of alternative explanations is the product of the process of induction. The data collected for this research indicate that both the timing of a negotiated settlement (whether during or after the Cold War) make negotiated settlements more likely and that the location of the settlement (whether inside or outside of Africa) also affects the relationship.

As discussed in more detail below, this analysis provides some support for the use of bargaining theory as an explanation of the factors that influence state concessions. 
However, it also suggests that a clearer and more accurate picture of the complex relationship can be gained by integrating the explanations drawn from existing literature and the inductive process. The results are summarized and discussed in what follows.

\section{Recapping the results}

The empirical analysis of the use of bargaining theory and the alternative explanations was conducted in two stages on a dataset specifically constructed for this purpose. The dataset described every civil war that met the Correlates of War definition of a civil war and started between 1945 and 1992. The first stage of the analysis attempted to determine the factors that influence the type of the maximum concession made by the state by using Tobit analysis on all incidences of civil war within the dataset. For this purpose, the maximum concession in each of the written agreements was coded along an ordinal scale that distinguished between policy, power-sharing, and territorial concessions. The ordering of categories was based on the assumption that policy concessions, which involve one-time concessions, are least valuable to the state and the rebels. Power-sharing concessions, which increase the access of the rebels to the political decision-making system, were considered to be more important than policy concessions because they in effect grant the rebels long-term and wide-ranging influence in the affairs

of the state. Territorial concessions concern what states considered to be most valuable (territory) and therefore most generous.

For the second stage of the analysis, each maximum concession was categorized according to whether it represented a high or low level concession for that type of concession (policy, power-sharing, or territorial). This stage focused the analysis on only 
those civil wars that ended in a negotiated settlement and only those that produced each type of maximum concession. Probit analysis was used to asses the presence of a relationship between the dependent variable and the independent variables in each case where policy and power-sharing concessions appeared as the maximum concession, while the relatively small number of territorial concession (three) required the use of qualitative methods.

To empirically test the propositions of bargaining theory and the alternative explanations, a set of seven formal and two informal hypotheses were developed. Data on the independent variables was utilized from existing data sources (such as the Correlates of War dataset, Walter’s 2002 Civil War Resolution Dataset, and Hartzell and Hoddie’s 2003 data from Institutionalizing Peace). This effort produced a set of 91 civil wars, 27 of which ended in a negotiated settlement. The hypotheses and empirical results of the analysis are summarized below.

Bargaining theory contends that one of the preconditions for war is when private information regarding a potential combatant's abilities or resolve is present. This makes it difficult for an opponent's adversary to accurately determine what the real costs of conflict are going to be. Furthermore, bargaining theory contends that political actors are most likely to hide or disguise there true abilities or intentions when conflict is likely. While this may be so, it stands to reason that once conflict actually occurs, participants immediately begin to gain information about the true abilities or intentions of their adversary. As a result, while both sides are not able to accurately measure their expected utility for fighting versus not fighting prior to the onset of fighting, both become better able to do so once the fighting starts. In other words, once war begins information is 
necessarily passed between opponents. As each side gains new information about their opponent, each becomes better able to assess its expected utility and may therefore revise is preferences (or, in other words, adjust its bargaining space which increases the set of mutually acceptable resolutions). This leads to the general conjecture that the more successful a state is at fighting, the less generous it will be at the bargaining table. This research used to commonly used proxy measures to account for success: deaths sustained by the state and the duration of the conflict. These measures were justified on the grounds that the more successful a state was at fighting, the fewer deaths it would incur and the quicker it would end the war. This logic produced two hypotheses, both of which are reproduced below:

H1: As the number of deaths suffered by the state involved in civil war increases, the political concessions to the rebels will be more extensive.

H2: The longer a civil war lasts, the greater the political concessions offered by the state to the rebels will be.

The results of the quantitative analysis indicate that neither the number of deaths a state suffers nor the duration of the conflict exhibit a statistically significant relationship to the maximum concession offered, despite the fact that some analysts (e.g. Hartzell and Hoddie 2003, Mason and Fetts 1996) have indicated that these variables are related to the decision to negotiate. Several explanations exist as to why this may be so. First, it could be that the decision-makers of states do not integrate the number of deaths suffered or the duration of the conflict into their decision-making calculus of what type of concession to offer the rebels. In other words, the explanation proposed by bargaining theory may simply be erroneous in that no relationship exists. This could indicate the presence of emotional, rather than the rational decision-making process proposed by bargaining 
theorists. If this is so, then we cannot (or at least should not) expect statistical analysis to indicate the presence of a relationship that does not in fact exist. Second, decisionmakers may include these measures of success as a part of the process, but not in the way prescribed by bargaining theory. For instances, it may be that the leaders of states involved in civil wars are sensitive to the number of deaths suffered and the duration of the conflict, but view them as sunk costs. In an effort to recoup these costs, leaders may be less likely to negotiate in the first place because by negotiating, they would be walking away from costs they have already incurred.

However, when looking at the effects of these measures of success on the level of concession, the view is somewhat different. In the case of power-sharing concessions, the number of deaths suffered by the state and the duration of the conflict indicated opposite influences on the level power-sharing concessions, with deaths being positive and duration being negative. This indicates that states are more willing to grant the rebels guaranteed access to the political system when the conflict is long or when the rebels are able to impose a high number of deaths on the state. This finding supports the contention of bargaining theory. When examining the probit results for the level of policy concession, however, it appears that neither of these variables demonstrates a relationship. The most straightforward conclusion, then, is that the measures of success have only a specific effect - on the decision of what types of power-sharing concessions to extend. When looking at the qualitative analysis of territorial concessions, it appears that deaths and duration condition the decision to grant territorial concessions. This is so because in two of the three conflicts addressed (Sudan and the Philippines), the duration was extremely long and because in all three of the conflicts (Sudan, the Philippines, and 
Bosnia) the number of deaths incurred by the state was high. Thus, while there is some evidence to suggest that the success in war influences the decision of whether or not to negotiate, this analysis indicates that success does not directly condition the maximum concession offered by the state, although it may influence the degree of power-sharing that is extended and possibly the decision to extend territorial concessions.

The second contention put forth by bargaining theory is that conflict is more likely to occur when an incentive to cheat is present. If this is so, then removing the incentive should lead to peace. The presence of a security guarantee (or what Walter 2002 calls a "credible commitment”) should enable adversaries to be more successful at the bargaining table. To account for the presence of a security guarantee, this research borrowed from Walter (2002), who codes a "credible commitment" to be present when an outside actor promises to enforce an agreement reached by combatants at the bargaining table. This led to the following hypothesis:

H3: Political concessions made by the state to the rebels will be greater when a third-party guarantee is present.

The results of the Tobit analysis of the effect of a "credible commitment" on the maximum type of concession the state is willing to offer supports the contention of bargaining theory. It appears that reducing the incentive to cheat, states are willing to grant greater concessions to their adversaries. Such a finding is also in line with Walter's (2002) contention that negotiations are more likely to produce a settlement and the settlements are more likely to be implemented when a "credible commitment" is present.

Two prominent explanations for this relationship exist. First, it may be that states are more willing to grant greater concessions when a "credible commitment" is in place because it increases the likelihood that the state will get what it bargained for - peace for 
political concessions. In this way, "credible commitments" may act more like insurance that encourages states to extend greater concessions. A second possibility is that “credible commitments" may resolve what is commonly referred to as a security dilemma (Snyder and Jervis, 1999). As Licklider (1993) points out, in the aftermath of a civil war, the former adversaries must live either in the same state or as neighbors. This creates at least the possibility of renewed conflict. However, when a "credible commitment" is in place and implementation is insured, then both the state and the rebels may feel more protected, thereby resolving the security dilemma.

When considering the level of concession granted within each type of concession, the results are somewhat less clear. In cases in which the state grants power-sharing concessions, this analysis indicates that the state is more likely to grant a high rather than a low level concession. This means that when a "credible commitment" is present, states are more willing to guarantee the rebels a place in the decision-making process of the state. Again, this may point to the insurance effect or the resolution of a security dilemma, both of which are discussed above. In the case of policy concessions, however, no relationship was found. Of course, as discussed in Chapter 6, this may be because no relationship exists or the failure of the model to detect a relationship that does in fact exist.

When considering territorial concessions, the lack of variation between high and low territorial concessions in the presence of security guarantees indicates that states are not more likely to relinquish full sovereignty over territory, even in the presence of such a promise. In the three cases addressed by this research, Walter (2002) codes only two (Bosnia and Sudan) as having a credible commitment, while such a promise is not in 
place in the case of the Philippines. However, the promise of Ethiopia to ensure the implementation of the Addis Ababa agreement was one described by Walter (2002, p. 68) as being "weak". Viewed from this perspective, an argument could be put forth that states would be more likely to grant full territorial independence when a strong "credible commitment” is in place. Thus, the findings of this analysis support that of Hartzell and Hoddie (2003), Walter (2002), and Mason and Fetts (1996), who contend that guaranteed enforcement of treaty provisions increase the likelihood of a negotiated settlement.

The third and final contention put forth by bargaining theory is that conflict is more likely when the stakes at issue are not easily shared. The basic logic is that not all issues are equally easy to subdivide and share which makes it difficult for the combatants to identify a bargaining space. However, it should be noted that the presence of indivisible stakes is considered by some (Lake 2003, Fearon 1995) to be the weakest proposition made by bargaining theory because such problems can be overcome by linking multiple issues together or side payments. This research used ethnic conflicts and territorial disputes to signify the presence of indivisible issues. While these two measures represent only a partial list of indivisible issues, and are imperfect proxies at that, they do adequately address the issues at hand. Ethnic conflicts, in which combatants are organized along the lines of a shared identity, are between two adversaries who are distinguished by immutable cultural and physical characteristics. As a result, these types of conflicts may be more susceptible to problems of issue divisibility. In the case of territory, it represents a reasonable proxy for issue indivisibility because land is something that is not easily shared. This logic produced the following two hypotheses:

H4: Territorial disputes will result in less extensive concessions being made by the state to the rebels. 
H5: Conflicts in which combatants are organized along ethnic lines will result in less extensive being made by the state to the rebels.

The Tobit analysis of the effect of indivisibility indicates that there is no effect on the maximum concession offered by a state. Neither ethnicity nor territory appears to have a statistically significant effect on maximum concessions. Thus, this component of bargaining theory (as developed and tested here) does not hold up to empirical scrutiny. This may indicate the complete absence of a causal relationship. On the other hand, it may substantiate the claims that issue invisibility can be overcome through linkages and side payments as proposed by Fearon (1995) and Lake (2003). This explanation would imply that combatants are more concerned with the overall terms of settlement and not just one or two issues. Determining the presence or absence of such decision-making, however, is beyond the scope of this study.

When it comes to levels of policy and power-sharing concessions, there again appears to be no relationship between indivisibility and levels of concessions, as neither probit model indicated the presence of a statistically significant relationship. In the case of territorial concessions, however, an argument can be made that states were unwilling to completely grant territorial independence to the rebels but instead extended only partial autonomy. This outcome, as previously discussed, indicates strong reluctance on the part of the state to subdivide and share its territory.

This analysis also includes explanations generated from existing within the literature and an examination of variables inductively generated from the data in addition to the variables proposed by bargaining theory. The first of these is the presence or absence of a stalemate as a precursor to negotiations. Within the literature, it has been 
proposed by Zartman (2001) that negotiated settlements are much more likely to occur when the adversaries find themselves in a position such that neither is able to gain the upper hand on the battlefield and both incur costs. One way of removing themselves from this position is by entering into a negotiated settlement in which both sides are able to partially achieve their goals driving the fighting as well as peace. If this is true, then it follows that states involved in civil war may be more willing to grant greater concessions to their adversaries in order to bring about a resolution. To account for the presence of a “mutually hurting stalemate” this researched borrows Walter’s (2002) measure for stalemate. The proposed relationship between state concessions and the presence of a stalemate was tested by the following hypothesis:

H6: When a civil war produces a "mutually hurting stalemate", the concessions made by the state to the rebel will be more extensive than when such a stalemate does not occur

The results of the Tobit analysis indicate that the presence of a "mutually hurting stalemate” does in fact demonstrate a positive influence on the maximum concessions offered by states. In other words, when states fighting a civil war choose to resolve a stalemate by entering into a negotiated settlement is appears that they are more likely to offer more extensive concessions than otherwise. This lends support to the contention developed by Zartman (2001) and adopted by Walter (2002) and this research that states are willing to make a trade-off between fully achieving their goals and resolving a costly conflict when forced to do so, presumably because they can not achieve their goals through combat.

However, when looking at levels of power-sharing and policy concessions, it does not appear that the presence of a "mutually hurting stalemate" influences the concessions 
extended by the state. This is so because neither probit model indicates the presence of a statistically significant relationship between stalemate and levels of power-sharing or policy concessions. This indicates that while stalemates can influence the type of concession a state makes, it does not influence how much of a particular concession type is extended. As discussed above, it does appear that the presence of a stalemate does affect the extension of territorial concessions, but the lack of variation in the levels of territorial concessions prevents an analysis of a relationship. Thus, the results of this analysis indicates that the presence of a stalemate is positively associated with the state extending greater types of concession, but that it does not influence the level within each type.

The second proposition drawn from the existing literature addresses the level of democracy of the state. Based on the logic of the democratic peace, it is argued that democracies may be more willing to extend concessions to resolve an ongoing conflict. Three explanations of why democratic states may be more willing to offer concessions exist. First, decisions made by leaders in democracies are conditioned by the degree of popular support they receive. Since citizens more directly bear the costs of civil war, it seems logical to expect that they will apply pressure to their leaders to end the war with the fewest costs as possible, which may be through a negotiated settlement. Second, democracies are more credible because they are publicly bound by their proclamations, a contention which integrates the decision-making of the rebels and is therefore beyond the scope of this analysis. Third, leaders of democracies are more culturally disposed to negotiation and compromise. As a result, they may be more willing to work to resolve conflicts at the bargaining table. This logic produces the following hypothesis: 
H7: The more democratic the state is, the more the concessions granted to the rebels will be.

The results of the Tobit analysis indicates that the level of democracy of the state (as measured by its Polity IV score) does not directly influence the choice between types of concessions. In other words, the findings of this research do not indicate that a relationship exists between the level of democracy of the state and the maximum concession it offers to the rebels. Perhaps this is so because the leaders of the state do not identify the rebels as sharing the same predisposition towards the peaceful resolution of conflicts as they do. Another possible explanation is that the citizens of the state are willing to support the leadership in its decision to fight a civil war to an end on the battlefield.

Similarly, the level of democracy does not appear to directly affect the decision to grant higher levels of concessions within each policy type. The probit analysis of powersharing concessions does not support the contention that democracies will grant higher levels of concessions, as evidenced by the lack of a statistically significant relationship. In addition, the level of democracy is not addressed by any of the analyses of territorial concessions as a causal factor. It therefore seems reasonable to conclude that the level of democracy does not directly influence the concessions made by states.

The final two factors addressed by this research that may influence the concessions granted by states were derived inductively from the data. This produced two possible factors: the timing and location of the conflict. The data indicate that that prevalence of civil wars ending in negotiated settlements increased after the end of the Cold War. This raises the question of whether or not the timing of a negotiated settlement affected the concessions extended by states as well, which leads to the 
informal hypothesis that state concessions are affected by the timing of the negotiated settlement.

The empirical analysis of the data indicates that the maximum concessions extended by states increase in those cases that were resolved following the Cold War, as indicated by the presence of the positive and statistically significant relationship. While this observation may possibly be a spurious correlation generated from the data, there are theoretical reasons to expect the presence of a causal relationship. One possible explanation is that the changes in the international political system brought about changes in the way civil wars are fought. Specifically, when the competition between the US and the Soviet Union ended, it may be that many of the resources available to groups sharing a similar ideology to one of the two superpowers dried up. As the case of Angola indicates, the superpower rivalry extended to civil wars. In this case, the US provided political, military, and financial support to both the National Front for the Liberation of Angola (FNLA) and the National Union for the Total Independence of Angola (UNITA), while the Soviet Union provided similar support to the People's Movement for the Liberation of Angola (MPLA). In part, US involvement was driven by a desire to counter the possibility of Soviet influence in the region (Brogan 1998). However, in the post-Cold War world, such a rivalry obviously does not exist. As a result of the Soviet Union's demise, combatants can no longer turn there for support. And because the US is no longer involved in a Cold War rivalry, it has less motivation to step in to support combatants. The end of the Cold War, then, may have brought about a decline in the amount of external support available to one side or another. If this is so, bargaining theory (as developed and applied here) contends that combatants would respond by being 
more open to the possibility of extending concessions. An in-depth discussion of this matter, however, is beyond the scope of this project and will be left for a later date. Interestingly enough, the relationship between the timing of a negotiated settlement and maximum concessions does not hold when looking within specific types of concessions. The results of this analysis do not indicate the presence of a relationship between the levels of either power-sharing or policy concessions. Thus, the general conclusion of this research is that the timing of a negotiated settlement only generally affects the concessions extended by states, but that the effect does not influence the level of concessions offered.

The final relationship to be discussed is that between the location of the civil war and the concessions offered by states. The data indicate that Sub-Saharan Africa produces the greatest number of negotiated settlement. This raises the possibility that differences in the patterns of state concessions in Africa could possibly influence the overall outcomes of this research. Therefore, analyses were conducted to determine whether geography influenced state concessions.

The results of the Tobit analysis do not indicate a direct relationship between location and maximum concessions. This finding is indicated by the lack of a statistically significant relationship between the variable Africa and maximum concession. Furthermore, the probit analysis indicates that the levels of power-sharing and policy concessions in Africa do not vary from other similar state concessions in a statistically significant way. Thus, this research indicates that the location of a negotiated settlement does not directly affect state concessions. 


\section{Conclusion}

The basic conclusion of this research is that bargaining theory by itself does not adequately identify the factors that influence state concessions. It does, however, provide some explanatory power and can be enhanced by the inclusion of existing literature and the results of the inductive analysis. This is most evident in the strong and positive relationship between the presence of a “credible commitment” and state concessions, a relationship that holds in both maximum and high level power-sharing concessions. This indicates that states are reluctant to extend generous concessions, especially high level power-sharing ones, unless the incentive to cheat is addressed. Bargaining theory is also supported by the finding that high level power-sharing concessions are more likely to occur when the number of deaths suffered by the state is high or when the conflict is long. This indicates the reluctance of the state to concede guarantee access to the political system unless the rebels are able to maintain a long or bloody war.

Although the explanatory power of bargaining theory is limited, the existing literature addressing the presence of a "mutually hurting stalemate.” This analysis indicates that states are willing to extend greater concessions when such a condition emerges on the battlefield. This implies that states are willing to make greater concessions when it appears that doing so may be the only way to resolve a war. In addition, it appears that the timing of the resolution may have a significant impact on state concessions. This, however, is a matter that deserves further investigation.

In sum, this research adds to our existing knowledge base by indicating that, in addition to being reluctant to enter into negotiated settlements in the first place, states are reluctant to extend generous concessions when doing so can be avoided. In order for a 
rebel group to gain significant concessions from the state, it must be able and willing to fight a long and protracted war against the state and achieve rough military parity on the battlefield. In addition, several factors that influence the extent of state concessions are in large part out of control of either party. These include the presence of a security guarantee and the timing of the resolution. 


\section{References}

Amemiya, Takeshi. 1995. Advanced Econometrics. Cambridge, MA: Harvard University Press.

Bates, Robert H. 2001. Prosperity and Violence: The Political Economy of Development. New York: Norton.

Betts, Richard. 1994. “The Delusion of Impartial Interventions.” Foreign Affairs 73(6):20-33.

Bobrow, Davis B. and Mark A. Boyer. 1997. "Maintaining System Stability: Contributions To International Peacekeeping Operations,” Journal of Conflict Resolution, 41(6):723-748.

Brass, Paul. 1985. Ethnic Groups and the State. London: Croom-Helm Brown.

Breen, Richard. 1996. Regression Models; Censored, Sample Selected, or Truncated Data. Thousand Oaks: Sage.

Brogan, Patrick. 1998. World Conflicts: A Comprehensive Guide to World Strife Since 1945. Lanham, MD: Scarecrow Press.

Brown, Michael E. 1996. The International Dimensions of Internal Conflict. Cambridge, MA: The MIT Press.

. “The Causes of Internal Conflict: An Overview.” In Brown, Michael E., Owen R. Cote, Jr., Sean M. Lynn-Jones, and Steven F. Miller, ed. Nationalism and Ethnic Conflict, revised edition. Cambridge: The MIT Press.

Brown, Michael E., Owen R. Cote, Jr., Sean M. Lynn-Jones, and Steven F. Miller, ed. 2001. Nationalism and Ethnic Conflict, revised edition. Cambridge: The MIT Press.

Brito, D. L. and M. D. Intrilligator. 1990. “A Predator-Prey Model of Guerilla Warfare.” International Interaction 15(3-4):235-244.

Bueno de Mesquita, Bruce and David Lalman. 1992. The War Trap. New Haven: Yale University Press.

Cagoco-Guiam, Rufa. "Negotiations and Detours: The Rocky Road to Peace in Mindanao.” In Stankovitch, Mara. 1999, 2003. Compromising on Autonomy: Mindanao in Transition. London: Conciliation Resources. 
Carter, Ralph G. 2005. Contemporary Cases in U. S. Foreign Policy, $2^{\text {nd }}$ ed. Washington, D.C.: CQ Press.

von Clausewitz, Carl. 1832/1976. On War. Edited and Translated Michael Howard and Peter Paret. Princeton: Princeton University Press.

Collier, Paul and Anke Hoeffler. 2000. "Greed and Grievance in Civil War.” World Bank working paper no. 2355, May, Washington, DC.

Cousens, Elizabeth M. "From Missed Opportunities to Overcompensation: Implementing the Dayton Agreement on Bosnia”. In Stedman, Stephen John, Donald Rothchild, and Elizabeth M. Cousens, eds. Ending Civil Wars: The Implementation of peace Agreements. Boulder, CO: Lynne-Riener Publishers.

Daalder, Ivo. "Fear and Loathing in the Former Yugoslavia.” In Brown, Michael E., ed. 1996. The International Dimensions of Internal Conflict. Cambridge, MA: The MIT Press.

Deng, Francis M. “Negotiating a Hidden Agenda: Sudan’s Conflict of Identities.” In Zartman, I. William, ed. 1995. Elusive Peace: Negotiating an End to Civil War. Washington, DC: Brookings Institution.

DeRouen, Karl R. Jr. and Sobek, David. 2004. “The Dynamics of Civil War Duration and Outcome.” Journal of Peace Research 41(3):303-320.

Doyle, Michael W. and Nicholas Sambanis. 2000. "International Peacebuilding: A Theoretical and Quantitative Analysis. American Political Science Review. 94(4):779-802.

Eckstein, Harry, ed. 1964. Internal War: Problems and Approaches. New York: Free Press of Glencoe.

Elbadawi, Ibrahim and Nicholas Sambanis. "External Interventions and the Duration of Civil Wars.” World Bank Policy Research Paper, July 25, 2000.

Europa World Year Book, various editions 1990-.

Fearon, James. 1995. "Rationalist Explanations for War.” International Organization 49(3): 379-414.

. "Why Do Some Civil Wars Last So Much Longer Than Others?” Paper prepared for the World Bank-University of California at Irvine Conference on Civil War Duration and Post-conflict Peace Building, May 18-20, Irvine, California. 
Fearon, James and David Laitin. 2003. "Ethnicity, Insurgency and Civil War.” American Political Science Review 90(4):715-735.

Foyle, Douglas C. "Public Opinion and Bosnia: Anticipating Disaster.” In Carter, Ralph G. 2005. Contemporary Cases in U. S. Foreign Policy, $2^{\text {nd }}$ ed. Washington, D.C.: CQ Press.

Gleditsch, Nils Petter, Havard Strand, Mikael Erikson, Margareta Solenberg and Peter Waalenstein. 2001. “Armed Conflict 1945-99: A New Dataset.“ Paper prepared for presentation at the Conference of Identifying Wars, Uppsala, Sweden, June 89.

Goemans, H. E. 2000. War and Punishment: The Causes of War termination and the First World War. Princeton: Princeton University Press.

Gujarati, Damodar. 1995. Basic Econometrics, $3^{\text {rd }}$ edition. New York: McGraw-Hill.

Green, William H. 1997. Econometric Analysis. New York: Macmillan.

Gurr, Ted. 1970. Why Men Rebel. Princeton, NJ: Princeton University Press.

. 1993. Minorities at Risk: A Global View of Ethnopolitical Conflicts. Washington, DC: United States Institute of Peace Press.

. 2000. People versus States. Washington, DC: United States Institute of Peace Press.

Hegre, Havard, Tanja Ellingsen, Scott Gates, and Nils Petter Gleditsch. 2001. “Toward a Democratic Civil Peace? Democracy, Political Change, and Civil War, 19161992.” American Political Science Review 95(1):33-48.

Hartzell, Caroline and Matthew Hoddie. "Institutionalizing Peace: Power Sharing and Post-Civil War Conflict Management.” American Journal of Political Science 47(2):318-332.

Hoddie, Matthew and Caroline Hartzell. 2003. "Civil War Settlements and the Implementation of Military Power-Sharing Arrangements.” Journal of Peace Research 40(3): 303-320.

Holl, Jane E. “When War Doesn’t Work: Understanding the Relationship between the Battlefield and the Negotiating Table.” In Roy Licklider, ed. Stopping the Killing: How Civil Wars End. New York: New York University Press.

Horowitz, Donald. 1985. Ethnic Groups in Conflict. Berkley: University of California Press. 
Ikle, Fred. 1971. Every War Must End. New York: Columbia University Press.

Kaufman, Chaim. "Possible and Impossible Solutions to Ethnic Civil Wars." International Security. 20(4): 136-175.

Kaufman, Stewart J. 2001. Modern Hatreds: The Symbolic Politics of Ethnic War. Ithaca: Cornell University Press.

Keesing's Contemporary Archive, various years 1945-. 
King, Gary and Langche Zeng. 2001. "Improving Forecasts of State Failure.” World Politics. 53(4): 623-658.

Lake, David A. 2003. "The New Sovereignty in International Relations.” International Studies Review. 5(3):303-323.

Licklider, Roy, ed. 1993. Stopping the Killing: How Civil Wars End. New York: New York University Press. . 1995. "The Consequences of Negotiated Settlement in Civil Wars, 1945-1993." American Political Science Review 89(3): 681-689.

Lijphart, Arend. 1997. Democracy in Plural Societies: A Comparative Exploration. New Haven: Yale University Press.

Long, J. Scott. 1997. Regression Models for Categorical and Limited Dependent Variables Thousand Oaks: Sage.

Long, J. Scott and Jeremy Freese. 1996. Regression Models for Categorical Outcomes Using Stata. Thousand Oaks: Sage.

Maddala, M. S. 1983. Limited-Dependent and Qualitative Variables in Econometrics. Cambridge: Cambridge University Press.

Mansfield, Edward D. and Jack Snyder. 1995. "Democratization and the Danger of War.” International Security 20(1):5-38.

Mason, T. David and Patrick J. Fett. 1999. "How Civil Wars End: A Rational Choice Approach.” Journal of Conflict Resolution 40(4): 546-568.

Mason, T. David, Joseph Weingarten and Patrick Fett. 1999. "Win, Lose or Draw: Predicting the Outcome of Civil Wars. Political Research Quarterly: 52(2):239268.

de Mesquita, Bruce and David Lalman. "Reason and War." American Political Science Review 80(1):113-129.

Minorities at Risk Project. n.d. "Minorities at Risk Data." Online at: http://cidcm.umd.edu. (various countries).

Modelski, George. 1964. "International Settlement of Internal War.” In International Aspects of Civil Strife, ed. James Roseneau. Princeton: Princeton University Press. 
Morrow, James D. 1989. “Capabilities, Uncertainty, and Resolve: A Limited Information Model of Crisis Bargaining.” American Journal of Political Science 33(November): 941-972.

Muslim, Macapado A. "Sustaining the Constituency for Moro Autonomy” In Stankovitch, Mara. 1999, 2003. Compromising on Autonomy: Mindanao in Transition. London: Conciliation Resources.

Muslim, Macapado A. and Rufa Cagoco-Guiam. "Mindanao: Land of Promise” In Stankovitch, Mara. 1999, 2003. Compromising on Autonomy: Mindanao in Transition. London: Conciliation Resources.

Pillar, Paul R. 1983. Negotiating Peace: War Termination as a Bargaining Process. Princeton: Princeton University Press.

Regan, Patrick M. 2002. Civil Wars and Foreign Powers: Outside Intervention in Intrastate Conflict. Ann Arbor, Michigan: The University of Michigan University Press.

. 1996. "Conditions of Successful Third-Party Intervention in Intra-State Conflicts.” Journal of Conflict Resolution 40(1): 336-359.

Roseneau, James, ed. 1964. International Aspects of Civil Strife. Princeton, NJ: Princeton University Press.

Rothchild, Donald. 1997. Managing Ethnic Conflict in Africa: Pressures and Incentives for Cooperation. Washington, D.C.: Brookings.

Rothchild, Donald and Caroline Hartzell. "The Peace Process in the Sudan, 19711972.” In Licklider, Roy, ed. 1993. Stopping the Killing: How Civil Wars End. New York: New York University Press.

Rothchild, Donald and Caroline Hartzell. "Interstate and Intrastate Negotiations in Angola.” In Zartman, I. William, ed. 1995. Elusive Peace: Negotiating an End to Civil War. Washington, DC: Brookings Institution.

Rule, James B. 1988. Theories of Civil Violence. Berkley: University of California Press.

Russet, Bruce. 1993. Grasping the Democratic Peace. Princeton: Princeton University Press.

Saideman, Stephen M. 2001. The Ties that Divide: Ethnic Politics, Foreign Policy, and International Conflict. New York: Columbia University Press. 
Sambanis, Nicholas. 2001a. "A Note on the Death Threshold in Coding Civil War Events.” Conflict Processes Newsletter, June.

. 2001b. "Do Ethnic and Non-Ethnic Civil Wars Have the Same Causes? A Theoretical and Empirical Inquiry (Part 1).” Journal of Conflict Resolution 45(3)259-282.

Santos, Soliman M. Jr. "Islamic diplomacy: consultation and consensus.” In Stankovitch, Mara. 1999, 2003. Compromising on Autonomy: Mindanao in Transition. London: Conciliation Resources.

Sarkees, Meredith Reid and J. David Singer. "The Correlates of War Datasets: The Totality of War." Paper prepared for the $42^{\text {nd }}$ Annual Convention of the International Studies Association, Chicago, IL, February 20-24, 2001.

Singer, J. David and Melvin Small. 1972. The Wages of War 1816-1965: A Statistical Handbook. New York: John Wiley and Sons.

Small, Melvin and J. David Singer. 1982. Resort to Arms: International and Civil Wars, 1816-1980. Beverly Hills, CA: Sage Publications.

Snyder, Jack. 2000. From Voting to Violence: Democratization and Nationalist Conflict. New York: WW Norton and Company.

. "Civil War and the Security Dilemma.” In Walter, Barbara and Jack Snyder, eds. 1999. Civil Wars, Insecurity, and Intervention. New York: Columbia University Press.

Snyder, Jack and Robert Jervis. “Civil War and the Security Dilemma.” In Walter, Barbara and Jack Snyder, eds. 1999. Civil Wars, Insecurity, and Intervention. New York: Columbia University Press.

Stankovitch, Mara. 1999, 2003. Compromising on Autonomy: Mindanao in Transition. London: Conciliation Resources.

StataCorp. 2001. Statistical Software: Release 7.0. College Station, TX: Stata Corporation.

Stedman, Stephen John. 1991. Peacemaking in Civil War: International Mediation in Zimbabwe, 1974-1981. Boulder, CO: Lynne Rienner.

. 1996. "Conflict and Conciliation in Sub-Saharan Africa." In Michael E. Brown, ed. The International Dimensions of Internal Conflict. Cambridge, MA: The MIT Press. 
. “Negotiation and Mediation in Internal Conflict.” In Brown, Michael E., ed. 1996. The International Dimensions of Internal Conflict. Cambridge, MA: The MIT Press.

. "Spoiler Problems in the Peace Process.” In Brown, Michael E., Owen R. Cote, Jr., Sean M. Lynn-Jones, and Steven F. Miller, ed. Nationalism and Ethnic Conflict, revised edition. Cambridge: The MIT Press.

Stedman, Stephen John, Donald Rothchild, and Elizabeth M. Cousens, eds. Ending Civil Wars: The Implementation of peace Agreements. Boulder, CO: Lynne-Riener Publishers.

Tilly, Charles. 1978. From Mobilization to Revolution. New York: McGraw Hill.

Touval, Saadia and I. William Zartman, eds. 1985. International Mediation in Theory and Practice. Boulder, CO: Westview Press.

Uppsala University. n.d. “Uppsala Conflict Database” online at: http:/www.pcr.uu.se. (various countries).

Van Evera, Stephen. “Hypotheses on Nationalism and War.” In Brown, Michael E., Owen R. Cote, Jr., Sean M. Lynn-Jones, and Steven F. Miller, ed. Nationalism and Ethnic Conflict, revised edition. Cambridge: The MIT Press.

Walter, Barbara. 1997. “The Critical Barrier to Civil War Settlement.” International Organization 51(3): 336-364.

. 2002. Committing to Peace: The Successful Settlement to Civil War. Princeton, NJ: Princeton University Press.

Walter, Barbara and Jack Snyder, eds. 1999. Civil Wars, Insecurity, and Intervention. New York: Columbia University Press.

Wagner, R. Harrison. 1994. "Peace War and the Balance of Power.” The American Political Science Review 88(3):593-607. . 2000. "Bargaining and War.” American Journal of Political Science 44(3):469484.

• “The Causes of Peace.” In Licklider, Roy, ed. 1993. Stopping the Killing: How Civil Wars End. New York: New York University Press.

Werner, Suzanne. 1998. "Negotiating the terms of settlement: War aims and bargaining leverage.” Journal of Conflict Resolution 42:321-343.

Wittman, Donald. 1979. “How a War Ends: A Rational Model Approach.” Journal of Conflict Resolution 23(4):743-763. 
Woodward, Susan L. "Bosnia and Herzegovina: How Not to End a Civil War.” In Walter, Barbara and Jack Snyder, eds. 1999. Civil Wars, Insecurity, and Intervention. New York: Columbia University Press.

Wright, Quincy. 1956. A Study of War. Chicago: Chicago University Press.

Zartman, I. William. 1989. Ripe for Resolution: Conflict and Intervention in Africa. Oxford: Oxford University Press.

. 1993. "The Unfinished Agenda: Negotiating Internal Conflicts.” In Roy Licklider, ed. Stopping the Killing: How Civil Wars End. New York: New York University Press.

, ed. 1995. Elusive Peace: Negotiating an End to Civil War. Washington, DC: Brookings Institution.

. 2001. "The Timing of Peace Initiatives: Hurting Stalemates and Ripe Moments.” The Global Review of Ethnopolitics. 1(1):8-18.

Zartman, I. William and J. Lewis Rasmussen, eds. 1997. Peacemaking in International Conflict. Washinton, DC: The Unite States Institute of Peace. 